\author{
Monograph \\ urn:1sid:zoobank.org:pub:861CF951-45BE-458F-B0F7-79530DEE06CE
}

\title{
Studies on neotropical Phasmatodea XVII: Revision of Phantasca Redtenbacher, 1906, with the descriptions of six new species (Phasmatodea: Diapheromeridae: Diapheromerinae)
}

\author{
Frank H. HENNEMANN ${ }^{1, *}$, Oskar V. CONLE ${ }^{2}$, \\ Yannick BELLANGER ${ }^{3}$, Philippe LELONG $^{4} \&$ Toni JOURDAN ${ }^{5}$ \\ ${ }^{1}$ Reiboldstrasse 11, 67251 Freinsheim, Germany. \\ ${ }^{2}$ Am Freischütz 16, 47058 Duisburg, Germany. \\ ${ }^{3}$ La Ville-Jouy, 22250 Trédias, France. \\ ${ }^{4}$ Le Ferradou n³, 31570 Sainte-Foy-d Aigrefeuille, France. \\ ${ }^{5} 95$ chemin des Chevêches, 74150 Vallières, France. \\ ${ }^{*}$ Corresponding author: hennemann@phasmatodea.com \\ 2Email:conle@phasmatodea.com \\ ${ }^{3}$ Email: yannick.bellanger@wanadoo.fr \\ ${ }^{4}$ Email: plelong@wanadoo.fr \\ 5Email: toni-jourdan@wanadoo.fr \\ ${ }^{1}$ urn:lsid:zoobank.org:author:651FCCFA-271B-48A3-A58E-A30FDC739493 \\ ${ }^{2}$ urn:1sid:zoobank.org:author:D2712C02-7973-4FAA-A186-5F8540A66691 \\ ${ }^{3}$ urn:lsid:zoobank.org:author:03D1668F-A5E5-449B-96B8-0EAAE6D32216 \\ ${ }^{4}$ urn:Isid:zoobank.org:author:5949656F-C20F-4001-8812-CED7586269B1 \\ ${ }^{5}$ urn:1sid:zoobank.org:author:66209034-74A0-4648-A87E-862ED5661DE6
}

Hennemann F.H., Conle O.V., Bellanger Y., Lelong P. \& Jourdan T. 2018 Studies on neotropical Phasmatodea XVII: Revision of Phantasca Redtenbacher, 1906, with the descriptions of six new species (Phasmatodea: Diapheromeridae: Diapheromerinae). European Journal of Taxonomy 435: 1-62. https://doi.org/10.5852/ejt.2018.435

\begin{abstract}
The South American genus Phantasca Redtenbacher, 1906 (Phasmatodea: Diapheromeridae: Diapheromaerinae) is re-diagnosed and revised at the species level. The precedingly unknown eggs are described for the first time. The genus Pterolibethra Günther, 1940 (type species: P. heteronemia Günther, 1940) is re-synonymised, with Phantasca (syn. nov.) and consequently the two species originally contained, P. heteronemia Günther, 1940 and P. poeciloptera Günther, 1940, are transferred to Phantasca (comb. rev.). P. laeta Conle, Hennemann \& Gutierréz, 2011 is not congeneric and is transferred to the genus Jeremiodes Hennemann \& Conle, 2007 (Cladomorphinae: Cladomorphini; comb. nov.). Two species are removed from Bacteria Berthold, 1827 and transferred to Phantasca; these are B. quadrilobata Chopard, 1911 and B. montana Redtenbacher, 1906 (comb. nov.). Six new species are described: P. adiposa sp. nov., $P$. amabile sp. nov., $P$. femorata sp. nov., $P$. guianensis sp. nov., $P$. nigrolineata sp. nov. and $P$. ruboligata sp. nov. The male and egg of $P$. quadrilobata (Chopard, 1911) are described and illustrated for the first
\end{abstract}


time. The genus now contains 13 species that are distributed throughout the northern half of South America. A key as well as detailed descriptions and illustrations are presented for all known species.

Keywords. Phasmatodea, Neotropical Region, Phantasca, new species, revision.

\section{Introduction}

The present paper is the $17^{\text {th }}$ part of an on-going study of the New World Phasmatodea and provides a revision of the genus Phantasca Redtenbacher, 1906, a very poorly known genus of the subfamily Diapheromerinae, whose systematic position is still not fully known and has precedingly been debated by several authors. During the past years a good number of specimens has become available, mainly from French Guiana, which considerably broadens our knowledge of the genus and allows a more comprehensive definition of it. The extensive material at hand includes the precedingly unknown females and eggs of several species as well as six so far unknown species, which are described herein. Apart from the relevant type specimens, the following study is based on the examination of the complete material collected in 1908 and in the collection of E. Le Moult now in MNHN (Paris), the numerous specimens collected by the Groupe d'Etude des Phasmes in 1992 and 1993 also in MNHN (Paris), extensive material collected by the Société Entomologique Antilles-Guyane (S.E.A.G.) since 2009 as well as specimens from various other museums and collections carried out by the two first authors in 2001 and the three last authors in 2013, 2015 and 2016. Pictures of live specimens of various species of Phantasca Redtenbacher, 1906 can be viewed on the first two authors website; www.phasmatodea.com.

\section{Material and methods}

This study is based on the examination of all relevant type material, for which we have received much support from the curators of all corresponding museums and institutions. The material at hand for this study is exclusively dried and pinned. Insects and eggs were examined using an entomological lens, with $4 \times$ magnification and a stereoscope (Zeiss Stemi SV 6). Eggs were examined at $10 \times$ magnification. Measurements were taken using a long ruler or a digital caliper and are given to the nearest $0.1 \mathrm{~mm}$. If more than one egg has been examined, average measurements are given. All eggs examined were already laid or removed from the female's ovipositor, and hence were fully developed. The terminology used for the descriptions of external and internal egg structures follows that of Clark Sellick (1997 \& 1998). If not differently cited and no live material was available, the colouration is described from dried specimens. Collecting data are reproduced exactly as on the original labels, and hence are presented in quotation marks.

\section{Abbreviations \\ $\mathrm{FH}=$ Private collection of Frank Hennemann, Freinsheim, Germany \\ $\mathrm{OC}=$ Private collection of Oskar V. Conle, Duisburg, Germany \\ $\mathrm{PL}=$ Philippe Lelong, Ste Foy d'Aigrefeuille, France \\ $\mathrm{YB}=$ Yannick Bellanger, Trédias, France}

\section{Institutional abbreviations}

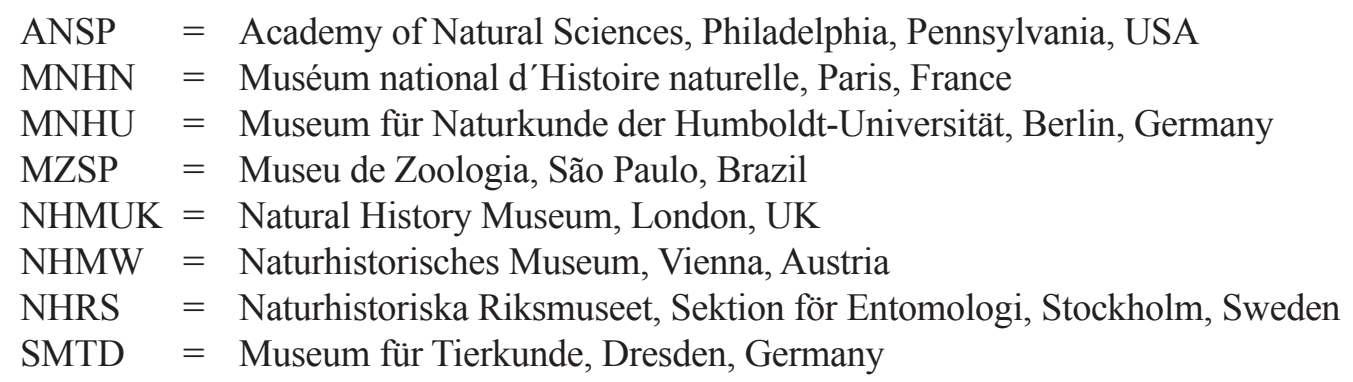




$$
\begin{aligned}
\text { ZMPA = } & \text { Polish Academy of Sciences, Warsaw, Poland } \\
\text { ZSMC }= & \text { Zoologische Staatsammlung München, Munich, Germany } \\
\text { ASPER = } & \text { Collection of ASPER (Association pour la Systématique des Phasmes et l'Etude de leur } \\
& \text { Répartition) }
\end{aligned}
$$

\title{
Results
}

\author{
Order Phasmatodea Jacobson \& Bianchi, 1902 \\ Suborder Verophasmatodea Zompro, 2004 \\ Infraorder Anareolatae Bradley \& Galil, 1977 \\ Family Diapheromeridae Kirby, 1904 \\ Subfamily Diapheromerinae Kirby, 1904 \\ Tribe Diapheromerini Kirby, 1904
}

Genus Phantasca Redtenbacher, 1906

Phantasca Redtenbacher, 1906: 111 ( $\rightarrow$ Phasmini) (type species: Phasma phantasma Westwood, 1859: 126, pl. 12, fig. 5a-b (ठ), by subsequent designation of Zompro 2001: 223).

Pterolibethra Günther, 1940: 498 (type species: Pterolibethra heteronemia Günther, 1940: 499 by original designation) syn. nov.

Phantasca - Günther 1940: 500 (Pterolibethra Günther, 1940 listed as a synonym). — Bradley \& Galil 1977: 180 ( $\rightarrow$ Heteronemiinae: Libethrini). — Zompro 2001: 223, fig. 32 (designation of type species, $\rightarrow$ Diapheromerinae: Diapheromerini: „Clonistria-group“). — Bragg 2001: 641. — Zompro 2004a: 318. — Zompro 2004b: 142. — Otte \& Brock 2005: 264. — Jourdan, Lelong \& Bellanger 2014: 490.

Pterolibethra - Bradley \& Galil 1977: $180(\rightarrow$ Heteronemiinae: Libethrini). — Zompro 2001: 225 (reestablished as a valid genus, $\rightarrow$ Diapheromerinae: Diapheromerini: „Clonistria-group“). — Bragg 2001: 643. - Zompro 2004a: 320. — Otte \& Brock 2005: 294. — Conle, Hennemann \& Gutiérrez 2011: 56.

non Bacteria - Chopard 1911: 343 (in part).

non Phasma - Westwood 1859: 117 (in part).

\section{Description}

Small to medium sized and mostly very slender Diapheromerinae (body length $\widehat{\partial} \hat{\delta}<75.0 \mathrm{~mm}$, females $<130.0 \mathrm{~mm}$ ), with strong sexual dimorphism; females apterous, males much more slender and very delicate winged insects. Body of uniform width and smooth or, with mesothorax at best sparsely granulose. Colour of females mostly green, grey or various shades of brown. Males usually ranging from green to brown but may be fairly colorful; often, with conspicuous dark markings or stripes on head, pronotum, mesonotum and abdominal tergites VII-X or, with annulated legs or colorful apices and/or bases of femora and tibiae. Anal region of alae of males transparent but dark brown, with the basal portion orange in a single species. Head longer than wide,, with vertex flattened or at best gently convex; unarmed. No ocelli. Gula covering more than $1 / 4$ of cervical membrane. Eyes large and projecting hemispherically in males. Antennae long and filiform, at least $3 / 4$ the length of body in males and more than $2 / 3$ the length of body in females. Scapus compressed dorsoventrally and longer than wide; rectangular. Pedicellus cylindrical and antennomere III considerably longer than preceding or following three antennomeres. Pronotum longer than wide and narrower than head. Mesothorax very elongate, $>2 \times$ as long as than head and pronotum in females and up to $3.5 \times$ as long as head and pronotum combined in males. Mesosternum simple. Tegmina of males slender, squamiform, with apical portion angular and basal portion strongly narrowed. Alae of males of moderate length and reaching to abdominal segment IV or V; anal region considerably longer than wide. Median segment $>2 / 3$ the length 
of metanotum in females and several times longer than metanotum in males. Abdominal segment II of males shorter than median segment. II-VII longer than wide and roughly of uniform width in both sexes. VI in females occasionally, with a pair of swellings. Sterna smooth but VII of females, with an indistinct praeopercular organ formed by a node or wart-like posteromedian swelling. Stigmae of tergum VIII close to anterior margin of segment. Epiproct of females small, scale-like and at best slightly projecting from apex of anal segment. Cerci of females straight, cylindrical and variable in length. Gonapophyses VIII slender and longer than IX and at best reaching to apex of subgenital plate. Gonoplacs distinct and equal in length to slightly longer than gonapophyses IX. Subgenital plate small, short and carinate longitudinally, with apex \pm acutely pointed; variable in length but at best reaching to apex of abdomen. Terminalia of males, with conspicuous specialisations. Tergum and sternum VIII partly to almost fully fused, with lateral margins of tergum VIII, often no more than indicated by a fine fissure. Sternum $\mathrm{VIII} \pm$ enlarged and fused, with sternum IX, which is reduced and has its borders at best indicated by an obsolete fissure. Poculum small, scaphiform and variable in shape,, with apex specialised. Tergum IX, with lateral margins approaching each other ventrally and partly or completely fused, with each other; in the latter case forming a closed tube. Anal segment much shorter than tergum IX, variable in shape and with posterior margin \pm distinctly notched medially; ventral surface of posterior margin, with a pair of small, \pm developed thorn pads. Vomer increasingly reduced, variable in size, ranging from fairly distinct to very small and triangular in shape,, with a single terminal hook. Cerci very variable in size and shape and of specific structure; ranging in length from being no longer than anal segment to more than twice the length of that segment, and in shape from straight, over gently upcurving or arcuate to strongly incurving and hook-like. Legs of both sexes elongate and \pm slender (males in particular) and entirely unarmed. Profemora compressed and curved basally, trapezoidal in cross-section,, with dorsal carinae strongly approaching and anterodorsal carina distinctly raised; medioventral carina moderately distinct and somewhat displaced towards anteroventral carina. Meso- and metafemora and all tibiae trapezoidal in cross-section,, with a fine longitudinal median carina. In females the two outer ventral carinae of meso- and metafemora occasionally, with a sub-apical rounded lobe or medioventral carina of mesoand metatibiae protuded into a rounded lobe sub-basally. Cerci slender and without specializations. Basitarsus strongly elongated (males in particular) and considerably longer than following three tarsomeres combined; trapezoidal in cross-section and sulcate dorsally.

Eggs: Capsule ovoid, longer than wide and \pm compressed laterally. Surface ranging from almost smooth and glossy over minutely punctured to slightly rugulose; \pm glossy. Micropylar plate elongate, slender and roughly parallel-sided, with only posterior portion very gently widened; $>3 / 4$ the length of capsule. Micropylar cupe near posterior end of plate. Median line distinct and variable in length. Internal plate open,, with a short median line that is distinctly separated from the plate itself. Operculum oval and inserted into capsule at a right angle or at best, with an angle of $10^{\circ}$. In centre, with a low, open and netor sponge-like capitulum. Colour mid to very dark brown.

\section{Diagnosis}

The relationships of Phantasca are not yet fully clarified, but in several aspects a relationship to sections of Libethra Stål, 1875 (strigiventris species group in particular) and certain Jamaican species of Clonistria Stål, 1875 (e.g., C. annulipes Rehn \& Hebard, 1938, C. bicoloripes Rehn \& Hebard, 1938, C. latebricola Rehn \& Hebard, 1938, C. monticola Rehn \& Hebard, 1938) appear likely (see remarks below).

From representatives of the strigiventris species group of Libethra, both sexes of Phantasca may be distinguished by the much longer median segment, which is several times longer than the metanotum in males and at least $2 / 3$ the length of the metanotum in females. Males also differ by the presence of wings, smaller poculum, partially to almost fully fused abdominal tergum and sternum VIII and the not conspicuously node-like lateral swellings of the anal segment, females can readily be distinguished by 
the unspecialised apex of the subgenital plate (deeply median notched and bifid in Libethra). The eggs are averagely less elongate than in Libethra and have the operculum inserted into the capsule roughly at a right angle (inserted at an angle of about $70^{\circ}$ in Libethra)

From the above mentioned Jamaican species of Clonistria Stål, 1875 representatives of Phantasca are readily distinguished by the considerably longer median segment and presence of wings in males. While the genital morphology is very similar in most aspects, males of Phantasca have the stigmae of abdominal tergum VIII very close to the anterior margin (somewhat displaced towards the posterior in the mentioned species of Clonistria), the poculum averaging smaller, and tergum and sternum VIII partly to almost fully fused. Differences between the females are as yet difficult to define, since only the female of one of the Jamaican species of Clonistria is known.

\section{Remarks}

There has been uncertainty about the systematic position of Phantasca Redtenbacher, 1906, mainly because the genus was precedingly only known from the males. Redtenbacher (1906: 111) originally established Phantasca for three small and very slender, winged species described by Westwood (1859), namely Phasma phantasma (Westwood, 1859), Ph. puppeius (Westwood, 1859) and Ph. valgius (Westwood, 1859), and placed the genus in his areolate tribe Phasmini. Günther (1940: 500) recognized that none of these species exhibits an area apicalis and suggested a close relationship to Libethra Stål, 1875 and the strigiventris species-group of that genus in particular (see Günther 1932: 258; Conle, Hennemann \& Gutiérrez 2011: 205). Zompro (2001: 220) placed Phantasca in his "Clonistria-group" of the subfamily Diapheromerinae: Diapheromerini and stated the genus to "show similarity" to Clonistria Stål, 1875 (type species: Clonistria bartholomaea Stål, 1875) and Libethroidea Hebard, 1919 (type species: Libethroidea inusitata Hebard, 1919) in being slender and lacking conspicous metamorphosis of the body. While this assumption is fairly meaningless, the generic diagnosis of Phantasca presented by Zompro (2001: 223) was only based on the males and is inaccurate in some aspects. The mentioned characters "Metathorax half as long as metathorax [should be: mesothorax] and 3 times as long as median segment" and "[abdominal segment] II less than two times as long as median segment" are not true, since the median segment is several times longer than the metanotum.

Günther (1940: 498) described Pterolibethra (type species: Pterolibethra heteronemia Günther, 1940) for the two newly described species P. heteronemia and P. poeciloptera and stated that it was closely related to Libethra Stål, 1875, but in the appendix of the same publication (Günther 1940: 500) he synonymised Pterolibethra, with Phantasca. This synonymy was revised by Zompro (2001: 225), who re-establised Pterolibethra as a valid genus on the basis that the genitalia of Phantasca resembled those of Clonistria and those of Pterolibethra were similar to those of Libethra. However, the "similarities" postulated were not defined in any more detail by Zompro and examination of all concerned species does in fact not show any differences in the genital morphology that would distinguish Pterolibethra from Phantasca. Hence, the synonymy established by Günther (1940: 500) is correct and Pterolibethra is consequently re-synonymised, with Phantasca herein (syn. nov.). Zompro (2001: 226) furthermore stated that Günther was in error about the length of the median segment of Pterolibethra heteronemia and that it was obvious that the median segment measured only two-thirds of the metanotum. In fact, however, the median segment of the concerned species is several times longer than the metanotum, these two segments showing a similar length relationship as in all other species of Phantasca.

The true systematic position and relationships of Phantasca are still not fully clarified, but the conspicuous genital morphology of the males suggests close relationships to sections of the South American Libethra Stål, 1875 (the strigiventris species group in particular), certain species of the exceptional Caribbean Clonistria Stål, 1875 from the Greater Antilles as well as some species of as yet unknown generic position that are distributed throughout southern Brazil and Paraguay. Furthermore, the often partly to 
almost fully fused abdominal tergum und sternum VIII, increasingly approaching and sometimes partly ventrally fused lateral margins of tergum IX, as well as the small poculum in males of Phantasca indicate a relationship to Caribbiopheromera Zompro, 2001 (type species: Caribbiopheromera jamaicana Zompro, 2001), which does obviously not belong in a close relationship to the "Diapheromera group" of Diapheromerinae: Diapheromerini where it was originally placed by Zompro (Bradler 2009: 102). In addition to the genital morphology of males, a relationship between Phantasca and the aforementioned genera is also supported by the morphology of the genitalia of females and egg morphology. However, any broader discussion on the placement and relationships of Phantasca appears premature at this point and apart from a better knowledge of the as yet generically unassigned but possibly closely related species that occur throughout southern Brazil and Paraguay (see above) warrant a comprehensive phylogenetic study that incorporates all of the mentioned genera and support by molecular analyses. These are the subject of forthcoming studies conducted by the authors and will hopefully provide clarification of the true systematic position of Phantasca.

Examination of the genital morphology of the male (the only sex known) of Pterolibethra laeta Conle, Hennemann \& Gutiérrez, 2011 from Colombia has shown it to be misplaced. Although the poculum is comparatively small, the short abdominal tergum VIII, which is strictly separated from sternum VIII, the large vomer and broad, dorsoventrally flattened and hook-like cerci place this species in the genus Jeremiodes Hennemann \& Conle, 2007, hence now Jeremiodes laetus (comb. nov.).

\section{Distribution}

North Brazil, French Guiana, east Peru, east Ecuador and southeast Colombia. The genus is very likely to also be represented in Suriname, but there are no records so far.

\section{Species included}

1. Phantasca adiposa sp. nov. (French Guiana)

2. Phantasca amabile sp. nov. (Ecuador: Napo Prov.)

3. Phantasca femorata sp. nov. (French Guiana)

4. Phantasca guianensis sp. nov. (French Guiana)

5. Phantasca montana (Redtenbacher, 1908) comb. nov. (east Peru: Dept. Loreto)

6. Phantasca heteronemia (Günther, 1940) comb. rev. (east Peru: Dept. Loreto)

7. Phantasca nigrolineata sp. nov. (French Guiana)

8. Phantasca phantasma (Westwood, 1859) (northeast Brazil \& French Guiana)

9. Phantasca poeciloptera (Günther, 1940) comb. rev. (southeast Colombia \& East Peru)

10. Phantasca puppeia (Westwood, 1859) (northeast Brazil (Tapajós))

11. Phantasca quadrilobata (Chopard, 1911) comb. nov. (French Guiana)

12. Phantasca ruboligata sp. nov. (French Guiana)

13. Phantasca valgius (Westwood, 1859) (not known)

\section{Key to the species of Phantasca}

\section{Males}

1. Cerci short, arcuately upcurving and not projecting over posterior margin of anal segment ..........2

- Cerci long and projecting distinctly over posterior margin of anal segment .......................

2. Apex of cerci blunt; poculum large,, with posterior margin labiate and angled downward (Fig. 68); posteriormargin of anal segment, with a wide triangularmedian excavation; head, without a distinctpale marking on frons (Fig. 67) ...

P. phantasma (Westwood, 1859)

- Apex of cerci acutely pointed; poculum small, cup shaped (Fig. 96),, with the posterior margin obtusely angulate and dorsally directed; posterior margin of anal segment, with a small median indentation 
(Fig. 95); head, with a large, distinctly pale cream to whitish marking on frons (Fig. 92)

P. quadrilobata (Chopard, 1911)

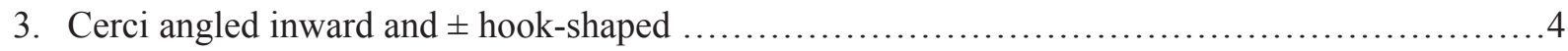

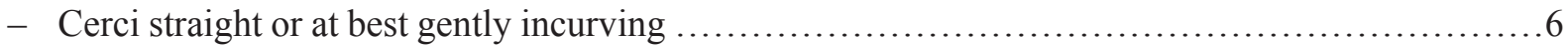

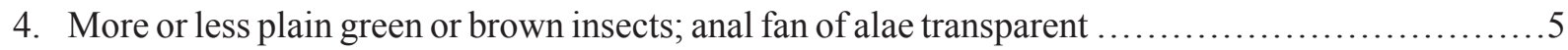

- Very colourful insects, with head, most of legs and cerci red (Fig. 71); anal fan of alae dark brown, with the basal half bright orange (Fig. 74); SE Colombia \& E Peru ...P. poeciloptera (Günther, 1940)

5. Very slender, bright green insects; scapus, coxae and bases of all tibiae bright red; base of alae, with a black marking interiorly; posterior margin of poculum slightly narrowed and gently bilobate (Fig. 114); French Guiana .... P. ruboligata sp. nov.

- Stocky, dull greenish brown; abominal sternites II-V black; base of alae, without a dark marking; posterior margin of poculum widened, obtusely angular and preceded by a conspicuous narrowing (Fig. 44); E Peru .P. heteronemia (Günther, 1940)

6. Head \pm unicoloured, without conspicuous dark markings .7

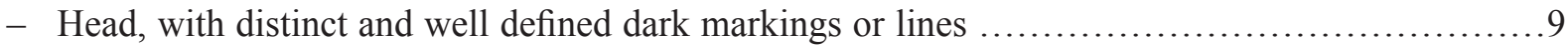

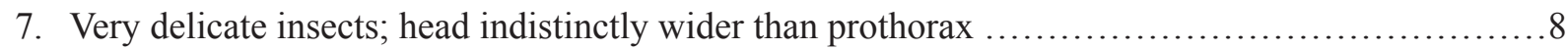

- Comparatively stocky; head globose and almost $2 \times$ as wide as prothorax (Fig. 8) ...P. adiposa sp. nov.

8. All longitudinal veins of tegmina and alae marked, with brown (Fig. 120)

- Tegmina and costal region of alae plain green (Fig. 78) .P. puppeia (Westwood, 1859)

9. Head, with a single bold central black marking or longitudinal stripe 10

- Head, with various dark markings .......................................................... 11

10. Colourful insects, green, with bases of tibiae red and apices of femora and tibiae black; costal region of alae, with a dark brown longitudinal stripe interiorly (Fig. 15); posterior margin of anal segment bilobate, with a deep and narrow median incision; E Ecuador ........P. amabile sp. nov.

- Greenish brown insects; no dark longitudinal stripe on costal region of alae; posterior margin of anal segment only, with a very slight median indentation(Fig. 59); French Guiana ...P. nigrolineata sp. nov.

11. Anal segment \pm cucullate; cerci short and projecting beyond apex of abdomen by no more than half the length of the anal segment

- Anal segment flattened and almost parallel-sided, the posterior margin, with a wide triangular excavation (Fig. 30); cerci very long and projecting beyond apex of abdomen by almost the length of the anal segment; French Guiana P. guianensis sp. nov.

12. Head elongate, cheeks parallel-sided and with two fine dark longitudinal postocular stripes (Fig. 21); pronotum, with a fine longitudinal black line along lateral margins; poculum, with lateral margins roundly emarginated and apical half strongly narrowed (Fig. 24); French Guiana

P. femorata sp. nov.

- Head ovoid, vertex, with two bold diverging dorsal stripes (Fig. 47); pronotum, without a dark lateral line; poculum cup-shaped, with lateral margins straight and posterior portion not conspicuously narrowed; East Peru P. montana (Redtenbacher, 1908) 


\section{Females*}

1. Cerci at best equal in length to anal segment

- Cerci lanceolate and distinctly longer than the anal segment (Figs 106-108) ...P. ruboligata sp. nov.

2. Cerci elongate and $>3 / 4$ the length of the anal segment; femora and tibiae, without lobes .............. 3

- Cerci $<2 / 3$ the length of the anal segment; femora or tibiae, with lobes .........................

3. Very slender insects (Figs 48-49), abdominal segments II-VII $>2 \times$ as long as wide; femora slender; subgenital plate flattened (Fig. 54)

.P. nigrolineata $\mathrm{sp}$. nov.

- Stocky insects (Figs 1-2), abdominal segments II-VII indistinctly longer than wide; femora broadened; subgenital plate strongly convex medially (Fig. 4) P. adiposa sp. nov.

4. Abdominal tergum VI smooth dorsally

- Abdominal tergum VI, with a pairoftransversely carinate swellings ...P. quadrilobata (Chopard, 1911)

5. Large insects (body length $>12 \mathrm{~cm}$ ); abdominal tergum VI slender; meso- and metatibiae, with a rounded sub-basal lobe on medioventral carina

P. guianensis $\mathrm{sp}$. nov.

- Smaller insects (body length $<12 \mathrm{~cm}$ ); lateral margins of abdominal tergum VI roundly deflexed; meso- and metafemora, with a rounded sub-apical lobe on both outer ventral carinae and these carinae gently deflexed sub-basally< (Fig. 20)

P. femorata sp. nov.

* The females of $P$. amabile sp. nov., P. heteronemia (Günther, 1940), P. montana (Redtenbacher, 1906), P. phantasma (Westwood, 1859), P. poeciloptera (Günther, 1940), P. puppeia (Westwood, 1859) and $P$. valgius (Westwood, 1859) are not known.
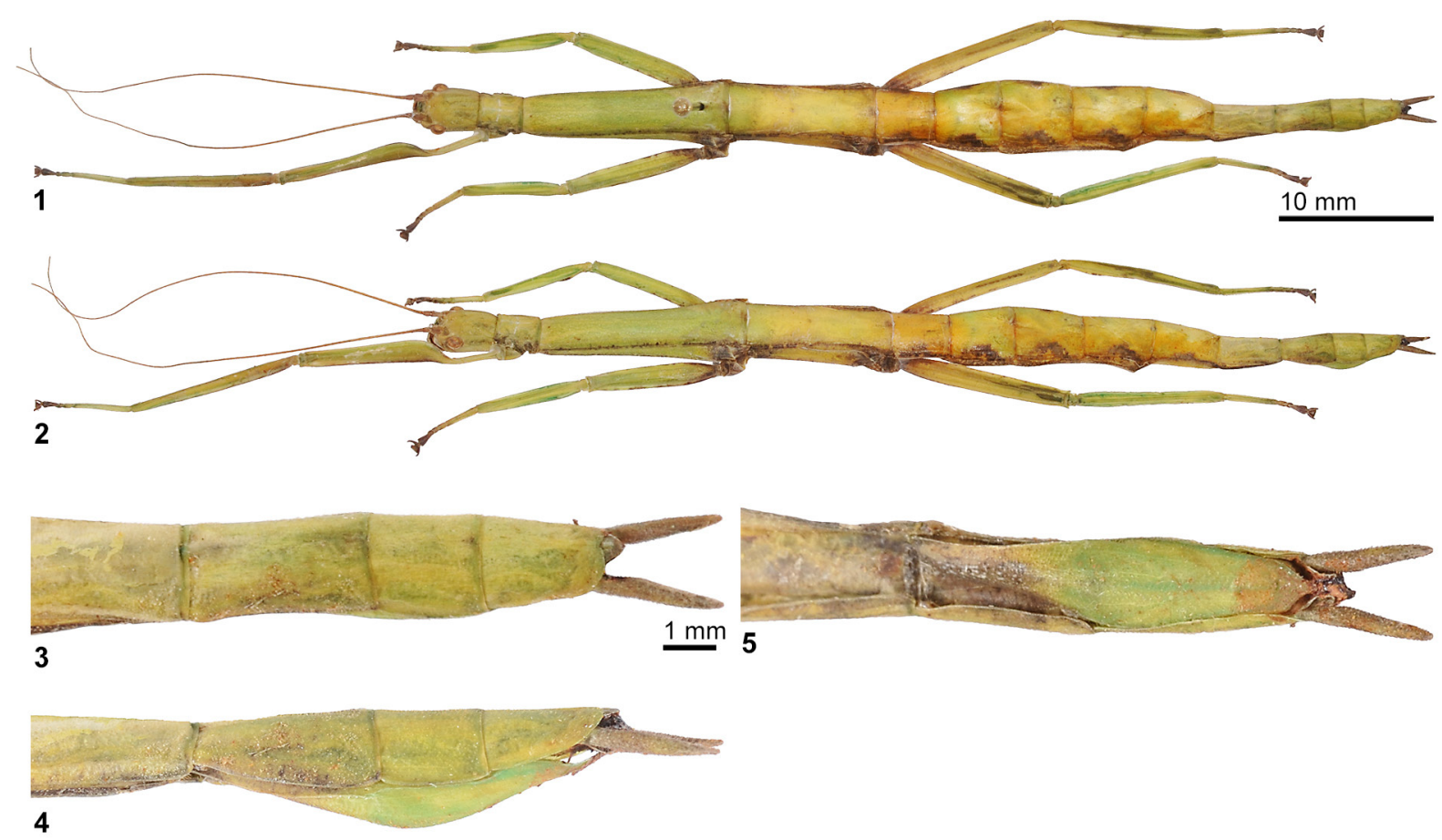

Figs 1-5. Phantasca adiposa sp. nov. Holotype, ${ }^{\circ}$. 1. Habitus, dorsal view. 2. Habitus, dorsolateral view. 3. Apex of abdomen, dorsal view. 4. Apex of abdomen, lateral view. 5. Apex of abdomen, ventral view. 
Phantasca adiposa sp. nov.

urn:1sid:zoobank.org:act:EFA1585C-19A6-41CA-8D64-7FED6BBF6E77

Figs $1-13$

\section{Material examined}

Holotype

FRENCH GUIANA: + , “Guyane, Petit Saut, 20-31 VII 92, Roubaud, Auvray, Rarchaert rec.” (MNHN).

Paratype

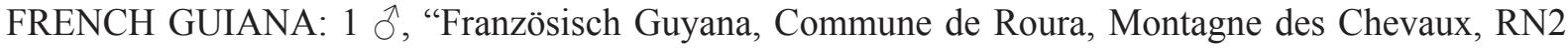
PK22, 444'56"N - 52²6'28" W, alt. 75 m SEAG, leg. Stéphane Brule 04.03.2013” (OC 0336-1).

\section{Diagnosis}

Females of this species readily differ from all other known ones of the genus by the much stockier appearance, which includes a considerably broader body and relatively shorter body segments (abdominal segments II-VI being no more than $1.2 \times$ as long as wide) as well as strongly broadened mid and hind legs, which have the outer ventral carinae strongly deflexed (Figs 1-2). The subgenital plate has the sub-basal portion more convex and bulgy than in all other species (Fig. 4), while the very elongate cerci resemble those of $P$. nigrolineata sp. nov. and P. ruboligata sp. nov. Males are readily distinguished from all other species in the genus by the fairly stocky body, large and globose, unicoloured head, which

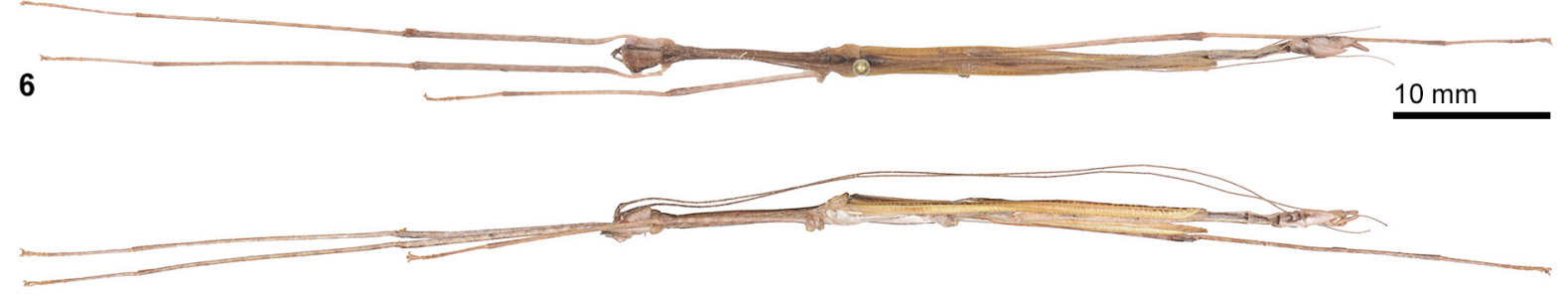

7
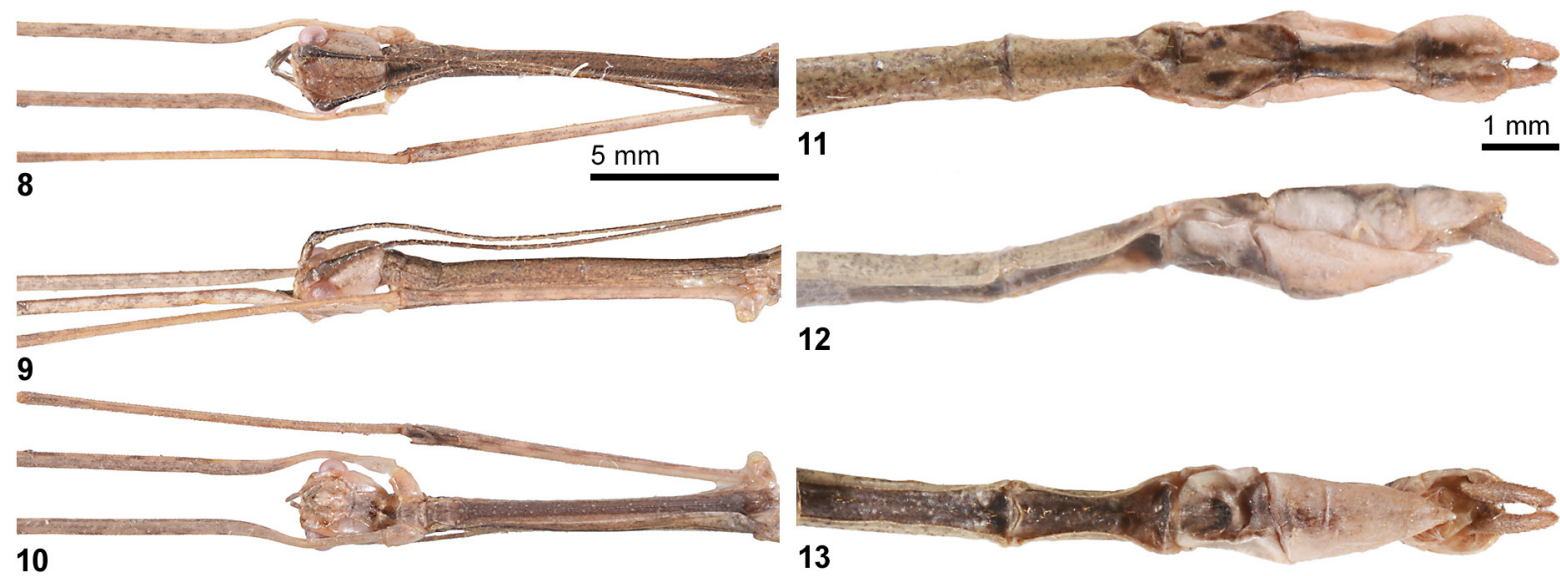

12

Figs 6-13. Phantasca adiposa sp. nov. Paratype, ภ․ 6. Habitus, dorsal view. 7. Habitus, lateral view. 8. Head, pro- and mesothorax, dorsal view. 9. Head, pro- and mesothorax, lateral view. 10. Head, proand mesothorax, ventral view. 11. Apex of abdomen, dorsal view. 12. Apex of abdomen, lateral view. 13. Apex of abdomen, ventral view. 
is almost $2 \times$ as wide as the prothorax (Fig. 8), as well as the large and elongate-triangular poculum (Fig. 13).

\section{Etymology}

The name of this new species (adiposus Lat. $=$ fat, corpulent) emphasizes on the very stocky appearance of females, which are unusually broad-bodied for the genus and have remarkably strong legs.

\section{Description}

Male (Figs 6-7)

Body. Size small (body length $47.0 \mathrm{~mm}$, Table 1); form fairly stocky for the genus.

CoLour. Colour pale brown to ochre, the pro- and mesonotum somewhat darker and all over, with small dark speckles. Head unicoloured, with only a very faint and slender dark longitudinal coronal line. Antennae mid brown, with the basal 4-5 segments blackish brown ventrally. Pronotum, with a black longitudinal median stripe that is fairly broad but weakly defined on the anterior half and becomes increasingly more slender and less obvious towards the posterior. Mesosternum dark brown, with a few small white dots. Tegmina and costal region of alae buffy, with all major veins contrasting yellow; the basal portion of the latter dark brown. Anal fan of alae transparent grey, with the outer portion slightly brownish. Abdominal sternites II-VII dull brown. Tergites IX and X each, with two washed black longitudinal stripes, the basal portion of the poculum blackish brown. Legs, with a slight reddish hue and with very faint dark mottling, the apices of all femora and tibiae dark brown.

HEAD. Large, globose, hardly longer than wide, broadest at the eyes and almost $2 \times$ as wide as prothorax; vertex convex (Figs 8-9). Eyes large, projecting hemispherically and their length contained about 1.6× in that of cheeks. Antennae slightly longer than body. Scapus rectangular and $1.3 \times$ as long as wide, pedicellus sub-globose and antennomere III somewhat longer than pedicellus.

THorax. Pronotum considerably shorter and much narrower than head (Fig. 8), very gently narrowed towards the posterior and with the transverse median sulcus moderately distinct, slightly curved and expanding almost over entire width of segment. Mesothorax about $2.2 \times$ as long as head and pronotum combined; mesosternum, with a fine but fairly acute longitudinal median carina. Tegmina strongly narrowed in the basal half and with the apical portion moderately broadened and acutely angular. Alae reaching about $1 / 3$ along abdominal segment VI.

ABDOMEN. Segments II-VII slightly decreasing in length. II about $4.5 \times$ and VII about $3 \times$ as long as wide; the latter slightly deflexed posteriorly. Tergum VIII shortest of all segments, only about $1.3 \times$ as long as wide and slightly broader than preceding; the lateral margins well separated from sternum VIII. IX about $1.4 \times$ as long as VIII, narrowed in anterior half and with the posterior increasingly broadened; the lateral margins deflexed and curved inward ventrally but well separated. Anal segment noticeably broader than tergum IX, slightly cucullate, with the lateral margins deflexed and gently rounded; the posterior margin, with a small but distinct triangular median notch (Fig. 11), the outer portions broadly rounded and with a few small black ventral denticles in the inner portion. Vomer large, triangular in shape and with a slightly upcurving, acute apical hook. Cerci obtuse, fairly long, almost straight and projecting beyond apex of abdomen by about $3 / 4$ length of anal segment (Fig. 12). Sternum VIII moderately swollen. Poculum large, elongate, triangular in ventral aspect and gradually narrowed towards an acutely pointed apex, which reaches about half way along anal segment (Fig. 13); lateral margins moderately excavated in lateral aspect. 
Table 1. Measurements of Phantasca adiposa sp. nov. (in mm). HT = Holotype, $\mathrm{PT}=$ Paratype.

\begin{tabular}{lcc}
\hline & P HT, (MNHN) & ô PT, (OC) \\
\hline Body & 65.3 & 47.0 \\
Pronotum & 3.0 & 1.5 \\
Mesonotum & 13.5 & 8.4 \\
Metanotum & 4.0 & - \\
Median segment & 5.3 & - \\
Tegmina & - & 2.0 \\
Alae & - & 23.0 \\
Profemora & 13.9 & 21.0 \\
Mesofemora & 9.7 & 9.0 \\
Metafemora & 11.7 & 15.0 \\
Protibiae & 12.4 & 17.0 \\
Mesotibiae & 8.5 & 10.7 \\
Metatibiae & 11.8 & 15.5 \\
Antennae & $>32.5$ & $>45.0$ \\
\hline
\end{tabular}

LEGS. All long and slender, profemora somewhat longer than head, pro- and mesothorax combined and metatibiae projecting considerably beyond apex of abdomen. All basitarsi longer than combined length of remaining tarsomeres, probasitarsi in particular very elongate.

Female (Figs 1-2)

Body. Size medium (body length $65.3 \mathrm{~mm}$, Table 1); form very robust and stocky for the genus, with a swollen abdomen and unusually thickened meso- and metafemora. Body surface very faintly subgranulose (although more decidedly so on thoracic sterna).

Colour. Colouration mid green (most of the metathorax and abdomen discoloured and yellowish in the HT caused by the process of preservation), the lateral margins of the meso- and metanotum and abdominal tergites II-VIII, with a washed dark brown stripe which forms a weakly defined roundly triangular median marking on abdominal tergites II-VI. Probasisternum, profurcasternum, abdominal sternum I and basal portion of subgenital plate greyish mid brown and with a weakly defined stripe of the same colour along the lower margins of the pleurae and outer lateral margins of the meso- and metasternum. Also, coxae and bases of meso- and metafemora greyish mid brown. Cerci dull green, with a brownish hue. Antennae buffy and gradually becoming paler towards the apex.

HEAD. About $1.3 \times$ as long as wide, flattened and very gently narrowing towards the posterior; smooth. Eyes circular, strongly projecting and their length contained about $2 \times$ in that of cheeks. Antennae reaching to posterior margin of median segment; scapus rectangular, with the lateral margins gently convex and about $1.6 \times$ as long as wide. Segment III somewhat shorter than pedicellus.

THORAX. Pronotum rectangular, about $1.2 \times$ as wide as long and considerably shorter than head; transverse median sulcus indistinct and gently curved. Mesothorax only about $2 \times$ as long as head and prothorax combined and very slightly widening towards the posterior; mesonotum parallel-sided and with a very weak longitudinal median carina. Metanotum rectangular and $1.2 \times$ as wide as long. 
AвDOMEN. Median sgement $1.3 \times$ as long as metanotum. Abdominal segments III-VI swollen and considerably broader than all other segments, IV and V longest; II-VI on average $1.25 \times$ as long as wide. Praeopercular organ formed by a shallow, chestnut-brown, wart-like median structure near posterior margin of sternum VII. Anal segment about $1.6 \times$ as long as wide, indistinctly tectinate longitudinally and gently gradually narrowing towards the apex; posterior margin, with a shallow emargination and the outer angles obtusely rounded. Epiproct small, roundly triangular and distinctly projecting beyond apex of anal segment (Fig. 3). Cerci about equal in length to anal segment, lanceolate,, with the basal portion compressed and gradually constricted towards a fairly pointed tip (Fig. 3). Subgenital plate boat-shaped and strongly convex in the median portion (Fig. 4); apex strongly narrowed and forming a slender, acute point that almost reaches to the posterior margin of the anal segment (Fig. 5).

Legs. All fairly stocky and relatively short for the genus, the meso- and metafemora remarkably thickened. Outer lower margins of meso- and metafemora and tibiae gently deflexed in the basal half and the medioventral carina distinct; that of the tibiae deflexed to form a shallow rounded lobe sub-basally. Profemora, with the anterodorsal carina strongly elevated. Pro- and metabasitarsus longer than remaining tarsomeres combined, mesobasitarsus a little shorter than the combined length of the remaining tarsomeres.

\section{Remarks}

This unusually stocky species is so far only known from the two type specimens. Egg unknown.

\section{Distribution}

French Guiana: Petit Saut (MNHN); Commune de Roura, Montagne des Chevaux (coll. OC).

Phantasca amabile sp. nov. urn:1sid:zoobank.org:act:8CD3A681-8A46-42EF-A54C-44244424D20A

\section{Figs 14-15}

\section{Material examined}

Holotype

ECUADOR: đ̂, "jungle vegetation; Ecuador: Napo Province, Coca, iv-ix.1982, G. Onore, B.M. 198561" (NHMUK).

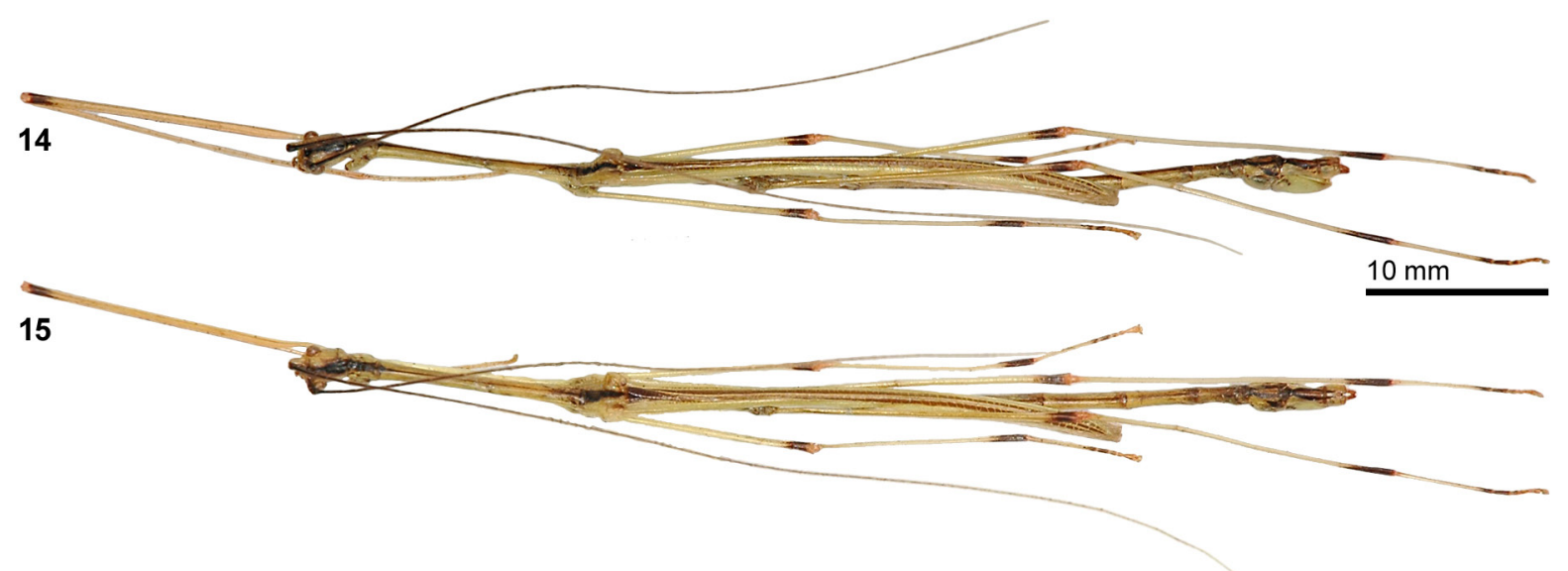

Figs 14-15. Phantasca amabilis sp. nov. Holotype, đิ. 14. Habitus, dorsolateral view. 15. Habitus, dorsal view. 


\section{Diagnosis}

Males of this new species (the only sex known) are well characterized by the distinctive colouration and large poculum, which is very bulgy for the genus, larger than sternum VIII and IX combined and almost reaches to the apex of the abdomen. They are similar to those of $P$. ruboligata sp. nov. from French Guiana but differ from this species by the somewhat shorter and straight cerci, more slender and deeply incised anal segment, much larger poculum, broad black longitudinal stripe on the head and pronotum, fine dark longitudinal median line along the mesonotum and abdominal tergites II-VI, brown mesosternum, two dark brown stripes on the costal region of the alae and differently shaped black markings on abdominal tergites VIII and IX.

\section{Etymology}

The name of this new species (amabilis Lat. = lovely) refers to the pretty colouration of males, which includes bright red bases of all tibiae and basitarsi, black apices of all femora and tibiae as well as black markings and stripes on the head, thorax, three terminal abdominal segments and costal region of the alae.

\section{Description}

Male (Figs 14-15)

Body. Size medium (body length $58.0 \mathrm{~mm}$, Table 2); form fairly slender for the genus.

CoLour. General colour of the holotype dull yellow, with a greenish wash (most certainly green when alive). Head and pronotum, with a broad black longitudinal median streak, which is considerably narrowed on frons between the eyes. Mesonotum, with a very fine, longitudinal median sepia stripe which is somewhat broadened and becomes black anteriorly and posteriorly; mesosternum brown. Metanotum mostly blackish brown and metasternum, with a faint brownish longitudinal median stripe on posterior half. Tegmina, with a washed brown posteromedian marking. The costal region of the alae, with fairly broad sepia stripe near interior margin, the anal region hyaline. Abdominal tergites II-VI, with a fine longitudinal dark brown line, VII-IX each, with two black longitudinal stripes (faint and only in posterior portion on VII) and VIII, with an additional roughly semicircular black marking posterolaterally. Anal segment, with two elongate black markings at anterior margin. Antennae dull greyish brown basally and becoming paler brown towards the apex. Apex of all femora and tibiae as well as base of all tibiae and basitarsi red, the red apical portions each preceded by a broad blackish brown annulus. Cerci red.

HEAD. Roundly rectangular, about $1.2 \times$ as long as wide and flattened dorsally, with a very fine longitudinal median sulcus. Eyes large, projecting hemispherically and their length contained almost $1.5 \times$ in that of cheeks. Antennae reaching to abdominal segment IX. Scapus compressed dorsoventrally, rectangular and about $1.2 \times$ as long as wide. Pedicellus globose and antennomere III somewhat longer than pedicellus.

THORAX. Pronotum rectangular and considerably narrower and shorter than head, transverse median sulcus fairly decided, curved and expanding over entire width of segment. Mesothorax almost $2.7 \times$ as long as head and pronotum combined; smooth. Tegmina roundly spatulate in shape,, with the anterior portion considerably narrowed and the posterior half broadened and obtusely angular. Alae reaching to posterior margin of abdominal segment $\mathrm{V}$.

ABDomEn. Segments II-VI somewhat unequal in length and on average $5 \times$ as long as wide. VII about $3 / 5$ the length of VI and decidedly constricted medially. Tergum VIII swollen and broadest of all segments, the lateral margins well separated from sternum VIII; the latter strongly swollen and rounded in all aspects. IX somewhat longer than VIII, constricted medially, the lateral margins straight and well separated. Anal segment less than half the length of IX, hardly longer than wide, rectangular and with a very deep and narrow incision posteromedially; the outer posterior portions obtusely angular. Cerci straight, with the apex 
Table 2. Measurements of Phantasca amabile sp. nov. (in mm). HT = Holotype.

\begin{tabular}{lc}
\hline & $\hat{\jmath}$, HT (NHMUK) \\
\hline Body & 58.0 \\
Pronotum & 2.0 \\
Mesonotum & 11.6 \\
Metanotum & - \\
Median segment & - \\
Tegmina & 2.0 \\
Alae & 28.5 \\
Profemora & 18.3 \\
Mesofemora & 12.7 \\
Metafemora & 16.3 \\
Protibiae & 19.9 \\
Mesotibiae & 12.2 \\
Metatibiae & 18.1 \\
Antennae & $>55.0$ \\
\hline
\end{tabular}

somewhat club-shaped, a little longer than anal segment and projecting beyond apex of abdomen by about $2 / 3$ the length of anal segment. Vomer small, triangular and with a single terminal hook. Poculum large, tub-shaped and reaching about half way along anal segment; the apex, with a faint median indention.

Legs. Profemora longer than head, pro- and mesothorax combined, mesofemora longer than mesothorax and metatibiae, projecting considerably beyond apex of abdomen. Basitarsi more than $1.5 \times$ the length of remaining tarsomeres combined.

\section{Remarks}

This distinctive species is so far only known from the single male holotype in NHMUK. The specimen is obviously discoloured by provisional storage in spirits. Females and eggs are unknown.

\section{Distribution}

East Ecuador: Oriente, Prov. Napo, Coca (NHMUK).

Phantasca femorata sp. nov. urn:1sid:zoobank.org:act:C7A05228-22CB-497E-AA5B-21B53449ABC8

Figs 16-24

\section{Material examined}

\section{Holotype}

FRENCH GUIANA: + , penultimate instar, “25.VII, A7 S1 N12, P.E. Roubaud det.” (MNHN).

\section{Paratypes}

FRENCH GUIANA: 1ㅇ, penultimate instar, "25.VII, A6 S1 N7, P.E. Roubaud det.” (MNHN); 10 , "GUY15016, 05-VIII-2015, Guyane française, St Elie, N5 ${ }^{\circ} 17.725^{\prime}$ W5303.093', rec. T. Jourdan, ASPER” (ASPER-PL); 10̄, "Französisch Guyana, Commune de Roura, Montagne des Chevaux, RN2 PK22, 444'56"N-52²6'28" W, alt. 75 m SEAG, leg. Stéphane Brûlé 24.06.2012” (OC 0335-1). 


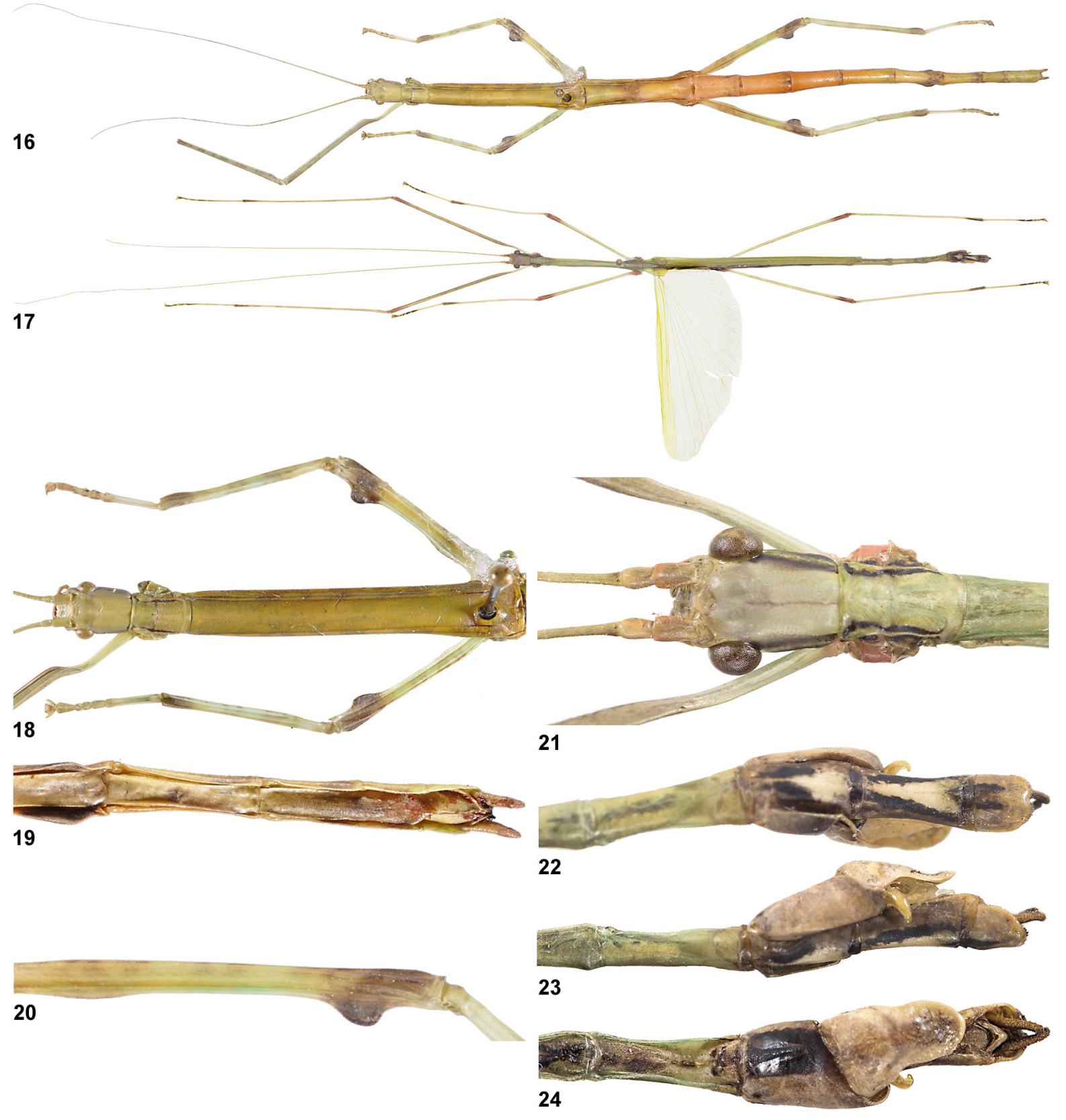

Figs 16-24. Phantasca femorata sp. nov. 16. Holotype, + , habitus, dorsal view. 17. Paratype, $\partial^{\lambda}$, habitus, dorsal view. 18. Holotype, $q$, head, pro- and mesothorax, dorsal view. 19. Holotype,, , apex of abdomen, ventral view. 20. Holotype, $q$, left mesofemur, anterior view. 21. Paratype, $\delta$, head and pronotum, dorsal view. 22. Paratype, $\partial^{\lambda}$, apex of abdomen, dorsal view. 23. Paratype, $\partial^{\lambda}$, apex of abdomen, lateral view. 24. Paratype, $\partial^{\lambda}$, apex of abdomen, ventral view. 


\section{Diagnosis}

Females of this new species are readily distinguished from all other known species by the large, rounded sub-apical lobe of the two outer ventral carinae of the meso- and metafemora and having these two carinae gently deflexed sub-basally (Fig. 20). The short cerci of males resemble those of P. quadrilobata (Chopard, 1911) and P. phantasma (Westwood, 1859), but the typical arrangement of black markings on the head and body, which includes a black postocular line, black ventro-lateral surfaces of the head capsule, a fine black longitudinal line along the lateral margins of the pronotum and a black line along the lateral margins of the meso- and metasternum, as well as the much more elongate apically narrowed and spatulate poculum clearly distinguish $P$. femorata sp. nov. from males of these two species. The cerci hardly project over the apex of the anal segment (Fig. 23) and are straight,, with only the apex slightly incurving (over entire length distinctly upcurving and sickle-shaped in P. quadrilobata and P. phantasma). Also, the considerably more elongate and flattened head readily distinguishes $P$. femorata sp. nov. from these two species.

\section{Etymology}

The name of this new species refers to the distinctive shape of the meso- and metafemora of females, which have the two outer ventral carinae gently expanded sub-basally and bear a prominent rounded lobe sub-apically.

\section{Description}

Male (Fig. 17)

BoDy. Size fairly large (body length 68.8-73.0 mm, Table 3); form very slender and elongate for the genus.

Colour. General colour of the two paratypic specimens at hand dull yellow to drab (believed to be green when alive), the head and three terminal abdominal segments somewhat darker and most of the mesosternum greyish mid brown. Head, with two fine and washed black postocular lines, the upper one of which fades some distance before the eye; the lower portions of the cheeks broadly black. Antennae pale greyish brown. Pronotum, with a fine black longitudinal line near lateral margins. Metapleurae, with a broad black stripe along lower margin and a washed, longitudinal black marking at lateral margins of abdominal tergites II and III. Tegmina, with the posterior margin faintly black, the anal region of the alae hyaline. Abdominal tergites VIII and IX each, with two broad black longitudinal stripes, those of VIII restricted to the anterior half; the posterior portion of both segments cream and with a faint washed yellow spot medially. Two short and fine slender black markings roughly in centre of anal segment and a large black median marking on sternum VIII. All femora and tibiae, with a washed blackish sub-apical spot on all four surfaces, the apex of the basitarsi and tarsomere II black.

HEAD. Elongate, rectangular, flattened dorsally and almost $1.3 \times$ as long as wide; broadest at the eyes. Vertex, with a very indistinct longitudinal median sulcus (Fig. 21). Eyes large, circular, projecting almost hemispherically and their length contained about $1.5 \times$ in that of cheeks. Antennae slightly longer than body. Scapus somewhat narrowed basally and almost $2 \times$ as long as wide, pedicellus sub-globose and antennomere III considerably longer than pedicellus.

THORAX. Pronotum shorter and much narrower than head, the transverse median sulcus somewhat displaced towards the anterior, faint, gently curved and expanding over entire width of segment (Fig. 21). Mesothorax some $2.7 \times$ as long as head and pronotum combined. Tegmina slender, spatulate and gradually constricted towards the base; roughly reaching to posterior margin of metanotum. Alae reaching about halfway along abdominal segment IV.

Abdomen. Median segment almost $3 \times$ as long as metanotum. Segments II-V roughly equal in length and about $6.5 \times$ as long as wide; VI somewhat shorter than preceding. VII $3 / 4$ the length of VI and constricted medially. VIII constricted, with lateral margins concave pre-basally and well separated from sternum VIII; 
Table 3. Measurements of Phantasca femorata sp. nov. (in mm). HT = Holotype; PT = Paratype.

\begin{tabular}{|c|c|c|c|c|}
\hline & q, HT (MNHN) & q, PT (MNHN) & $\widehat{\partial}$, PT (OC) & $\hat{o}$, PT (YB) \\
\hline Body & 83.3 & 90.4 & 73.0 & 68.8 \\
\hline Pronotum & 3.2 & 3.5 & 2.5 & 2.5 \\
\hline Mesonotum & 18.9 & 20.7 & 14.0 & 13.8 \\
\hline Metanotum & 5.9 & 6.5 & 3.0 & 2.5 \\
\hline Median segment & 6.8 & 7.3 & 9.0 & 8.1 \\
\hline Tegmina & - & - & 5.0 & 3.7 \\
\hline Alae & - & - & 32.0 & 30.6 \\
\hline Profemora & 17.4 & 20.3 & 21.0 & 22.2 \\
\hline Mesofemora & 10.5 & 12.4 & 15.0 & 14.2 \\
\hline Metafemora & 14.3 & 15.5 & 20.5 & 18.7 \\
\hline Protibiae & 16.0 & 17.7 & 25.8 & 22.7 \\
\hline Mesotibiae & 10.4 & 11.7 & 16.0 & 14.5 \\
\hline Metatibiae & 15.1 & 16.5 & 22.0 & 20.0 \\
\hline Antennae & 44.8 & 50.7 & $>70.0$ & 71.7 \\
\hline
\end{tabular}

the latter strongly swollen, bulgy, the widest of all segments and with the upper posterior angles somewhat protruded. Tergum IX about $1.3 \times$ as long as VIII and gradually constricted towards the anterior (Fig. 22); the lateral margins well separated ventrally. Vomer well developed, roughly triangular, tectinate, pale cream and with a single and fairly acute, slightly up-curving black terminal hook (Fig. 24). Anal segment slightly cucullate basally, increasingly flattened towards the posterior and somewhat longer than wide; posterior margin broadly rounded,, with a small median notch (Fig. 22); outer portions of posterior margin ventrally, with two small clusters of minute black denticles. Poculum, with the basal portion broad and strongly convex, the apical portion distinctly narrowed, elongated and linguiform, with the apex narrowly rounded; upper margins decidedly excavated (Fig. 23). Cerci roughly equal in length to anal segment,, with the apex gently incurving (Fig. 24); the interior surface blackish brown.

LEGs. Profemora a little longer than head, pro- and mesothorax combined, mesofemora somewhat longer than mesothorax and metatibiae, distinctly projecting beyond apex of abdomen. Basitarsi more than 1.5× the length of remaining tarsomeres combined.

Female (Fig. 16)

BoDy. Size fairly large (body length $83.3-90.4 \mathrm{~mm}$, Table 3); form moderately slender. Body entirely smooth.

CoLour. General colour dull yellowish green, with some faint and washed brown mottling, particularly on the meso- and metapleurae. Cheeks, with a very faint and weakly defined greyish postocular streak. Pronotum, with a well defined black longitudinal line near lateral margins. A very fine longitudinal brown line some distance off the lateral margins of meso- and metanotum. Posterior portions of abdominal tergites III-VIII, with a slight brownish wash (VI in particular). Cerci brown. All femora and tibiae, with the apical portion dark greyish brown (less distinct in front legs). Basal portion of profemora very pale green. Basitarsi pale cream, with the apex brown. Antennae dull green basally, then becoming straw and finally brown towards the apex. 
HEAD. Roundly rectangular, flattened, about $1.2 \times$ as long as wide, with the cheeks almost parallel-sided; vertex entirely smooth (Fig. 18). Eyes circular and their length contained $1.7 \times$ in that of cheeks. Antennae reaching about half way along abdominal segment II. Scapus rectangular and $1.9 \times$ as long as wide, pedicellus cylindrical, somewhat constricted apically and antennomere III very slightly longer than pedicellus.

THORAX. Pronotum shorter and narrower than head, rectangular, with the lateral margins somewhat concave and roughly $1.5 \times$ as long as wide; longitudinal median sulcus well defined and terminating some distance before posterior margin, transverse median sulcus distinct, gently curved and expanding over entire width of segment. Mesothorax $2.5 \times$ as long as head and pronotum combined.

AbDOMEN. Median segment about $1.2 \times$ as long as metanotum. Segments II-VI slightly unequal in length but of almost uniform width, on average $2.2 \times$ as long as wide. Tergum VI, with the lateral margins somewhat deflexed pre-posteriorly to form a narrow rounded lobe. Sternum VI, with the posterior margin somewhat deflexed into a scale-like structure. Praeopercular organ on sternum VII merely represented by two shallow humps and a rounded median impression (Fig. 19). VII shorter than all preceding. VIII-X of uniform width and slightly narrower than preceding. Anal segment about equal in length to IX, with the posterior margin broadly rounded and weakly notched medially. Epiproct small, roundly triangular, tectinate and decidedly projecting over posterior margin of anal segment. Cerci obtuse, straight, with a blunt apex and projecting beyond anal segment by about $3 / 4$ the length of that segment. Subgenital plate short, very flat, not keeled and with the acutely pointed apex very slightly projecting over posterior margin of tergum IX (Fig. 19).

LEGS. Stocky and fairly short for the genus, , with characteristic femoral lobes. Meso- and metafemora, with the two outer ventral carinae very weakly deflexed sub-basally and with a prominent, rounded lobe subapically, which extends by roughly the diameter of femur (Fig. 20). Meso- and metatibiae, with the two dorsal carinae very slightly deflexed apically. Mesobasitarsus about equal in length to combined length of remaining tarsomeres, pro- and metabsitarsus decidedly longer.

\section{Remarks}

It cannot be fully confirmed whether the only known two females (HT and PT) in MNHN are adult or still penultimate instar nymphs. It is hoped that more material including the still unknown eggs will soon become available for clarification.

\section{Distribution}

French Guiana: Montagnes de Kaw, Piste de Kaw (MNHN); Commune de Roura, Montagne des Chevaux (OC); St. Elie (ASPER).

Phantasca guianensis sp. nov. urn:1sid:zoobank.org:act:B03CA146-6F50-4925-AC6A-A72DC138FBB5

Figs $25-41$

\section{Material examined}

Holotype

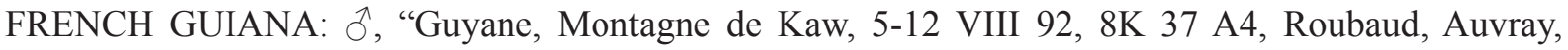
Rarchaert rec.” (MNHN).

\section{Paratypes}

FRENCH GUIANA: 1 , , “Guyane, Piste de Kaw, 5-VII-92, Roubaud, Rarchaert, Morin, Auvray rec.; 5“ (MNHN); 1 9 , “GUY15-050 13-VII-2015, Guyane française, Route de Roura, N442.148' W52 ${ }^{\circ} 18.262^{\prime}$, rec. T. Jourdan, coll. ASPER" (ASPER-PL); 1ㅇ, "Guyane, Roura, route de Kaw, VIII-2014, Christian Bouladou-Dupré rec.“ (ASPER-YB); 10 eggs, "Guyane, Roura, route de Kaw, VIII.2014“ (ASPER-PL); 

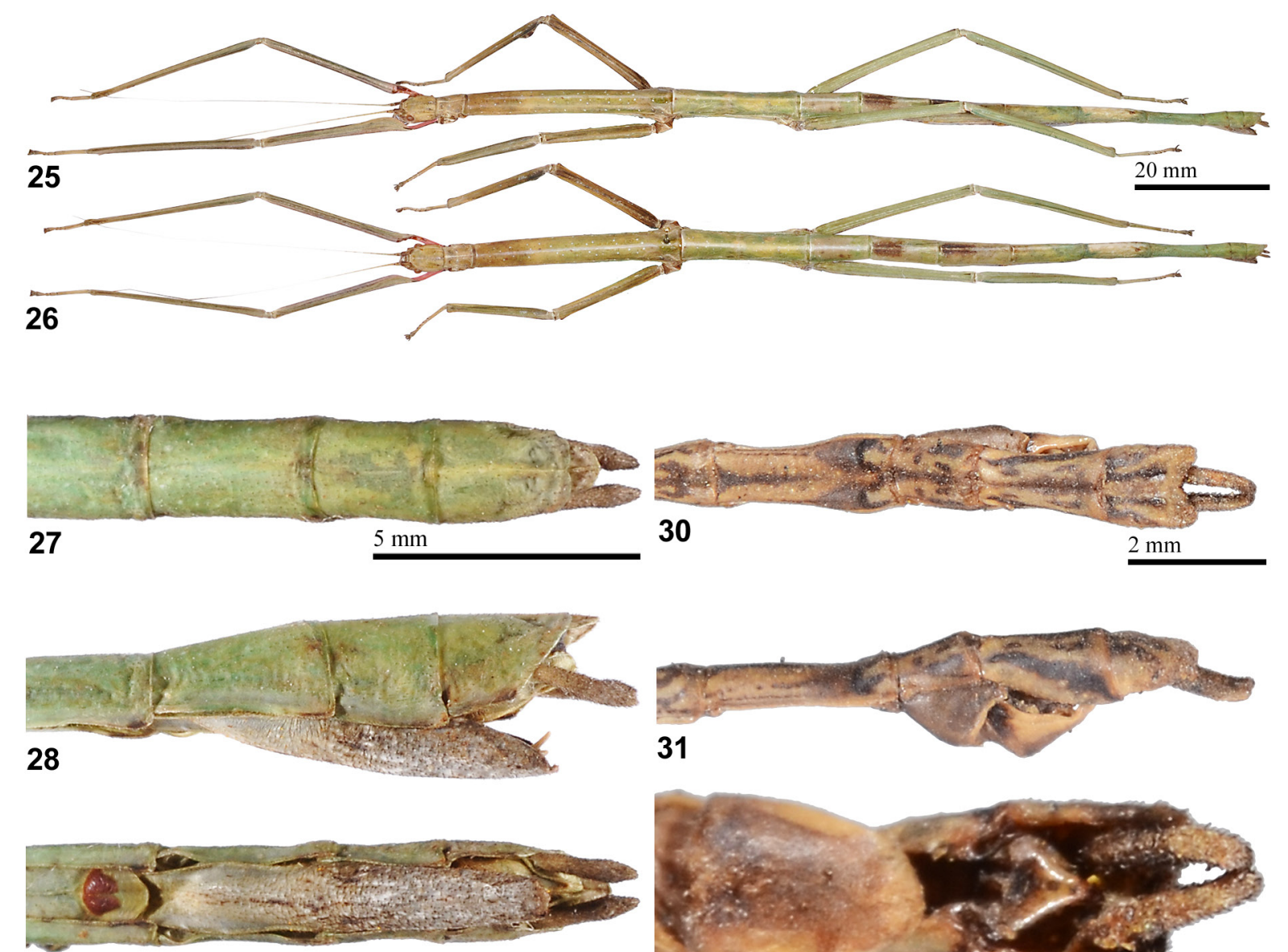

29
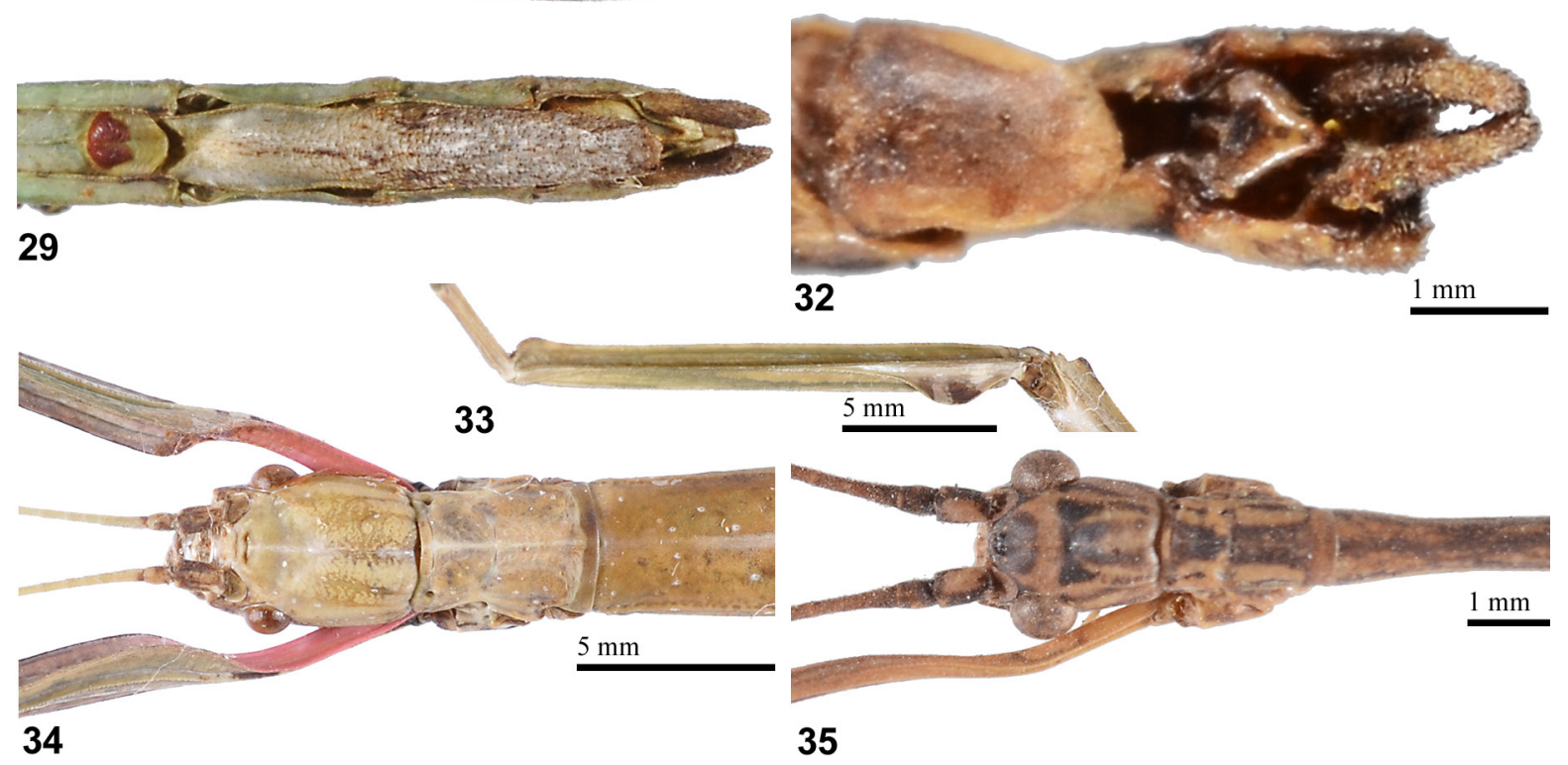

Figs 25-35. Phantasca guianensis sp. nov. 25. Holotype, + , habitus, dorsolateral view. 26. Holotype,, , habitus, dorsal view. 27. Holotype, $q$, apex of abdomen, dorsal view. 28. Holotype, $q$, apex of abdomen, lateral view. 29. Holotype, + , apex of abdomen, ventral view. 30. Paratype, $\partial$, apex of abdomen, dorsal view. 31. Paratype, $\hat{\partial}$, apex of abdomen, lateral view. 32. Paratype, $\hat{\partial}$, apex of abdomen, ventral view. 33. Holotype, $q$, left mesotibia, ventrolateral view. 34. Holotype, $q$, head, pro- and mesothorax, dorsal view. 35. Paratype, $\widehat{\jmath}$, head, pro- and mesothorax, dorsal view. 
27 eggs, "Guyane, Roura, route de Kaw, VIII.2014“" (ASPER-YB); 10 eggs, "Guyane, Route de Roura, 13-VII-2015“ (ASPER-YB).

\section{Diagnosis}

Males of this new species resemble those of P. quadrilobata (Chopard, 1911) and P. phantasma (Westwood, 1859), with respect to the colouration of the head and body, but the very elongate and almost straight cerci, which project beyond the apex of the abdomen by almost the length of the anal segment, readily distinguish $P$. guianensis sp. nov. from these two species (Fig. 31). Furthermore, the anal segment is almost parallel-sided (Fig. 30) and has the broad posterior margin, with a fairly wide triangular excavation (narrowed posteriorly, with the posterior margin deeply incised in P. phantasma and with the lateral margins rounded and the posterior margin only, with a small triangular median incision in P. quadrilobata). Females are similar to those of P. quadrilobata (Chopard, 1911) but differ by the somewhat larger size, less globose and unicoloured head, lack of paired humps on abdominal tergum VI, larger epiproct (Fig. 27), slightly longer cerci (Fig. 28), broader legs which have all carinae more decidedly deflexed, as well as the interiorly bright red bases of the profemora (Fig. 34).
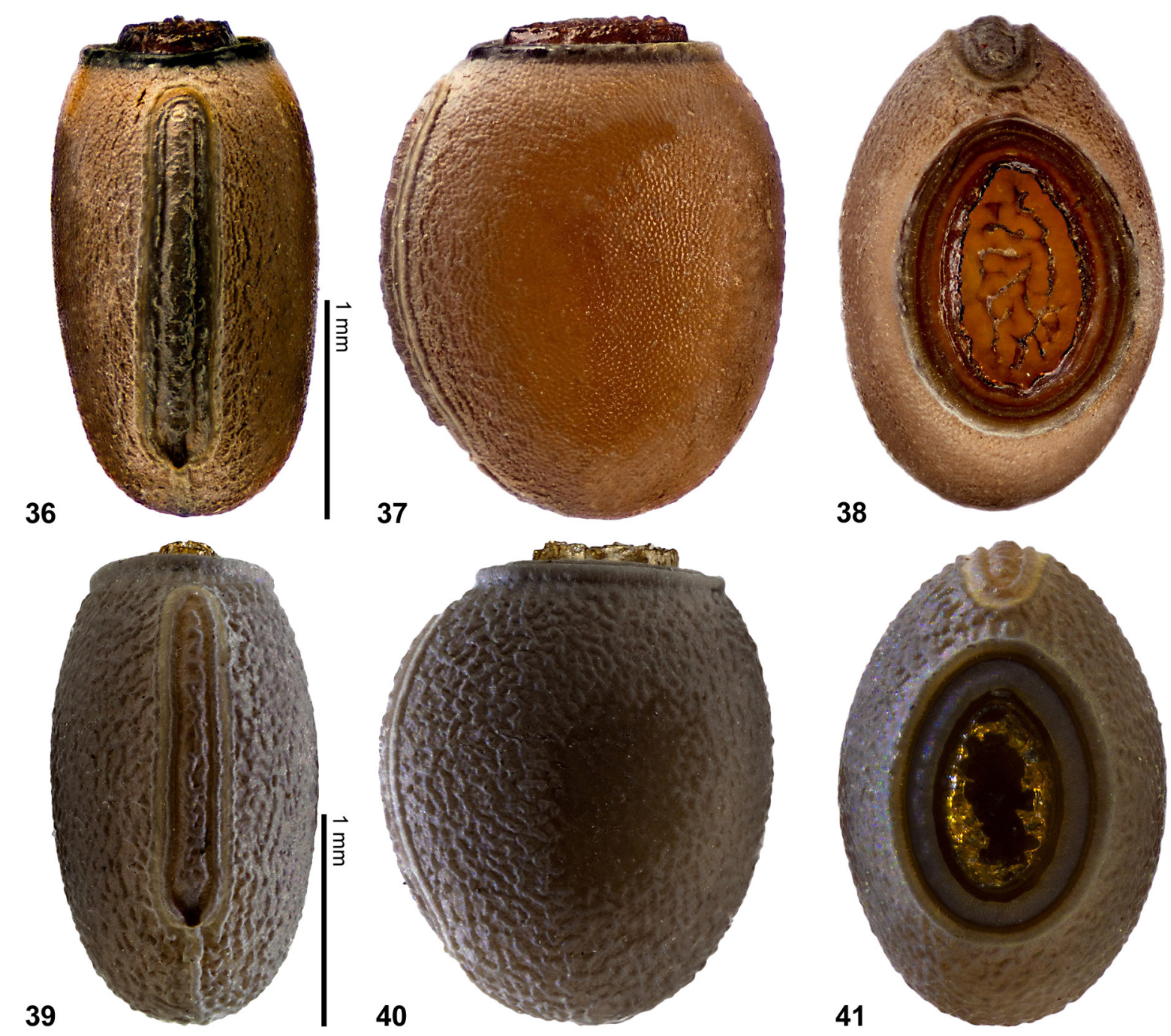

Figs 36-41. Phantasca guianensis sp. nov., eggs. 36. Type A, dorsal view. 37. Type A, lateral view. 38. Type $A$, anterior view. 39. Type $C$, dorsal view. 40. Type $C$, lateral view. 41. Type $C$, anterior view. 
Table 4. Measurements of Phantasca guianensis sp. nov. (in mm). HT = Holotype; PT = Paratype.

\begin{tabular}{lccc} 
& $\hat{0}, \mathbf{H T}(\mathbf{M N H N})$ & q, PT $(\mathbf{M N H N})$ & q, PT (ASPER-YB) \\
Body & 63.5 & 125.0 & 102.0 \\
Pronotum & 1.6 & 4.1 & 3.5 \\
Mesonotum & 14.2 & 28.8 & 23.5 \\
Metanotum & 4.6 & 7.9 & 6.1 \\
Median segment & 12.3 & 8.7 & 8.2 \\
Tegmina & 3.6 & - & - \\
Alae & 25.6 & - & - \\
Profemora & 21.1 & 27.5 & - \\
Mesofemora & 14.8 & 18.2 & 16.1 \\
Metafemora & 19.3 & 24.0 & 21.3 \\
Protibiae & 23.4 & 28.0 & - \\
Mesotibiae & 16.1 & 18.2 & 15.6 \\
Metatibiae & 22.4 & 26.6 & 21.2 \\
Antennae & 48.0 & $>54.0$ & $>50.0$ \\
\hline
\end{tabular}

\section{Etymology}

Named after its distribution in French Guiana.

\section{Description}

\section{Male}

BoDy. Size fairly large (body length $63.5 \mathrm{~mm}$, Table 4); form slender and fairly usual for the genus.

Colour. HT discoloured by preceding storage in ethanol. Colour pale to mid brown, with a slight greenish hue on legs in particular and irregular dark brown mottling on thorax and abdomen. Head, with a bold black marking on frons and four black markings on vertex, each of which continue in a longitudinal streak that becomes increasingly less defined and terminates just before posterior margin of head capsule; the two outer markings triangular. Between the eyes, with a bold pale transverse stripe (Fig. 35). Cheeks, with two faint dark postocular lines and the lower portions of head capsule black. Scapus blackish brown,, with a bold pale brown spot intero-medially. Pronotum, with the median portion broadly blackish brown and with a short, longitudinal stripe near lateral margins on the anterior and posterior half. Probasisternum, with a black T-shaped marking. Posterior portion of mesonotum black, the lateral margins straw; mesosternum dark brown. Anal region of alae transparent grey. Abdominal sternites blackish on the posterior portion and with a pale median marking close to posterior margin; the fine longitudinal median carina pale brown. Abdominal tergum VII, with a pair of distinct C-shaped markings close to posterior margin, VIII and IX each, with a black median line, a black stripe laterally and four black spots between these lines. Anal segment, with two fine longitudinal black lines. Femora dull green, tibiae straw and both, with the apex brown.

Head. Ovoid, with the vertex very gently convex and smooth; broadest at the eyes (Fig. 35). Eyes large, projecting hemispherically and their length contained about $1.3 \times$ in that of cheeks. Antennae longer than body. Scapus rectangular and $1.4 \times$ as long as wide, pedicellus cylindrical and somewhat constricted apically, antennomere III decidedly longer than pedicellus. 
THORAX. Pronotum slightly shorter but distinctly narrower than head and very gently narrowed towards the posterior (Fig. 35). Transverse median sulcus moderately distinct, straight and expanding over entire width of segment. Mesothorax $3.3 \times$ as long as head and pronotum combined; mesosternum, with a fine longitudinal median carina. Tegmina slender, spatulate, strongly constricted in the basal half and with the apical portion moderately broadened and acutely angular. Alae reaching to posterior margin of abdominal segment IV.

AвDomen. Median segment almost $3.7 \times$ as long as metanotum. Segments II-VII slightly decreasing in length. II about $5.5 \times$ and VII about $3 \times$ as long as wide; the latter somewhat deflexed posteriorly. Sternites II-VII, with a very fine but acute longitudinal median carina. Tergum VIII shortest of all segments, hardly longer than wide and not broader than preceding; the lateral margins well separated from sternum VIII. IX about $1.7 \times$ as long as VIII, narrowed in anterior half and with the posterior increasingly broadened; the lateral margins deflexed and curved inward ventrally, but well separated. Anal segment as broad as posterior portion of VII, parallel-sided, a little longer the wide; the posterior margin, with a broad triangular excavation (Fig. 30), the outer angles obtusely triangular and with several minute denticles ventrally. Vomer small, triangular in shape and with a slightly upcurving, acute apical hook (Fig. 32). Cerci long, slender, very gently upcurving and projecting beyond anal segment by almost the length of that segment (Fig. 30). Sternum VIII moderately swollen and with the posterior margin deflexed into a straight, labiate carina. Poculum small, roundly angular in basal portion and roundly triangular in ventral aspect,, with the apex obtusely rounded (Fig. 32), somewhat upcurving and just not reaching posterior margin of tergum IX; lateral margins moderately excavated in lateral aspect (Fig. 31).

LEGS. All very long and slender, profemora somewhat longer than head, pro- and mesothorax combined and metatibiae projecting considerably beyond apex of abdomen. All basitarsi decidedly longer than combined length of remaining tarsomeres.

Female (Figs 25-26)

Body. Size large (body length 102.0-125.0 mm, Table 4) and apparently the largest known species in the genus; form slender, with fairly stocky and distinctly carinate legs. Body smooth except for a longitudinal line of minute white granules on mesopleurae.

CoLour. Colour of paratype in MNHN (Figs 25-26) dull green, with a few small, irregularly dispersed white spots on head, thorax and the basal abdominal segments. Mesonotum, with a very faint whitish longitudinal median streak, most of ventral body surface greyish. Abdominal tergites III and IV each, with a bold, washed brown marking on anterior half and most of tergum VI whitish, with two small brown spots near posterior margin. Bases of profemora bright red interiorly (Fig. 34) and the posterodorsal carina on the basal portion marked by a distinct black line. Other specimens greyish brown.

HEAD. Roundly rectangular, the vertex very gently convex and with a scarce longitudinal median sulcus, the cheeks widened (Fig. 34). Eyes fairly small, circular and their length contained about $2.5 \times$ in that of cheeks. Antennae reaching about half way along median segment. Scapus rectangular and very slightly narrowed sub-basally, $1.5 \times$ as long as wide. Pedicellus sub-globose, antennomere III some $1.5 \times$ as long as pedicellus.

THORAX. Pronotum rectangular and somewhat narrowed medially, shorter and narrower than head; transverse median sulcus indistinct, very short and expanding no more than half of segment (Fig. 34). A deep impression near anterolateral angles. Mesothorax almost $3 \times$ as long as head and pronotum combined, of uniform width.

ABdomen. Median segment slightly longer than metanotum; gently constricted medially. Abdominal segments II-VII roughly of uniform width, II-IV slightly increasing and V-VII decreasing in length; 
V about $3.6 \times$ as long as wide. Tergum VII very gently deflexed posterolaterally. Sternites II-VI very slightly tectiform, VII, with a fine but acute longitudinal median carina. Praeopercular organ formed by a slightly deflexed and scale-like posterior margin of sternum VII and two fairly distinct, reddish brown swellings some distance before posterior margin (Fig. 29). Tergites VIII-X of uniform width and somewhat narrower than preceding. Anal segment a little longer than IX, narrowed towards the posterior and with a longitudinal median carina dorsally; posterior margin broadly rounded, slightly labiate and with a shallow notch medially. Epiproct large, scale-shaped, almost semicircular,, with an acute keel dorsally and projecting considerably over anal segment (Fig. 27). Gonapophyses VIII elongated, gently upcurving and reaching to apex of subgenital plate (Fig. 28). Cerci constricted sub-basally,, with the apical half appearing slightly club-shaped and the apex itself fairly acute (Fig. 28); about $3 / 4$ the length of anal segment. Subgenital plate spatulate, with an acute lateral carina in basal portion, the apex obtuse triangular and almost reaching to apex of abdomen (Fig. 29).

LEGS. All fairly stocky for the genus, with all carinae, but the outer ventral ones in particular, lamellate. Anterodorsal carina of profemora strongly raised sub-basally. Outer ventral carinae of meso- and metafemora and all tibiae much deflexed, the posterodorsal carina of the meso- and metafemora and tibiae terminating in a small rounded lobe apically (Fig. 33). Medioventral carina of meso- and metatibiae acute and sub-basally deflexed to form a distinctive, rounded lobe (Fig. 33). Basitarsi about equal in length to remaining tarsomeres combined.

\section{Egg (Figs 36-41)}

There are three different types of eggs in this species, whose differences in colour and surface sculpturing of the capsule are summarized separately below. Fairly large for the genus, ovoid, distinctly oval in crosssection, almost $1.2 \times$ as long as high and about $1.75 \times$ as long as wide. Dorsal surface considerably more convex than ventral surface and the posterior portion somewhat narrowed. Complete capsule surface minutely and densely granulose and to a variable degree covered by an irregular network of ridges; the latter are differently pronounced in the three types of eggs (see below). Micropylar plate elongate, slender and very gently widened posteriorly; on average some $4.6 \times$ as long as wide and almost $0.8 \times$ the length of capsule. Outer margin somewhat raised and the interior portion, with an irregularly sculptured, scabrous longitudinal median bulge. Micropylar cup small, bowl-shaped. Median line almost reaching to polar-area. Operculum flat and oval; capitulum represented by a raised rim and some irregularly shaped acute ridges in the centre.

Type A (Figs 36-38): General colour plain ochre, with the micropylar plate dark greyish brown. The opercular collar black and the operculum itself reddish brown, with the capitular structures very dark reddish brown. Network of ridges of capsule weakly pronounced and most obvious on dorsal surface around micropylar plate.

Type B: General colour glossy dark brown, with the micropylar plate sepia. Operculum black and capitular structures dull greyish brown. Network of ridges of capsule indistinct.

Type C (Figs 39-41): General colour plain dull greyish mid brown, with the micropylar plate dark brown. Operculum dark brown and the capitular structures brown, with a slight golden hue. Network of ridges of capsule considerably more pronounced than in the other two types, giving the egg a quite strongly sculptured overall appearance.

Measurements (in mm). Length (incl. operculum) 2.70, length 2.40, width 1.50, height 1.90, length of micropylar plate 1.80 . 


\section{Remarks}

Captive breeding has been attempted from parthenogenetically produced eggs laid by the female paratype collected along Route de Roura in 2015 but has proven difficult. Eucalyptus (Eucalyptus spp., Myrtaceae) was accepted as an alternative food plant by the nymphs, but none reached maturity.

\section{Distribution}

French Guiana: Commune de Roura, Montagnes de Kaw (MNHN); Commune de Roura, Route de Roura (ASPER); Commune de Roura, Route de Kaw (ASPER).

Phantasca heteronemia (Günther, 1940) comb. rev.

Figs $42-46$

Pterolibethra heteronemia Günther, 1940: 499.

Pterolibethra heteronemia - Zompro 2001: 225. — Otte \& Brock 2005: 294.

Phantasca heteronemia - Günther 1940: 500.

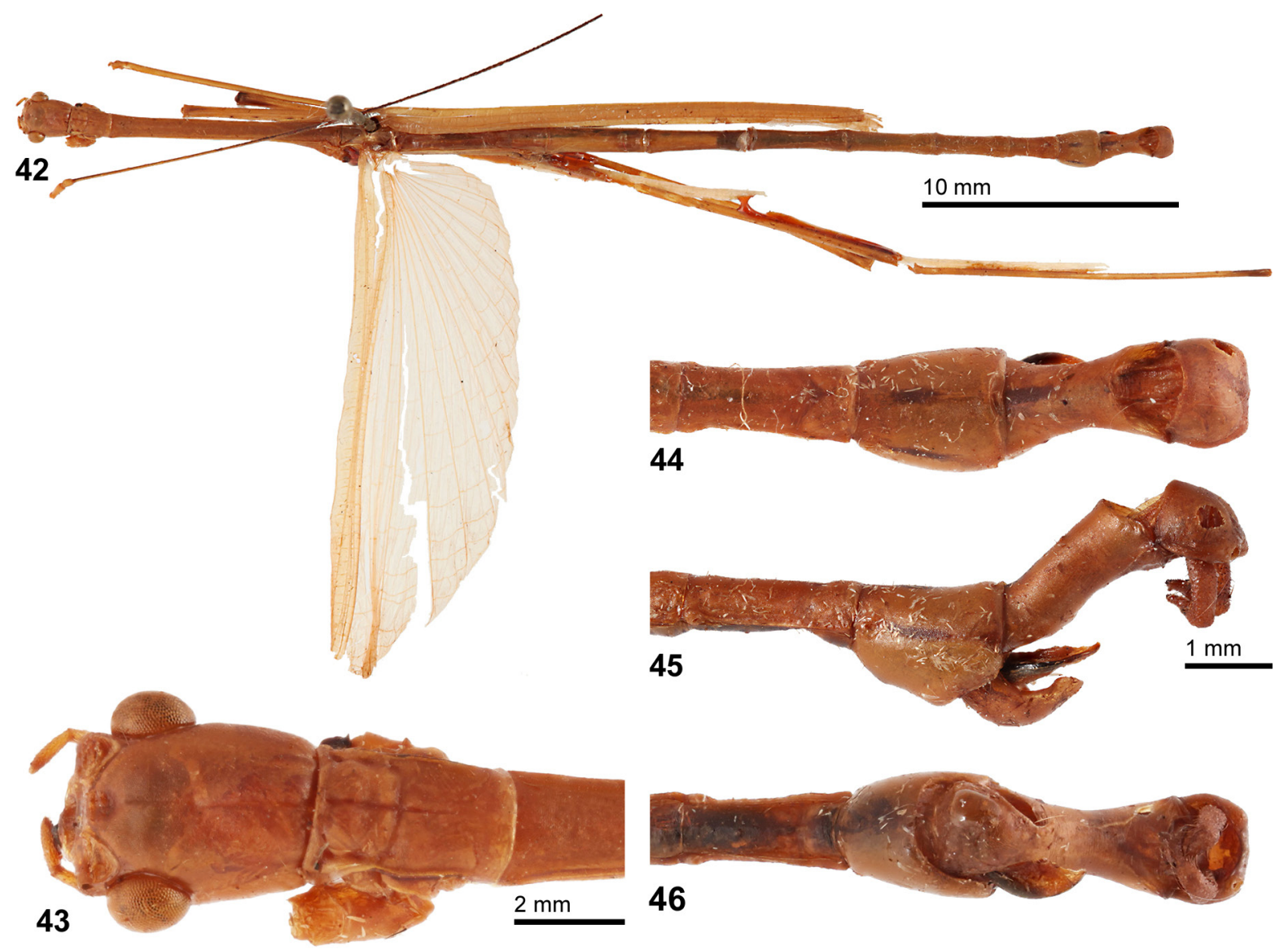

Figs 42-46. Phantasca heteronemia (Günther, 1940). Holotype, §.. 42. Habitus, dorsal view. 43. Head and pronotum, dorsal view. 44. Apex of abdomen, dorsal view. 45. Apex of abdomen, lateral view. 46. Apex of abdomen, ventral view. 


\section{Material examined}

Holotype

BRAZIL: $\widehat{\partial}$, "Sv. Amaz. Exp. Roman; S. Gabriel; 3 jan.; Pterolibethra heteronemia n. gen. n. sp. K. Günther det.; skadad aveld; Typus; NRM-PHAS 0000229“ (NHRS).

\section{Diagnosis}

Males of this species (the only sex known) are well characterised by the stocky body and having the body segments relatively shorter than in all other known species of Phantasca. The long and hook-like cerci (Fig. 45) are shared, with P. poeciloptera (Günther, 1940) and the bulgy anal segment, with its almost entire posterior margin is shared, with $P$. ruboligata sp. nov.; however, both features show distinctive characters. The cerci are comparatively longer than in P. poeciloptera, have only the very apical portion angled inward and the apex is much more acutely pointed. Furthermore, $P$. heteronemia differs from P. poeciloptera by the plain overall colour and transparent anal region of the alae (dark brown, with the basal half bright orange in P. poeciloptera) and lacking the distinct posteromedian emargination of the anal segment. From P. ruboligata sp. nov. it differs by the plain colouration as well as having the apex of the poculum constricted pre-apically and the posterior margin distinctly broadened (gently bilobate and without a pre-apical narrowing in $P$. ruboligata sp. nov.).

\section{Description}

Male (Fig. 42)

Body. Size very small (body length $45.5 \mathrm{~mm}$, Table 5); form fairly stocky for the genus.

CoLour. General colour of the holotype drab, with a slight greenish wash dorsally (possibly green when alive). Mesosternum brown and becoming blackish brown towards the posterior, metasternum dull blackish brown. Sternites II-IV black, V-VI, with a broad longitudinal black stripe, VII dark brown anteriorly and with a black spot at posterior margin. Tergum VIII, with a small, elongate black central marking and a short and faint black streak near lateral margins; IX, with a black longitudinal median stripe on anterior half. Sternum VIII, with a faint and washed black central marking. Cerci dull reddish brown. Costal region of alae plain pale drab, the anal region hyaline. Antennae, with scapus and pedicellus drab, the following antennomeres buff dorsally and black ventrally. Coxae reddish brown, all femora and tibiae, with the apex dark brown.

HEAD. Flattened and broadest just behind the eyes; cheeks gently narrowing and vertex, with a very weakly defined longitudinal median sulcus (Fig. 42). Eyes large, slightly oval in outline, projecting hemispherically and their length contained $1.4 \times$ in that of cheeks. Pedicellus rectangular, pedicellus subglobose, antennomere III slender and almost $3 \times$ as long as pedicellus.

THORAX. Pronotum decidedly shorter and narrower than head, rectangular,, with a well-defined longitudinal median sulcus, which fades considerably before the posterior margin, and a fairly distinct transverse sulcus that expands over the entire width of the segment (Fig. 42). Mesothorax moderately elongate and some $2.5 \times$ as long as head and prothorax combined. Tegmina lacking in the holotype. Alae reaching about halfway along abdominal segment $\mathrm{V}$.

AвDOMEn. Median segment about $3 \times$ as long as metanotum. Segments II-VI slightly subequal in length, all gently constricted medially; on average $5 \times$ as long as wide. VII considerably shorter than all preceding and very slightly thickened posteriorly. Tergum VIII strongly swollen, convex and widest of all segments, the lateral margins fully fused, with sternum VIII and fissure between these two segments scarcely indicated by a faint brown longitudinal streak (Fig. 45). IX a little longer than VIII and strongly constricted medially, its lateral margins completely fused, with each other ventrally to form a closed tube (Fig. 46). Anal segment strongly cucullate (Fig. 44), slightly wider than long and with a shallow median indentation at posterior 
Table 5. Measurements of Phantasca heteronemia (Günther, 1940) (in mm). HT = Holotype.

\begin{tabular}{lc}
\hline & $\hat{\jmath}$, HT (NHRS) \\
\hline Body & 45.5 \\
Pronotum & 1.4 \\
Mesonotum & 9.0 \\
Metanotum & 2.0 \\
Median segment & 6.0 \\
Tegmina & - \\
Alae & 21.0 \\
Profemora & 14.5 \\
Mesofemora & 10.5 \\
Metafemora & 15.0 \\
Protibiae & 14.4 \\
Mesotibiae & - \\
Metatibiae & - \\
Antennae & $>25.0$ \\
\hline
\end{tabular}

margin, the outer posterior portions obtusely rounded. Cerci large, hook-like, longer than anal segment, downward directed, with the apical half angled inward at an angle of $90^{\circ}$ and slightly directed cephalad; apex acutely pointed (Fig. 45). Poculum very small, slender, roundly bowl-shaped, with the dorsal margins concavely emarginated (Fig. 45), constricted pre-apically and the conspicuously widened posterior margin entire and almost straight; reaching no more than halfway along tergum IX (Fig. 46).

LEGS. All moderately long and slender for the genus; profemora slightly longer than head, pro- and mesothorax combined, mesofemora about equal in length to pro- and mesothorax combined and hind legs projecting distinctly over apex of abdomen. Metabasitarsus almost $2 \times$ the length of the remaining tarsomeres combined.

\section{Remarks}

So far only known from the unique male holotype, which has suffered from considerable damage since its original description. The specimen lacks most of the antennae, both tegmina and several parts of the legs including the pro- and mesotarsi. Female and egg unknown.

\section{Distribution}

North West Brazil: Amazonas State, Rio Negro, São Gabriel de Chachoiera (NHRS).

Phantasca montana (Redtenbacher, 1908) comb. nov.

Figs $47-48$

Bacteria montana Redtenbacher, 1908: 415.

Bacteria montana - Brock 1998: 43. — Otte \& Brock 2005: 65 


\section{Material examined}

\section{Holotype}

PERU: $\widehat{\partial}$, "Coll. Br. v. W., Alto Amazonas, Staudinger; det. Redtenb. Bacteria montana; 15.431" (NHMW 800).

\section{Diagnosis}

Males (the only sex known) are similar to those of P. puppeia (Westwood, 1859) but differ by the somewhat less elongate body and legs, slightly shorter cerci, smaller and apically labiate poculum, distinctive black markings on the head and pronotum, faint brown longitudinal stripe along the posterior margin of the tegmina and inner margin of the costal region of the alae, and the two dark elongate markings on the anal segment.

\section{Description}

\section{Male (Fig. 47)}

Body. Size medium (body length $52.5 \mathrm{~mm}$, Table 6); form moderately slender. Body surface entirely smooth.

Colour. Green, with a brownish wash, the mesonotum sepia except for the lateral portions and with a faint dark brown longitudinal line. Head, with two dark brown longitudinal stripes over entire dorsal

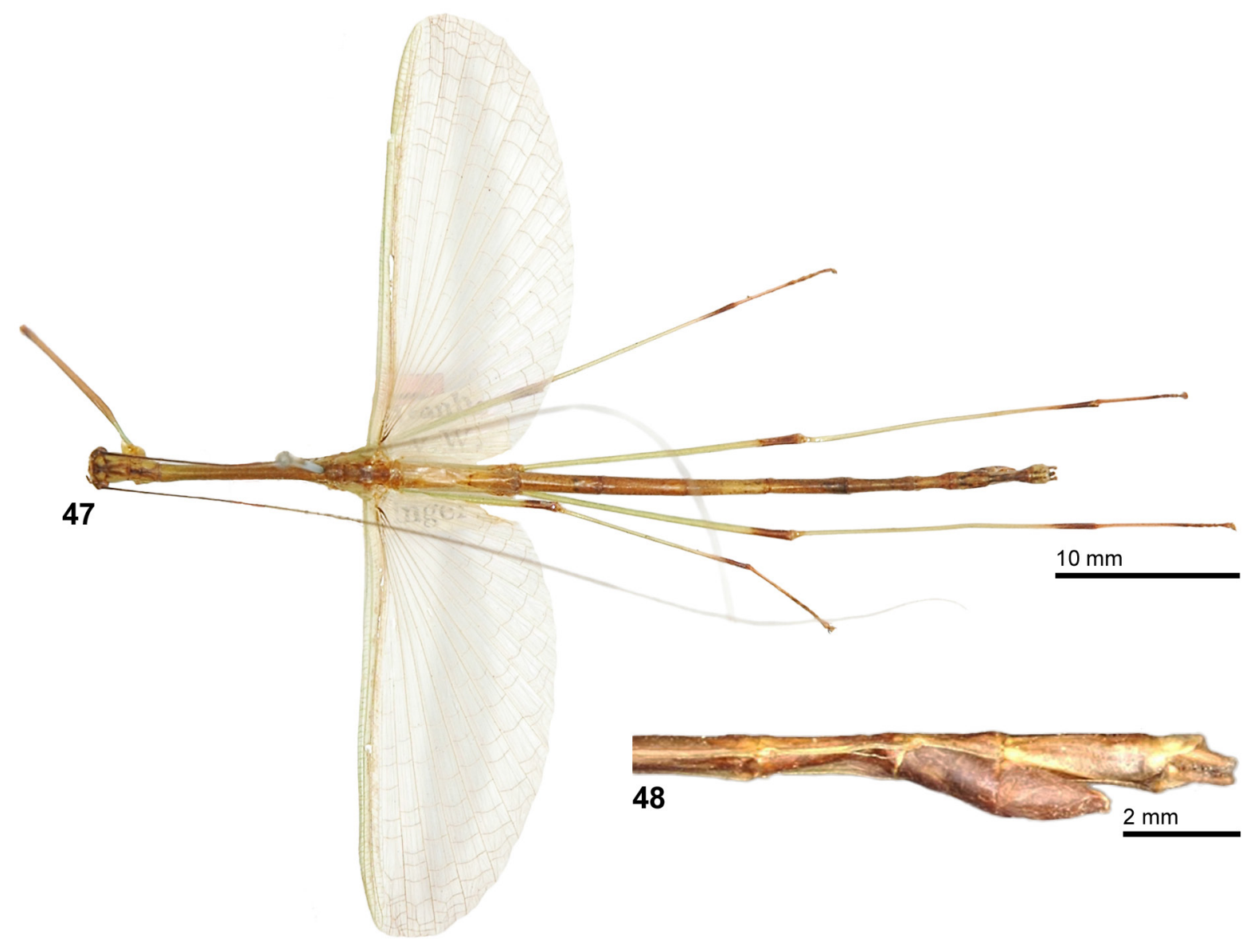

Figs 47-48. Phantasca montana (Redtenbacher, 1908). Holotype, ふ̋. 47. Habitus, dorsal view. 48. Apex of abdomen, ventrolateral view. 
Table 6. Measurements of Phantasca montana (Redtenbacher, 1908) comb. nov. (in mm). HT = Holotype.

\begin{tabular}{lc}
\hline & ô, HT (NHMW) \\
Body & 52.5 \\
Pronotum & 1.6 \\
Mesonotum & 10.0 \\
Metanotum & 2.7 \\
Median segment & 7.2 \\
Tegmina & 2.9 \\
Alae & 25.3 \\
Profemora & 17.6 \\
Mesofemora & 11.0 \\
Metafemora & 15.1 \\
Protibiae & - \\
Mesotibiae & 11.8 \\
Metatibiae & 17.0 \\
Antennae & $>51$ \\
\hline
\end{tabular}

surface, which slightly diverge towards the posterior. Above the eyes, with a small, roughly triangular dark brown spot and a black marking on frons. Antennae black except for scapus and pedicellus. Pronotum, with a black longitudinal median stripe on anterior half, which continues on the posterior half but becomes considerably more slender. Mesosternum brown, metasternum dull drab, with a sepia brown longitudinal line along lateral margins. Abdominal tergites II-VII, with a pair of blackish dots some distance off the posterior margin (indistinct on III-V) and VII, with two minute black spots near anterior margin. Tergites VIII-X each, with a pair of black stripes on anterior half. Tegmina and costal region of alae green, with the interior portions pale brown. Anal region of alae sub-hyaline, with all longitudinal veins and the major transverse veins on the outer portion marked, with brown; the four central longitudinal veins black at the base. Profemora pale brown, with the base pale green. Mid and hind legs pale green, with the apex blackish brown. Tarsi pale reddish brown,, with the apex of each segment dull brown.

HEAD. Sub-rectangular, flattened and the cheeks very slightly convex; indistinctly longer than wide and considerably wider than prothorax. Eyes large, circular in outline and projecting hemispherically, their length contained about $1.8 \times$ in that of cheeks. Antennae almost reaching apex of abdomen; scapus rectangular, pedicellus sub-globose and antennomere slender and considerably longer than pedicellus.

THORAX. Pronotum rectangular and about $1.2 \times$ as long as wide, the transverse median sulcus fairly distinct, gently curved and just not reaching lateral margins of segment. Mesothorax $2.6 \times$ as long as head and prothorax combined. Tegmina small, slender, spatulate, gradually narrowing towards the base, with the posterior margin obtusely angular. Alae reaching halfway along abdominal segment $\mathrm{V}$.

AвDomen. Median segment about $2.2 \times$ as long as metanotum. Segments II-VI slightly sub-equal in length, on average $4.5 \times$ as long as wide. VII shorter than all preceding and constricted medially. VIII almost equal in length to VII and slightly widening towards the posterior, the lateral margins distinctly separated from sternum VIII; the latter, with a slight transverse fissure medially. Tergum IX $1.2 \times$ as long as VIII and strongly constricted medially, the lateral margins deflexed ventrally and touching each other ventrally but clearly 
separated. Anal segment sub-quadrate and somewhat narrowed posteriorly, the posterior margin, with a shallow concave emargination medially. Cerci about $3 / 4$ the length of anal segment, straight and with the apex slightly club-like; projecting beyond apex of abdomen by about half the length of anal segment. Vomer very small and roundly triangular. Poculum tub-shaped, slightly carinate longitudinally and reaching about halfway along tergum IX; the posterior margin slightly labiate and with a minute median indention (Fig. 48).

LEGS. All moderately long and slender for the genus; profemora longer than head, pro- and mesothorax combined, mesofemora a little longer than mesothorax and hind legs projecting strongly beyond apex of abdomen. Mesobasitarsus roughly equal, metabasitarsus considerably longer than remaining tarsomeres combined.

\section{Remarks}

So far only known from the unique male holotype in NHMW. Female and egg unknown.

\section{Distribution}

East Peru: Dept. Loreto, Alto Amazonas (NHMW).

Phantasca nigrolineata sp. nov. urn:lsid:zoobank.org:act:36E32EBA-1BB0-4315-95F9-131346B85D25

Figs 49-65

Phantasca sp. I. - Jourdan, Lelong \& Bellanger 2014: 489.

\section{Material examined}

Holotype

FRENCH GUIANA: đ̊, “Guyane, Saül, rec. GEP” (MNHN).

\section{Paratypes}

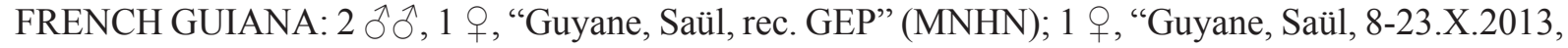
GUY13-035, leg. Y. Bellanger, P. Lelong \& T. Jourdan" (ASPER-PL); 1 + , "Guyane, Saül, 8-23.X.2013, GUY13-036, leg. Y. Bellanger, P. Lelong \& T. Jourdan" (ASPER-PL); 1 + , "Guyane, Saül, 8-23.X.2013, GUY13-096, leg. Y. Bellanger, P. Lelong \& T. Jourdan" (ASPER-YB); 1 đ’, “Guyane, Saül, 8-23.X.2013, GUY13-037, leg. Y. Bellanger, P. Lelong \& T. Jourdan" (ASPER-PL); 1 đ, "Guyane, Saül, 8-23.X.2013, GUY13-038, leg. Y. Bellanger, P. Lelong \& T. Jourdan" (ASPER-PL); 1 đ’, "Guyane, Saül, 8-23.X.2013, GUY13-097, leg. Y. Bellanger, P. Lelong \& T. Jourdan” (ASPER-YB); 1 đ’, “Guyane, Saül, 8-23.X.2013, GUY13-098, leg. Y. Bellanger, P. Lelong \& T. Jourdan" (ASPER-YB); 100 eggs, "Guyane, Saül, 8-23.X.2013, laid by GUY13-035, -036 and -096, leg. Y. Bellanger, P. Lelong \& T. Jourdan" (ASPER); 4 ổ, 58 eggs, "ex Zucht F. Hennemann 2015 (F2 Gen.), Herkunft: French Guiana, Commune de Saül, leg. Y. Bellanger, P. Lelong \& T. Jourdan 8.-23.X.2013" (FH 0867-4, E); 6 §ิో, 7 우, "Französisch Guyana, Ex Zucht O. Conle 2015, Gen F2, Commune de Saül, 10.2013, leg. Yannick Bellanger \& ASPER" (OC 0338-1-0338-13).

\section{Diagnosis}

Males of this new species are well characterised by the bold dark brown to black spot on the anterior portion of the head (Fig. 58), fine longitudinal median stripe on the vertex and pronotum, numerous small dark speckles on the mesonotum and costal region of the alae and having the main radial and transverse veins in the outer portion of the alae marked by dark grey or brown. The fairly long and almost straight cerci resemble those of $P$. puppeius (Westwood, 1859), but the smaller poculum, with its upcurving apex cleary distinguishes $P$. nigolineata sp. nov. from this species. Females are similar to those of $P$. ruboligata sp. nov. but readily differ by the more elongate and slender body and legs, plain 
green profemora (interior surface bright red in P. ruboligata) and somewhat shorter blunt cerci, which are at best equal in length to the anal segment (decidedly longer than the anal segment, with the apex acutely pointed in ruboligata). The eggs are distinctive by their lens-shaped capsule (Figs 63-65).

\section{Etymology}

The name of this new species refers to the distinctive black longitudinal median stripe on the head and pronotum of the males.

\section{Description}

Male (Figs 57-62)

Body. Size small (body length 46.0-52.6 mm, Table 7); form slender and fairly usual for the genus.

Colour. Ochre to pale brown, with a more or less distinct greenish hue and irregular dark brown mottling on thorax and abdomen. Head, with a bold dark brown to black longitudinal median streak, which is broadest and most prominent between the eyes and becomes increasingly less defined and narrower towards the posterior; on frons forming a weakly defined Y-shaped marking. Cheeks, with a faint brownish wash. Scapus dull ochre, the following antennomeres greyish mid brown, with the base pale ochre. Pronotum, with the median portion broadly blackish brown and with a short, longitudinal
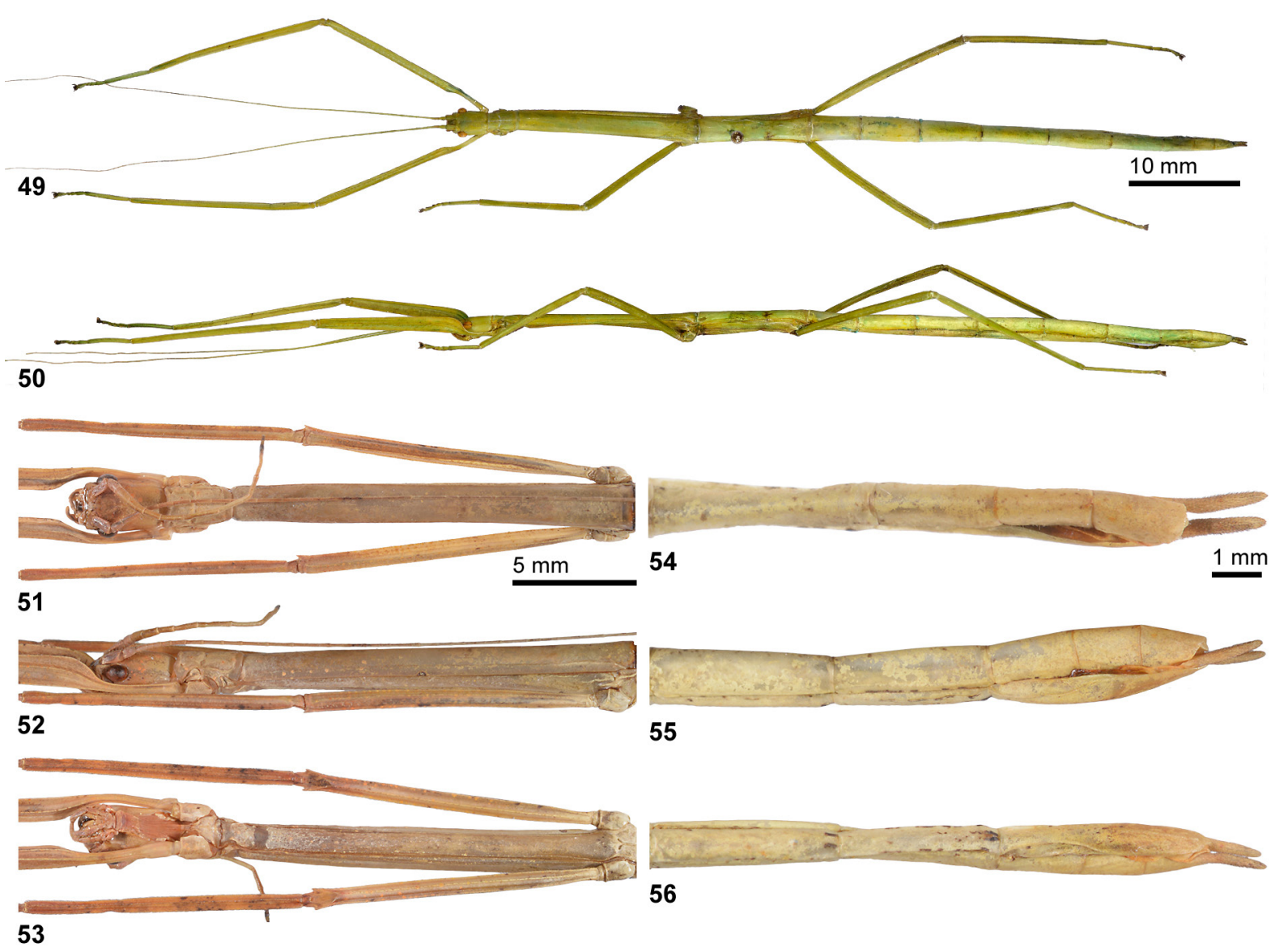

Figs 49-56. Phantasca nigrolineata sp. nov. Paratypes, + + . 49. Habitus, dorsal view. 50. Habitus, lateral view. 51. Head, pro- and mesothorax, dorsal view. 52. Head, pro- and mesothorax, lateral view. 53. Head, pro- and mesothorax, ventral view. 54. Apex of abdomen, dorsal view. 55. Apex of abdomen, lateral view. 56. Apex of abdomen, ventral view. 
stripe near lateral margins on the anterior half. Most of mesosternum dark brown. Tegmina and costal region of alae ochre to pale brown, with most of the transverse veins dark brown; occasionally, with some dark brown mottling. Anal region of alae transparent grey, with all veins dull grey; the radial veins 1-6 broadly black at the base. Abdominal sternum, with two black converging stripes on posterior half. Tergum VII, with a pair of distinct C-shaped markings close to posterior margin, VIII and IX each, with a fine black stripe laterally and VIII, with two black spots on basal half. Anal segment, with twofour short, diverging black stripes. Front legs ochre to pale brown, with faint irregular dark mottling. Meso- and metafemora, with the basal $2 / 3$ mid green, the tibiae and apical portion of femora straw, with irregular, more or less distintly defined dark brown annulations.

HEaD. Elongate-ovoid, with the vertex flattened and smooth; broadest at the eyes and the cheeks gently narrowing towards the posterior (Fig. 58). Eyes large, projecting hemispherically and their length
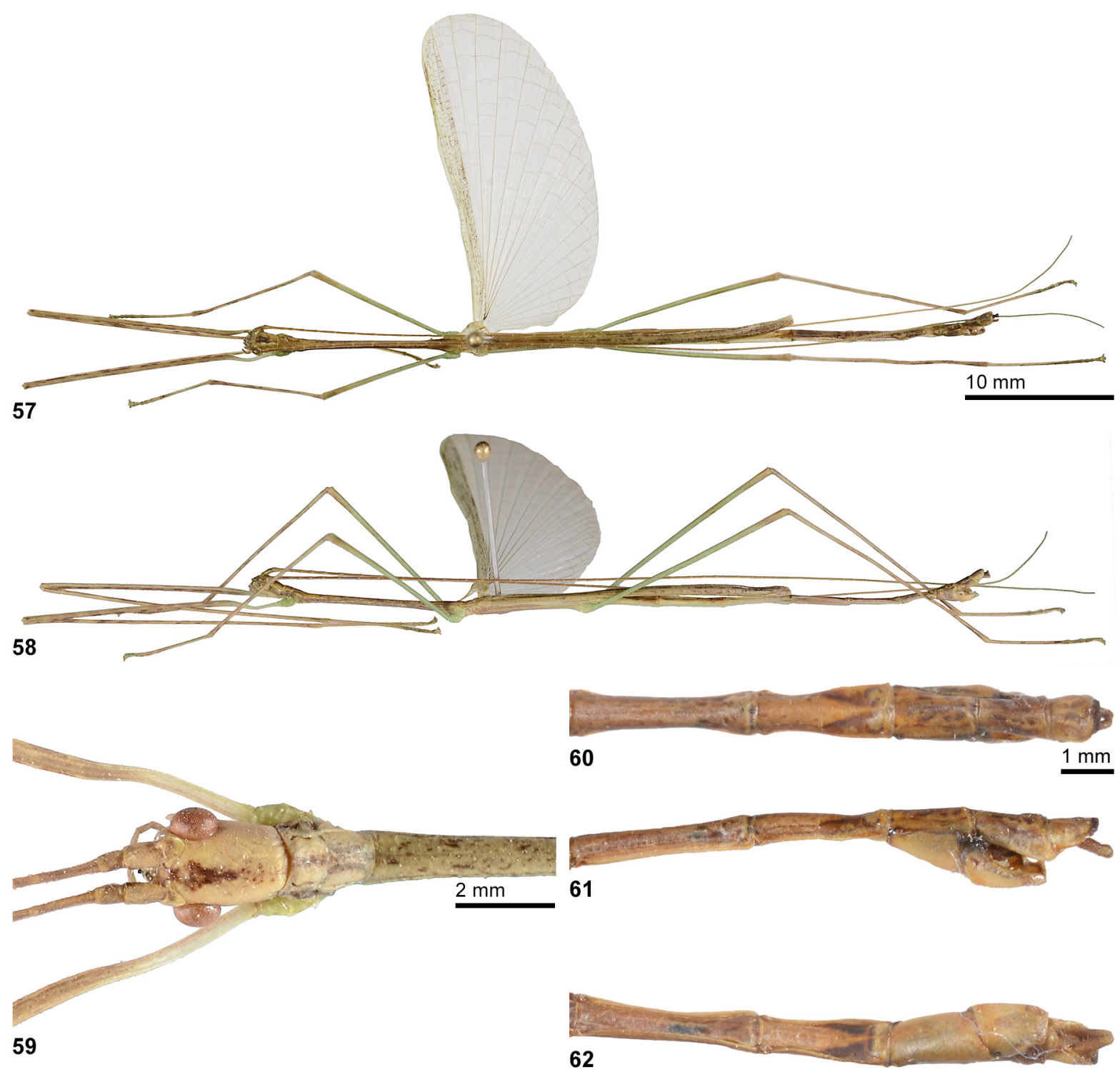

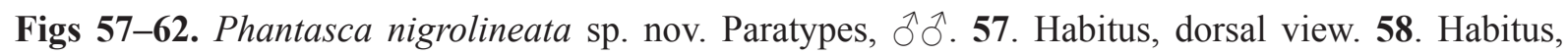
lateral view. 59. Head, pro- and mesothorax, dorsal view. 60. Apex of abdomen, dorsal view. 61. Apex of abdomen, lateral view. 62. Apex of abdomen, ventral view. 
contained almost $1.3 \times$ in that of cheeks. Antennae longer than body. Scapus rectangular and $1.5 \times$ as long as wide, pedicellus cylindrical and somewhat constricted apically, antennomere III decidedly longer than pedicellus.

Thorax. Pronotum about equal in length but distinctly narrower than head and very gently narrowed towards the posterior (Fig. 58). Transverse median sulcus moderately distinct, straight and expanding over entire width of segment. Mesothorax $2.8 \times$ as long as head and pronotum combined; mesosternum, with a very fine longitudinal median carina. Tegmina slender, spatulate, strongly constricted in the basal half and with the apical portion moderately broadened and acutely angular. Alae projecting somewhat over posterior margin of abdominal segment IV.

ABDOMEN. Median segment about $3.3 \times$ as long as metanotum. Segments II-VI about equal in length, VVII distinctly decreasing in length. II some $4.5 \times$ and VII only about $2.8 \times$ as long as wide; the latter roundly deflexed posteriorly. Sternites II-VII, with a very fine longitudinal median carina. Tergum VIII roughly equal in length to IX, the lateral margins well separated from sternum VIII. IX gradually widening towards the posterior; the lateral margins almost straight, somewhat deflexed and incurving in posterior portion but well separated ventrally. Anal segment as broad as posterior portion of VII, roundly rectangular and hardly longer than wide, posterior margin, with a very shallow concave indention (Fig. 59), the outer angles obtusely rounded and only, with a very few minute denticles ventrally. Vomer small, triangular in shape and with a slightly upcurving, acute apical hook. Cerci fairly long, slender, straight, with the apex slightly club-like and projecting beyond anal segment by about $2 / 3$ the length of that segment (Fig. 60). Sternum VIII obtusely swollen and considerably longer than tergum VIII. Poculum small, roundly triangular in ventral aspect, with the lateral margins strongly upcurving, roundly excavated sub-apically and forming two obtusely triangular projections apically (Figs 60-61); the apex V-shaped in caudal aspect.
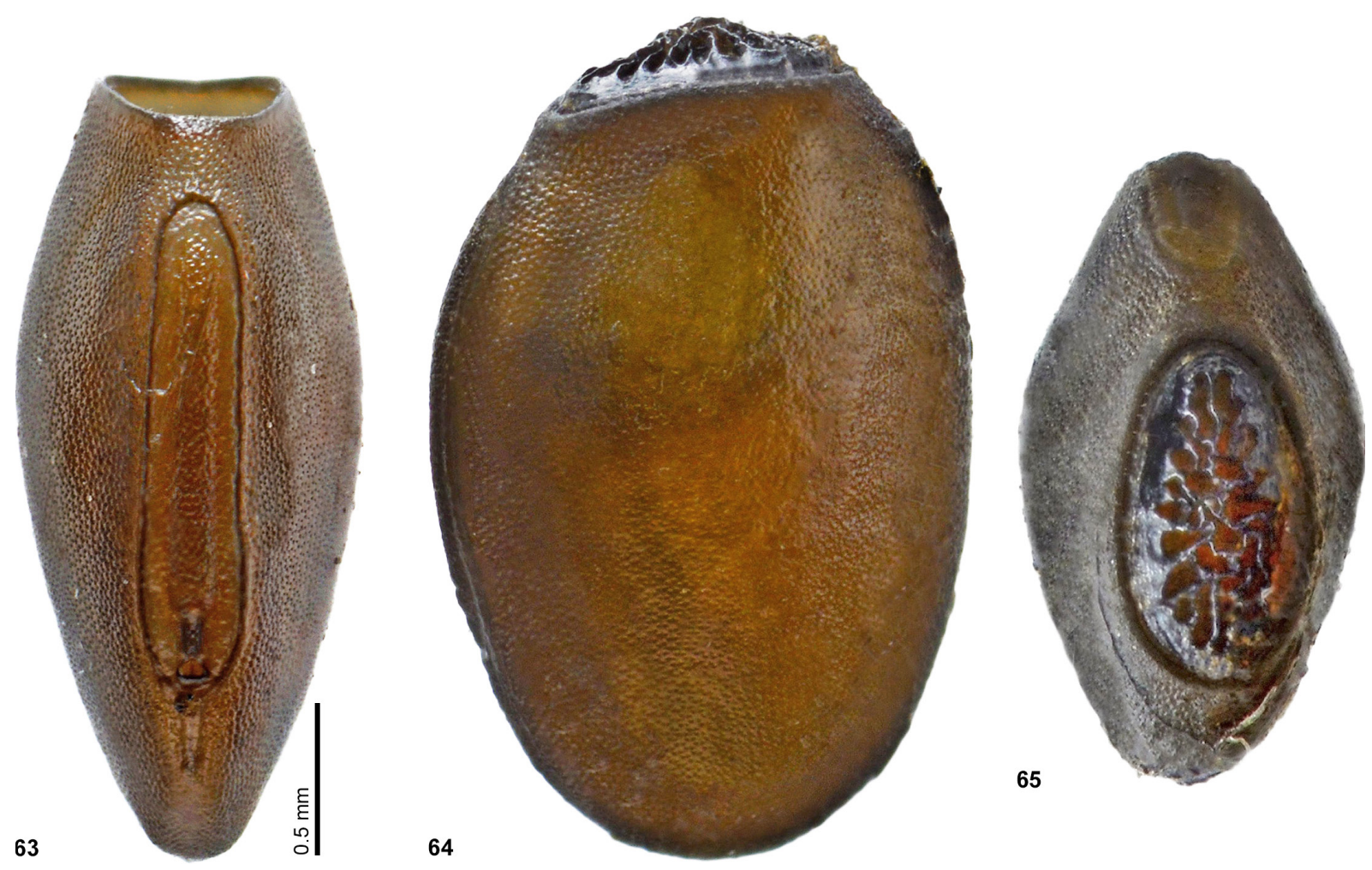

Figs 63-65. Phantasca guianensis sp. nov., egg. 63. Dorsal view. 64. Lateral view. 65. Anterior view. 
Table 7. Measurements of Phantasca nigrolineata sp. nov. (in mm). HT = Holotype; PT = Paratype.

\begin{tabular}{lccc}
\hline & $\hat{\jmath}, \mathbf{H T}(\mathbf{M N H N})$ & $\hat{\jmath}^{\wedge} \hat{\jmath}, \mathbf{P T}$ &,$++ \mathbf{P T}$ \\
\hline Body & 49.9 & $46.0-52.6$ & $65.0-77.2$ \\
Pronotum & 1.3 & $1.3-1.9$ & $2.8-3.5$ \\
Mesonotum & 10.5 & $9.7-10.7$ & $14.5-18.7$ \\
Metanotum & - & $2.0-2.9$ & $2.6-3.3$ \\
Median segment & - & $5.1-6.3$ & $6.9-7.8$ \\
Tegmina & 2.5 & $1.8-2.6$ & - \\
Alae & 21.6 & $20.0-23.0$ & - \\
Profemora & 16.8 & $15.0-18.0$ & $16.5-20.0$ \\
Mesofemora & 11.2 & $10.8-12.8$ & $10.6-13.8$ \\
Metafemora & - & $12.5-16.5$ & $14.0-16.9$ \\
Protibiae & 17.8 & $16.9-21.7$ & $17.9-21.0$ \\
Mesotibiae & 11.8 & $11.0-13.5$ & $11.3-13.0$ \\
Metatibiae & - & $15.3-18.7$ & $15.8-18.2$ \\
Antennae & 49.0 & $52.0-54.5$ & $42.0-43.9$ \\
\hline
\end{tabular}

LEGS. All very long and slender, profemora somewhat longer than head, pro- and mesothorax combined and metatibiae projecting much beyond apex of abdomen. All basitarsi decidedly longer than combined length of remaining tarsomeres.

Female (Figs 49-56)

Body. Size medium (body length 65.0-77.2 mm, Table 7); form slender, with long and slender legs. Body smooth except for a fine longitudinal median line on meso- and metanotum.

CoLour. Ranging from pale over dull green to mid brown; brown specimens usually, with a variable number of small, irregularly dispersed dark brown to black speckles. Abdominal tergites often, with a faint dark spot posteromedially. Cerci reddish brown.

HEAD. Roundly rectangular, the vertex flattened and with a scarce longitudinal median sulcus, cheeks slightly widened and roughly parallel-sided. Eyes of average size, circular and their length contained a little more than $2 \times$ in that of cheeks. Antennae roughly reaching to posterior margin of abdominal segment II; otherwise as in males.

Thorax. Pronotum rectangular, somewhat shorter and narrower than head and very gently narrowed medially; transverse median sulcus distinct, slightly curved and almost expanding over entire width of segment. Mesothorax about $2.3 \times$ as long as head and pronotum combined, uniform in width. Meso- and metasternum minutely and sparsely granulose.

ABDomen. Median segment only about $2 / 3$ the length of metanotum and gently constricted anteriorly. Abdominal segment II-VII roughly of uniform width, II-V slightly increasing in length, VI about as long as V and VII only $3 / 4$ the length of VI; V about $3.3 \times$ as long as wide. Tergites II-IX, with a shallow longitudinal carina near lateral margins. Sternum II sparsely granulose, remaining smooth. Praeopercular organ formed by a small wart-like median projection close to posterior margin of sternum VII. Tergites VIII-X of uniform width and somewhat narrower than preceding. Anal segment about equal in length to IX, with a fine longitudinal median carina and somewhat narrowed posteriorly (Fig. 53); the posterior margin, 
with a small median indention and the outer portions obtusely rounded. Epiproct small, scale-shaped, almost semicircular,, with an acute keel dorsally and just very slightly projecting over anal segment (Fig. 53). Gonapophyses VIII elongated, gently upcurving but staying considerably before apex of subgenital plate. Cerci long, slender, straight, gradually constricted towards a slender tip in the apical portion and projecting beyond apex of anal segment by about $3 / 4$ the length of that segment (Fig. 53). Subgenital plate keeled longitudinally, with the apex narrowed and forming a short triangular projection; almost reaching to posterior margin of anal segment (Figs 54-55). Lateral surfaces, with a curved longitudinal carina in basal half (Fig. 55).

LEGS. All long and slender. Anterodorsal carina of profemora moderately raised sub-basally. Profemora a little longer than mesothorax and metatibiae, reaching to abdominal segment VII or VIII. Pro- and metabasitarsus somewhat longer than remaining tarsomeres combined, mesobasitarsus about equal to combined length of remaining tarsomeres.

\section{Egg (Figs 63-65)}

Small, strongly laterally compressed and lens-shaped, with the dorsal and ventral surfaces as well as the polar-area strongly tectiform; the dorsal surface more convex than the ventral surface. Capsule about $1.5 \times$ as long as high and almost $2.3 \times$ as long as wide. Entire surface shiny and all over minutely granulose. Micropylar plate long, slender and parallel-sided, with only the posterior portion very slightly widened; on average some $5.1 \times$ as long as wide and almost $3 / 5$ the length of capsule. Interior portion somewhat raised and surface minutely granulose; the micropylar cup close to posterior end and bowl-shaped. Median line short and not reaching polar area. Operculum inserted at a slight angle and elongate-oval in shape. Capitulum gently convex and with an open network of irregularly shaped, roughly radially directed fringes. General colour of capsule plain dark brown, capitulum black.

Measurements (in mm). Length (incl. operculum) 2.77, length 2.59, width 1.16, height 1.78, length of micropylar plate 1.69 , diameter of operculum $0.58 \times 0.96$.

\section{Remarks}

Males in particular show some degree of variability concerning the overall colouration, as well as the shape of the black streak on the vertex. The latter ranges from a simple Y-shaped marking between the eyes to a streak that covers the entire length of the head capsule. While the pronotum has a washed dark longitudinal median stripe in most specimens at hand, it is almost completely lacking in some specimens.

Breeding in captivity from stock collected in Saül in 2013 has been attempted but the culture was lost after two generations. Bramble (Rubus fruticosus, Rosaceae) and rose (Rosa spp., Rosaceae) were readily accepted as alternative food plants. In Saül this species was exclusively found on guava (Psidium guyava, Myrtaceae) and also accepted this in captivity in French Guiana. Hence, guava is very likely to be part of the natural diet, but several other plants are believed to serve as food, since most species of Phantasca appear to be fairly polyphagous. Males are well capable of active flight and will frequently use this ability to escape when disturbed. On disturbance females usually drop to the ground and walk away quickly. Hatching rates of the eggs are fairly high and were at around $70 \%$ in the first generation. At average temperatures of $25^{\circ} \mathrm{C}$ incubation takes $10-12$ weeks, males reach maturity after five months and females take some six months to reach maturity. Parthenogenetic reproduction has been attempted, but hatching rates are very low and the incubation period for eggs extends to seven months.

\section{Distribution}

French Guiana: Commune de Saül (MNHN, ASPER, FH, OC). 
Phantasca phantasma (Westwood, 1859)

Figs 66-70

Phasma phantasma Westwood, 1859: 126, pl. 12: 5a-b (đ).

Cladoxerus phantasma - Kirby 1904: 358.

Phantasca phantasma - Redtenbacher 1906: 111. - Chopard 1911: 338. - Roubaud 1993: 11, fig. 1 (ふ). - Zompro 2001: 223, fig. 32 (ð). — Otte \& Brock 2005: 264. — Brock, Marshall, Beccaloni \& Harman 2016: 188.

non Phantasca phantasma - Chopard 1911: 338 (Misidentification, this is P. quadrilobata (Chopard, 1911).

\section{Material examined}

\section{Holotype}

BRAZIL: Ô, "Braz. Tapajos, 53 27; Type; Phantasma Westw.; Phasma phantasma Westw.; BMNH(E) \#844547” (NHMUK).

\section{Diagnosis}

The colouration of the males (the only sex known) is similar to that of $P$. guianensis sp. nov. and P. quadrilobata (Chopard, 1911). The genital morphology indicates a close relationship to the latter

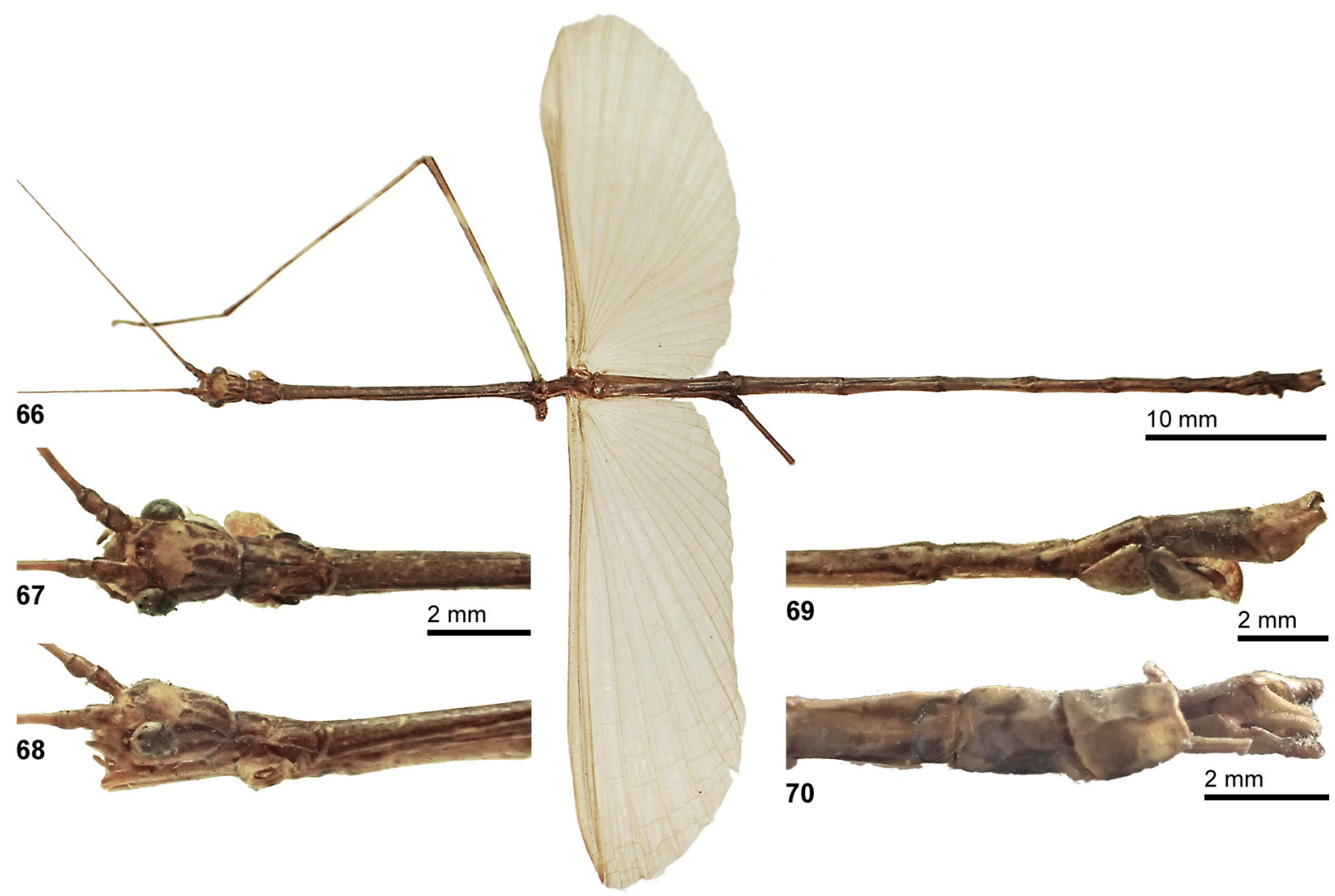

Figs 66-70. Phantasca phantasma (Westwood, 1859). Holotype, đ̊. 66. Habitus, dorsal view. 67. Head and pronotum, dorsal view. 68. Head and pronotum, lateral view. 69. Apex of abdomen, lateral view. 70. Apex of abdomen, ventral view. 
species,, with which it shares the short and upcurving cerci. However, the cerci in $P$. phantasma have the apex blunt (acutely pointed in P. quadrilobata), the anal segment has only the apical portion narrowed and with a very deep median incision, and the poculum is much larger and posteriorly labiate (small, roundly cup-shaped, with the lateral margins indented in P. quadrilobata). From P. guianensis sp. nov. it readily differs by the short cerci, which hardly reach to the posterior margin of the anal segment (very long and greatly projecting beyond apex of abdomen in $P$. guianensis sp. nov.), as well as the apically narrowed and deeply incised anal segment and decidedly larger, posteriorly labiate poculum.

\section{Description}

Male (Fig. 66)

BoDy. Size medium for the genus (body length $62.6 \mathrm{~mm}$, Table 8 ); form very slender and delicate.

CoLour. Pale greyish brown, with a slight greenish hue. Head buff, with several sub-parallel dark brown lines on cheeks and vertex (Figs 66-67). Pronotum, with a dark brown longitudinal median stripe on anterior half and several fine longitudinal stripes on posterior half. Mesonotum, with a very fine blackish longitudinal median and lateral line. Abdominal tergites II-IX, with a very fine dark brown longitudinal median line and a weakly defined dark brown line along lateral margins; III-VII, with four small dark brown dots posteriorly. Tergum VII, with a black lateral spot medially and two C-shaped black markings on posterior portion; VIII, with a black longitudinal lateral streak on posterior half. Anal segment, with a pair of very faint, washed brown, sub-parallel stripes. Tegmina and costal region of alae very pale brown, the anterior margin of the tegmina pale yellow near the base. Anal region of alae sub-hyaline, with a slight buffy wash and all longitudinal veins very slightly brown. All femora and tibiae, with three faint pale yellow annulations and the apex somewhat darker brown; basal portion of femora pale green.

HEAD. Ovoid, with vertex gently rounded and broadest at the eyes; considerably wider than prothorax (Fig. 66). Eyes fairly large, circular in outline and projecting hemispherically, their length contained about $1.5 \times$ in that of cheeks (Fig. 67). Antennae almost equal in length to body; scapus rectangular, with the lateral margins slightly rounded, the pedicellus sub-globose and antennomere III considerably longer than pedicellus.

THORAX. Pronotum rectangular, with lateral margins somewhat concave; the transverse median sulcus gently rounded, shallow (Fig. 66). Mesothorax very elongate and slender, some 3.6× as long as head and prothorax combined. Mesonotum, with a very fine longitudinal median carina. Tegmina oblique, spatulate, narrowed towards the base and with the apex truncated; hardly reaching to base of alae. Alae slightly projecting over posterior margin of abdominal segment IV.

Abdomen. Median segment almost $2 \times$ as long as metanotum. Segments II-VI slightly sub-equal in length and on average $5.5 \times$ as long as wide. VII shorter than all preceding, gently constricted sub-basally and very slightly widening towards the posterior. Sternites II-VII, with a fine longitudinal median carina (most decidedly on VII) and with two C-shaped dark brown markings near posterior margin. Tergum VIII thickened towards the posterior and almost fully separated from sternum VIII; the latter strongly globose, with the anterior margins rounded. Tergum IX some $1.5 \times$ as long as VIII, constricted basally and with the lateral margins straight and clearly separated ventrally. Anal segment somewhat longer than wide, slighly narrowed in the posterior portion, the posterior margin with a deep, roundly triangular median excavation and the outer angles obtusely projecting and with several black denticles ventrally (Fig. 69). Vomer small, scale-like, narrowed basally and with the apex obtusely bilobed. Cerci short, obtuse, arcuate, upcurving and not extending beyond posterior margin of anal segment (Fig. 69). Poculum fairly large, cup-shaped basally, carinate posteriorly, with the dorsal margins downcurving and the posterior margin distinctly labiate, gently indented medially and directed downward; almost reaching to posterior margin of tergum IX (Figs 68-69). 
Table 8. Measurements of Phantasca phantasma (Westwood, 1859) (in mm). HT = Holotype.

\begin{tabular}{lc}
\hline & $\hat{\text { ô, HT (NHMUK) }}$ \\
\hline Body & 62.6 \\
Pronotum & 1.9 \\
Mesonotum & 13.8 \\
Metanotum & 3.1 \\
Median segment & 7.9 \\
Tegmina & - \\
Alae & 26.8 \\
Profemora & - \\
Mesofemora & 14.0 \\
Metafemora & $>18.7$ \\
Protibiae & - \\
Mesotibiae & 15.8 \\
Metatibiae & 24.0 \\
Antennae & 59.0 \\
\hline
\end{tabular}

LEGS. All very long and slender, profemora somewhat longer than head, pro- and mesothorax combined, mesofemora about equal in length to mesothorax and hind legs projecting distinctly beyond apex of abdomen. All basitarsi very long, slender and considerably longer than remaining tarsomeres combined.

\section{Remarks}

In addition to the holotype, which lacks both front legs and tegmina, there are further, more complete specimens in NHMUK. The male recorded from French Guiana (Nouveau Chantier) in the Le Moult Collection in MNHN by Chopard (1911: 338) was misidentified and in fact is P. quadrilobata (Chopard, 1911). Female and egg unknown.

\section{Distribution}

North West Brazil: Pará State, Rio Tapajós (NHMUK).

Phantasca poeciloptera (Günther, 1940) comb. rev.

Figs $71-77$

Pterolibethra poeciloptera Günther, 1940: 500.

Pterolibethra poeciloptera - Conle, Hennemann \& Gutiérrez 2011: 56 (lectotype designation).

Phantasca poeciloptera - Liana 1996: 5. — Zompro 2003: 41. — Otte \& Brock 2005: 264.

\section{Material examined}

\section{Lectotype}

BRAZIL: 1 ○े, "Fonteboa; 123; Phantasca spec. ignota K. Günther, det.; Phantasca poeciloptera sp. n. in lit.. K. Günther, det." (ZMPA).

\section{Paralectotype}

COLOMBIA: 1 ô, "SE-Colombia, Rio Tacana, Waehner leg." (SMTD, not traced). 


\section{Other material}

PERU: 4 $\widehat{\partial}$, "Purma N 15 Ans; Dept. Loreto, Colonia Amont Confl. Rios Zumun et Yahausyacu XII1979, I-1980; Muséum Paris, Pérou, M. Descamps rec.” (MNHN).

\section{Diagnosis}

Males (the only sex known) of this very distinctive species are at once distinguished from all other species in the genus by the colouration of the anal fan of the alae, which is dark brown, with the basal half bright orange and all major transverse veins contrasting pale cream. Furthermore, P. poeciloptera is considerably more colourful than males of any of the other known species, with the head and most of the legs dull red, the cerci bright red and having the bases of all femora as well as the meso- and metapleurae bluish green. The genital morphology suggests a close relationship to P. heteronemia (Günther, 1940), with which it shares the long, hook-like cerci and bulgy anal segment.

\section{Description}

\section{Male (Fig. 71)}

Body. Size fairly small for the genus (body length $46.3-47.9 \mathrm{~mm}$, Table 9); form moderately slender. Entire body surface smooth.
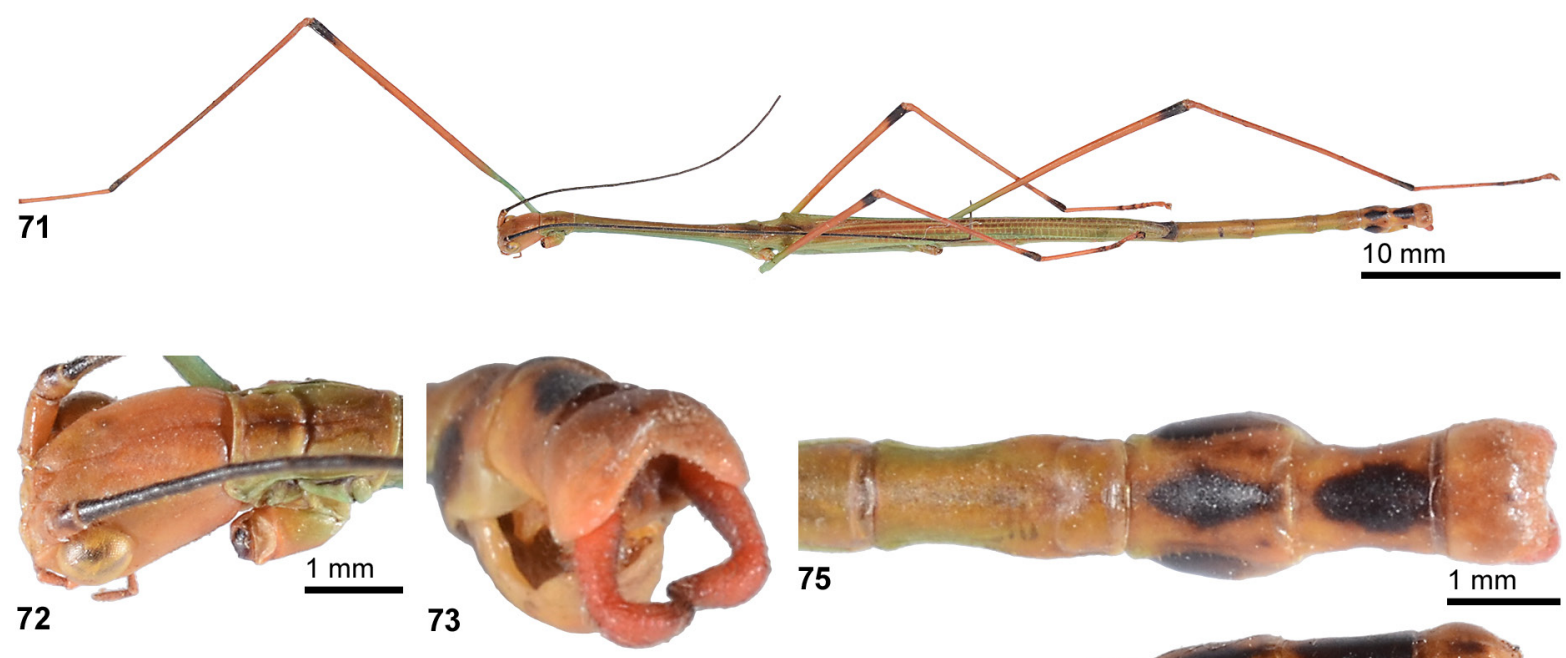

73

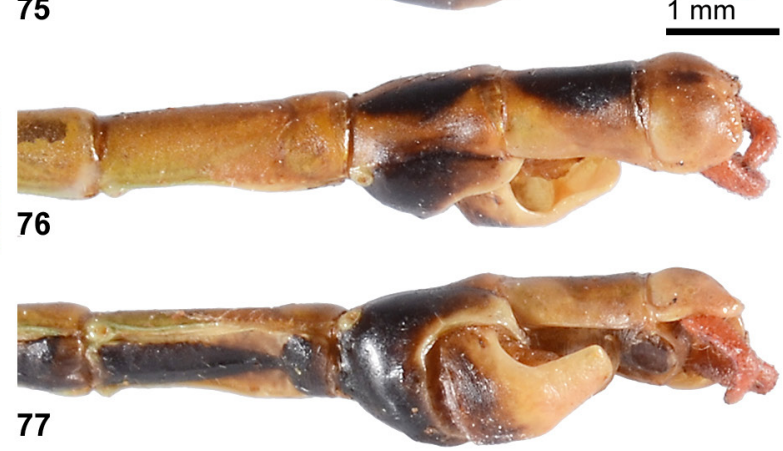

74

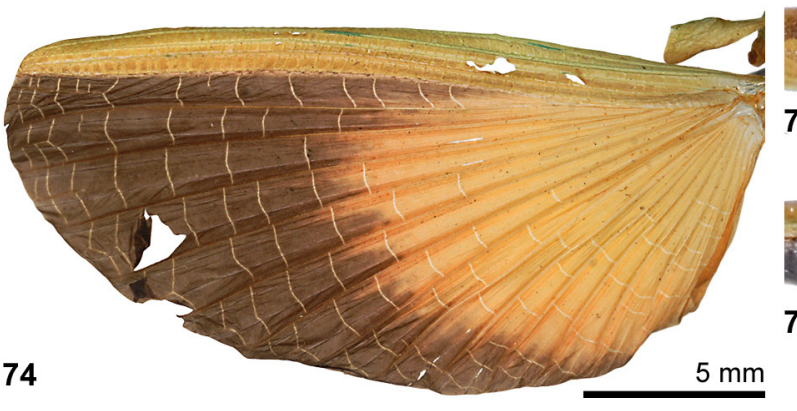

Figs 71-77. Phantasca poeciloptera (Günther, 1940) §. 71. Habitus, dorsolateral view. 72. Head and pronotum, dorsolateral view. 73. Anal segment and cerci, caudal view. 74. Holotype, $\widehat{\partial}$, left tegmen and ala. 75. Apex of abdomen, dorsal view. 76. Apex of abdomen, dorsolateral view. 77. Apex of abdomen, ventrolateral view. 
Table 9. Measurements of Phantasca poeciloptera (Günther, 1940) (in mm). LT = Lectotype.

\begin{tabular}{|c|c|c|}
\hline & o, LT (ZMPA) & ô, $(\mathbf{M N H N})$ \\
\hline Body & - & $46.3-47.9$ \\
\hline Pronotum & 1.7 & $1.4-1.8$ \\
\hline Mesonotum & 9.6 & $9.0-9.5$ \\
\hline Metanotum & 2.4 & - \\
\hline Median segment & 5.6 & - \\
\hline Tegmina & 3.2 & $2.7-3.2$ \\
\hline Alae & 20.0 & $19.1-22.1$ \\
\hline Profemora & 14.0 & $15.0-16.2$ \\
\hline Mesofemora & 10.5 & $9.3-11.4$ \\
\hline Metafemora & 12.5 & $13.8-15.0$ \\
\hline Protibiae & 15.0 & $14.2-16.0$ \\
\hline Mesotibiae & - & $10.2-10.9$ \\
\hline Metatibiae & - & $14.5-15.4$ \\
\hline Antennae & ca 56.0 & $38.0-46.0$ \\
\hline
\end{tabular}

CoLour. Very colourful insects. Head, scapus and base of pedicellus, dull red or reddish brown (Fig. 72); rest of antennae black. Pro- and mesonotum greenish brown and with a green stripe along lateral margins; meso- and metapleurae, with a broad bluish stripe along lower margin; meso- and metasternum dark brown to black. Abdomen green, with a bronze wash dorsally sternites II-VI, with a dark brown to black longitudinal median stripe, VI almost entirely black and VII, with an elongate triangular black marking and a black spot near posterior margin. Tergites VIII-X each, with a washed central black marking (very small and faint on X), sternum VIII almost entirely black and poculum, with the base slightly blackish. Cerci red (Fig. 73). Tegmina and costal region of alae pale to mid green anteriorly and becoming chestnut to reddish brown interiorly; radial vein green. Anal region of alae dark brown, with the basal portion bright orange; major transverse veins pale cream (Fig. 74). Coxae, legs and tarsi red; bases of all femora broadly green and apices of all femora, tibiae and basitarsi black.

HEAD. Large for the genus, elongate-ovoid, broadest at the eyes and slightly narrowed towards the posterior; vertex, with a weak longitudinal median sulcus (Fig. 72). Eyes slightly oval in outline, large, projecting hemisperically and their length contained about $1.4 \times$ in that of cheek. Antennae almost reaching to apex of abdomen. Scapus rectangular, pedicellus sub-globose.

Thorax. Pronotum much narrower and shorter than head, rectangular, with a fine longitudinal median sulcus and a very prominent transverse sulcus that expands over entire width of segment (Fig. 72). Mesothorax some $2.2 \times$ as long as head and prothorax combined. Tegmina oblique, spatulate, gradually narrowing towards the base, broadest apically, with the posterior margin acutely angular (Fig. 74); only the intero-posterior angles overlapping. Alae reaching about $2 / 3$ along abdominal segment IV.

AвDOMEN. Median segment $2.3 \times$ as long as metanotum. Segments II-VI slightly subequal in length and on average some $5.5 \times$ as long as wide. Sternites II-VII very weakly tectinate longitudinally. Tergum VII considerably shorter than all preceding, slightly thickened in posterior half. VIII widened towards posterior, broadest of all segments, with the lateral margins concave and weakly separated from sternum VIII; the latter strongly swollen and globose (Fig. 76). Tergum IX slightly longer than VIII and constricted medially; lateral margins almost straight and clearly separated ventrally. Anal segment 
short, somewhat wider than long and strongly cucullate, with the posterior margin roundly emarginated (Fig. 75). Vomer small, semi-circular and with a very short and blunt terminal process (Fig. 77). Cerci large and hook-shaped, longer than anal segment, downward directed, with the apical half obtuse and angled inward at an angle of about $90^{\circ}$ (Fig. 73). Poculum cucullate basally and increasingly flattened in the apical half; dorsal margins strongly emarginated and the posterior margin broadly rectangular, with the outer angles slightly protuded and forming a short, obtuse, gently upcurving process (Figs 76-77).

Legs. All long and moderately slender for the genus. Profemora longer than head, pro- and mesothorax combined, mesofemora longer than mesothorax and hind legs projecting considerably over apex of abdomen. Basitarsi very elongate and slender, longer than remaining tarsomeres combined.

\section{Remarks}

Phantasca poeciloptera (Günther, 1940) was originally described from two males. The lectotype in ZMPA lacks the terminal five abdominal segments and the paralectotype in SMTD could not be traced. The description above is supplemented by a series of four complete males from NE-Peru in MNHN. Female and egg unknown.

\section{Distribution}

South East Colombia: Prov. Imerí, Dept. Amazonas, Rio Tacana (SMTD); West Brazil: Amazonas State, Fonte Boa (ZMPA); North East Peru: Prov. Maynas, Dept. Loreto, junction of Rio Zumun and Rio Yahaus-Yacu (MNHN).

Phantasca puppeia (Westwood, 1859)

Figs $78-81$

Phasma puppeius Westwood, 1859: 125, pl. 10, fig. 1 (ふ).

Cladoxerus puppeius - Kirby 1904: 358.

Phantasca puppeia - Redtenbacher 1906: 111. — Zompro 2001: 223. — Otte \& Brock 2005: 264. — Brock, Marshall, Beccaloni \& Harman 2016: 190.

\section{Material examined}

Holotype

BRAZIL: ત̃, "Braz. Tapajos, 53 27; Type; Puppeius Westw.; Phasma puppeius Westw.; Cladoxerus puppeius; BMNH(E) \#844549” (NHMUK).

\section{Diagnosis}

Males (the only sex known) are similar to those of P. montana (Redtenbacher, 1908) from eastern Peru but differ by the somewhat more elongate body and legs, slightly longer cerci, larger and apically broadly rounded poculum, lack of distinctive markings on the head and pronotum, plain green tegmina and costal region of the alae as well as the unicoloured anal segment. The colouration resembles that of P. ruboligata sp. nov., but the genital morphology (e.g., more slender abdominal tergum IX and straight cerci) readily distinguishes $P$. puppeia from this species.

\section{Description}

Male (Fig. 78)

BoDy. Size very small (body length $46.1 \mathrm{~mm}$, Table 10); form very slender and delicate. Body surface entirely smooth. 
Colour. The colour of the unique holotype buff, with a pale greenish wash (almost certainly green when alive). Tegmina and costal region of alae pale green, anal region of alae hyaline, with the central longitudinal veins black at the base and the anterior longitudinal veins black at the apex (Fig. 78). Mesonotum, with a few small brownish speckles. Abdominal tergites VIII and IX each, with two longitudinal blackish markings, those on IX longer and forming two sub-parallel stripes. Apex of all femora, tibiae and basitarsi mid brown; the extreme apex of femora and tibiae reddish (believed to be bright red when alive).

HEAD. Ovoid, somewhat longer than wide, broadest at the eyes, considerably broader than prothorax, the vertex smooth and gently convex; unicoloured (Fig. 79). Eyes large, projecting hemispherically and their length contained only about $1.5 \times$ in that of cheeks. Antennae about as long as body (according to Westwood 1859: 126).

THORAX. Pronotum roundly rectangulate, about $1.3 \times$ as long as wide and with a shallow, curved transverse median sulcus. Mesothorax very slender and elongate, some $3 \times$ as long as head and pronotum combined. Mesonotum very weakly tectinate longitudinally. Tegmina small, elongate-oval, gradually

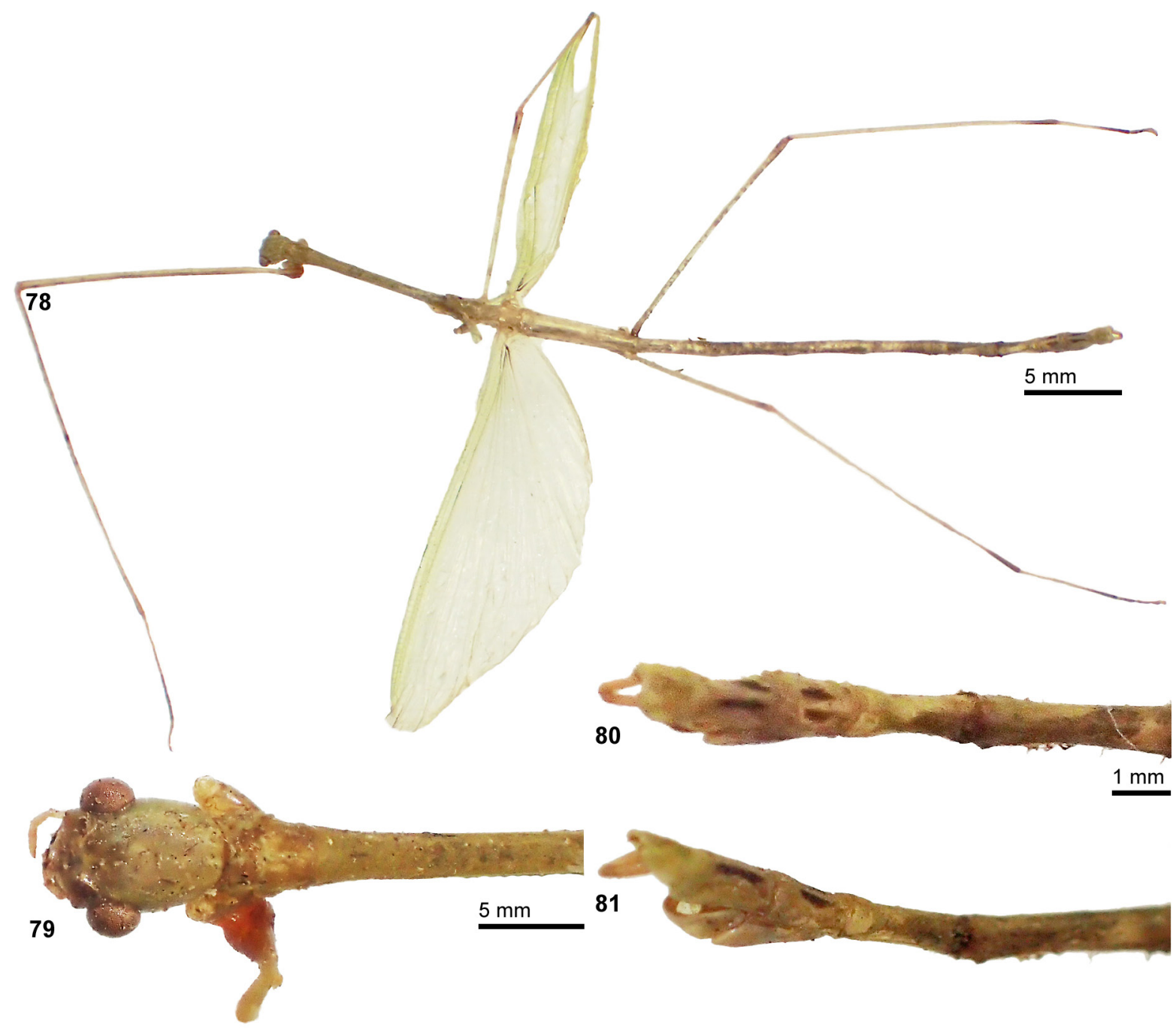

Figs 78-81. Phantasca puppeia (Westwood, 1859). Holotype, ふ̊. 78. Habitus, dorsal view. 79. Head and pronotum, lateral view. 80. Apex of abdomen, dorsal view. 81. Apex of abdomen, dorsal view. 
Table 10. Measurements of Phantasca puppeius (Westwood, 1859) (in mm). HT = Holotype.

\begin{tabular}{lc}
\hline & $\hat{\jmath}$, HT (NHMUK) \\
\hline Body & 46.1 \\
Pronotum & 1.6 \\
Mesonotum & 9.0 \\
Metanotum & 2.5 \\
Median segment & 5.8 \\
Tegmina & 1.9 \\
Alae & 27.0 \\
Profemora & 16.5 \\
Mesofemora & 10.4 \\
Metafemora & 14.3 \\
Protibiae & 18.3 \\
Mesotibiae & 10.4 \\
Metatibiae & 15.2 \\
Antennae & - \\
\hline
\end{tabular}

narrowed towards the base, with the apical portion widest and obtusely rounded; hardly reaching base of alae. Alae reaching about half way along abdominal segment $\mathrm{V}$.

ABDomen. Median segment $2 \times$ as long as metanotum. Segment IV longest and $5 \times$ as long as wide; III-VI gradually decreasing in length. VII much shorter than preceding and constricted medially. Tergum VIII slightly widening towards the posterior and fully separated from sternum VIII. IX some $1.3 \times$ as long as VIII, distinctly constricted medially, the lateral margins gently deflexed and rounded in the posterior half and clearly separated. Anal segment much shorter than all preceding, subquadrate, somewhat narrowed posteriorly and the posterior margin, with a well decided, rounded median emargination (Fig. 80); the outer posterior angles obtusely angular and with a few very minute teeth ventrally. Vomer broad, scalelike and almost semi-circular in shape. Poculum tub-shaped, with the posterior margin entire, obtusely rounded and reaching about $1 / 3$ along anal segment. Cerci cylindrical, almost straight, about $3 / 4$ the length of anal segment and distinctly projecting beyond its posterior margin (Figs 80-81).

LEGS. All very long and slender, the profemora decidedly longer than the combined length of head, proand mesothorax, the mesofemora a little longer than mesothorax and the hind legs distinctly projecting beyond apex of abdomen. Pro- and metabasitarsus very elongate and considerably longer than remaining tarsomeres combined.

\section{Remarks}

Only known from the unique male holotype, which has suffered some damage since its original description by Westwood in 1859. Both antennae, the right front leg, left mid leg and the mesotarsi are missing.

\section{Distribution}

North East Brazil: Pará State, Rio Tapajós (NHMUK). 
Phantasca quadrilobata (Chopard, 1911) comb. nov.

Figs $82-103$

Bacteria 4-lobata Chopard, 1911 : 343.

Bacteria quadrilobata - Otte \& Brock 2005: 66. — Jourdan, Lelong \& Bellanger 2014: 489, fig.1 (). Phantasca phantasma - Chopard 1911: 338.

Phantasca sp. II - Jourdan, Lelong \& Bellanger 2014: 489.

\section{Material examined}

Lectotype (here designated)

FRENCH GUIANA: + , "Museum Paris, Collection, Lucien Chopard, 191; Type; Bacteria 4-lobata Chopd. + ; Cayenne" (MNHN).

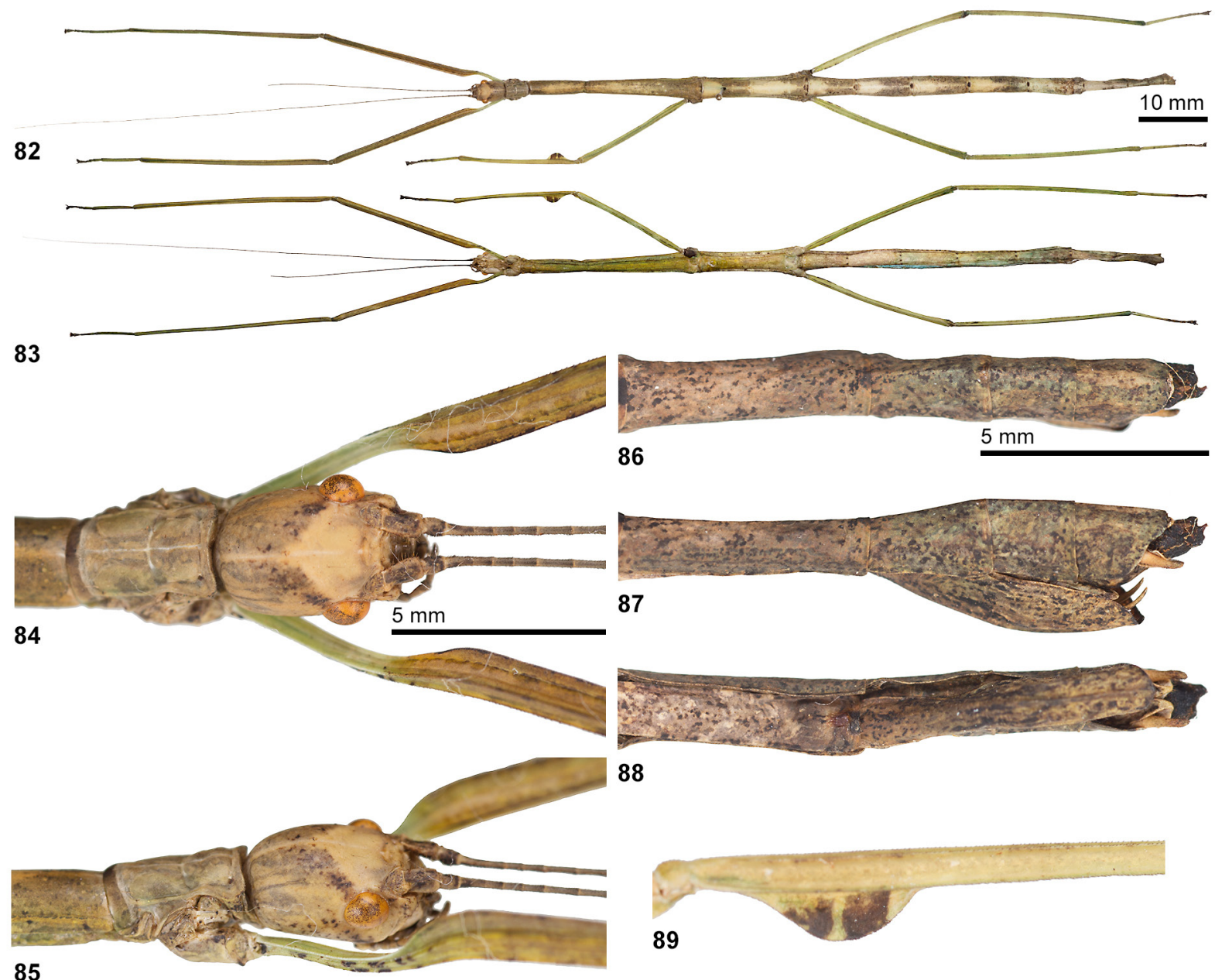

Figs 82-89. Phantasca quadrilobata (Chopard, 1911), 9 . 82. Habitus, dorsal view. 83. Habitus, ventral view. 84. Head and pronotum, dorsal view. 85. Head and pronotum, lateral view. 86. Apex of abdomen, dorsal view. 87. Apex of abdomen, lateral view. 88. Apex of abdomen, ventral view. 89. Basal portion of left mesotibia, dorsal view. 


\section{Paralectotype}

FRENCH GUIANA: + , “Guyane Française, Cayenne, Coll Le Moult; Fevrier; Museum Paris, collection Lucien Chopard, 191; Bacteria 4-lobata Chopd. o" (MNHN).

\section{Other material}

FRENCH GUIANA: 1 ðे, "Forêt de Balaté (St Laurent Du Maroni), km 28, 16.X.1969" (MNHN); 1 ð, "Guyane Françse, Nouveau Chantier, collection Le Moult; Museum Paris, Collection Lucien Chopard;

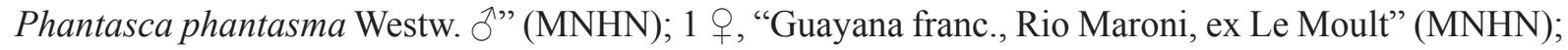
2 우, "Saut Boko, Crique Elepousing, 13-III-1976; Museum Paris, Guyane (Oyapock), M. Descamps Rec." (MNHN); 1 đ̃: Guyane, Montagne de Kaw, 5-12 VIII 92, Roubaud, Auvray, Rarchaert rec" (MNHN); 1 ㅇ, "Guyane Française, leg. GEP ㅇ, E. Delfosse Det. 07/05” (MNHN); 2 우, 42 eggs, "Guyane, Saül, 8-23.X.2013, GUY13-080, leg. Y. Bellanger, P. Lelong \& T. Jourdan" (ASPER); 1 , "Guyane, Saül, 8-23.X.2013, GUY13-040, leg. Y. Bellanger, P. Lelong \& T. Jourdan" (ASPER-PL); 1 ð”, "Guyane, Saül, 8-23.X.2013, GUY13-039, leg. Y. Bellanger, P. Lelong \& T. Jourdan" (ASPER-PL); 1 ð, "GUY15-049, Guyane, route de Roura, N4²42.905'W52 $18.252^{\prime}$, 25.VII.2015, rec T. Jourdan" (ASPERPL); 1 ก๊, "GUY15-084, Guyane, route de Mana, 21.VIII.2015, rec T. Jourdan" (ASPER-PL); 1 \%,

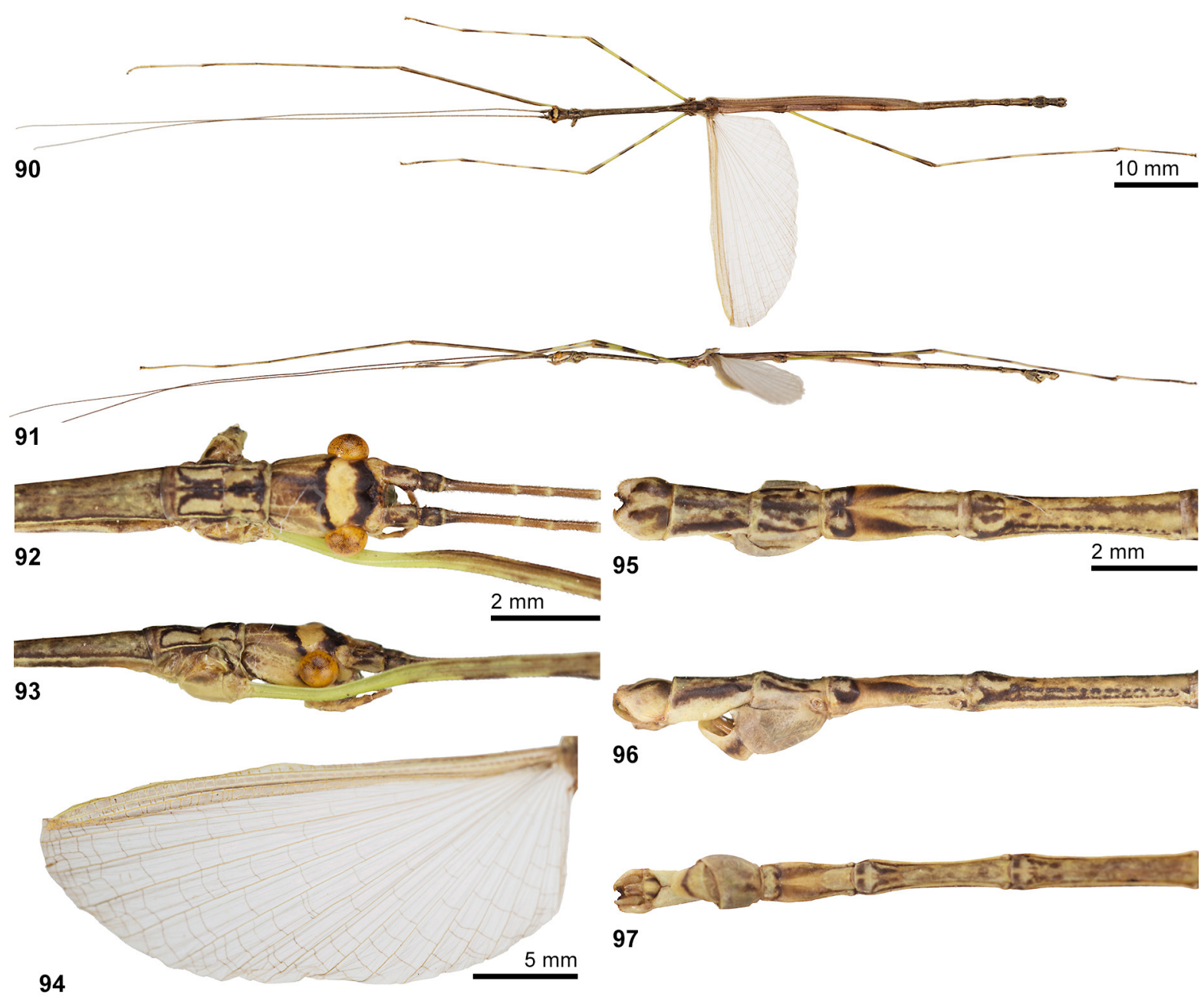

Figs 90-97. Phantasca quadrilobata (Chopard, 1911), ô. 90. Habitus, dorsal view. 91. Habitus, lateral view. 92. Head and pronotum, dorsal view. 93. Head and pronotum, lateral view. 94. Left ala. 95. Apex of abdomen, dorsal view. 96. Apex of abdomen, lateral view. 97. Apex of abdomen, ventral view. 
“GUY15-014, Guyane, St Elie, N5¹7.725'W5303.093', 05.VIII.2015, rec. T. Jourdan” (ASPER-PL); 1

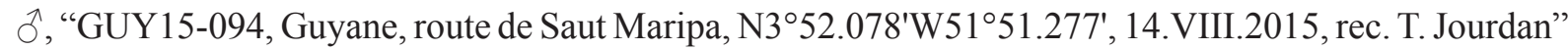
(ASPER-PL); 1 ô, "GUY15-099, Guyane, route de Roura, N441.757'W52¹8.339', 09.VIII.2015, rec. T. Jourdan" (ASPER-PL); 1 §, "GUYKAW16-044, 12.XI.2016, Guyane fr. - Route de Kaw, Camp Caïman, PK22 depuis Roura" (ASPER-YB); 1 ठ, "GUYKAW16-021, 11.XI.2016, Guyane fr. - Route de Kaw, Camp Caïman, PK28 depuis Roura, N4³4'11,7";W52¹2'41,8", alt. 300 m.” (ASPER-YB); 1 กै, "GUYKAW16-022, 11.XI.2016, Guyane fr. - Route de Kaw, Camp Caïman, PK28 depuis Roura, N4³4'11,7";W52 ${ }^{\circ} 12^{\prime} 41,8^{\prime}$ ", alt. 300 m." (ASPER-PL); 1 ㅇ, "GUYKAW16-051, 09.XI.2016, Guyane fr. - Route de Kaw, Camp Caïman, PK27 depuis Roura, N4³4'13,1";W52¹2'53,9", alt. 300 m.” (ASPERPL); 2 우, "GUYKAW16-052 \& -053, 09.XI.2016, Guyane fr. - Route de Kaw, Camp Caïman, PK27 depuis Roura, N4³4'13,1";W52 ${ }^{\circ} 12^{\prime} 53,9^{\prime \prime}$, alt. 300 m." (ASPER-YB); 1 స, "Französisch Guyana, Commune de Roura, Montagne des Chevaux, RN2 PK22, 444'56"N - 52 ${ }^{\circ} 26^{\prime} 28^{\prime \prime} \mathrm{W}$, alt. 75 m, SEAG, leg. Stéphane Brûlé 08.02.2014, Gen 0010" (OC 0334-1); 1 đે, "Französisch Guyana, Commune de Roura, Montagne des Chevaux, RN2 PK22, 444'56"N - 52²6'28"W, alt. 75 m, SEAG, leg. Stéphane
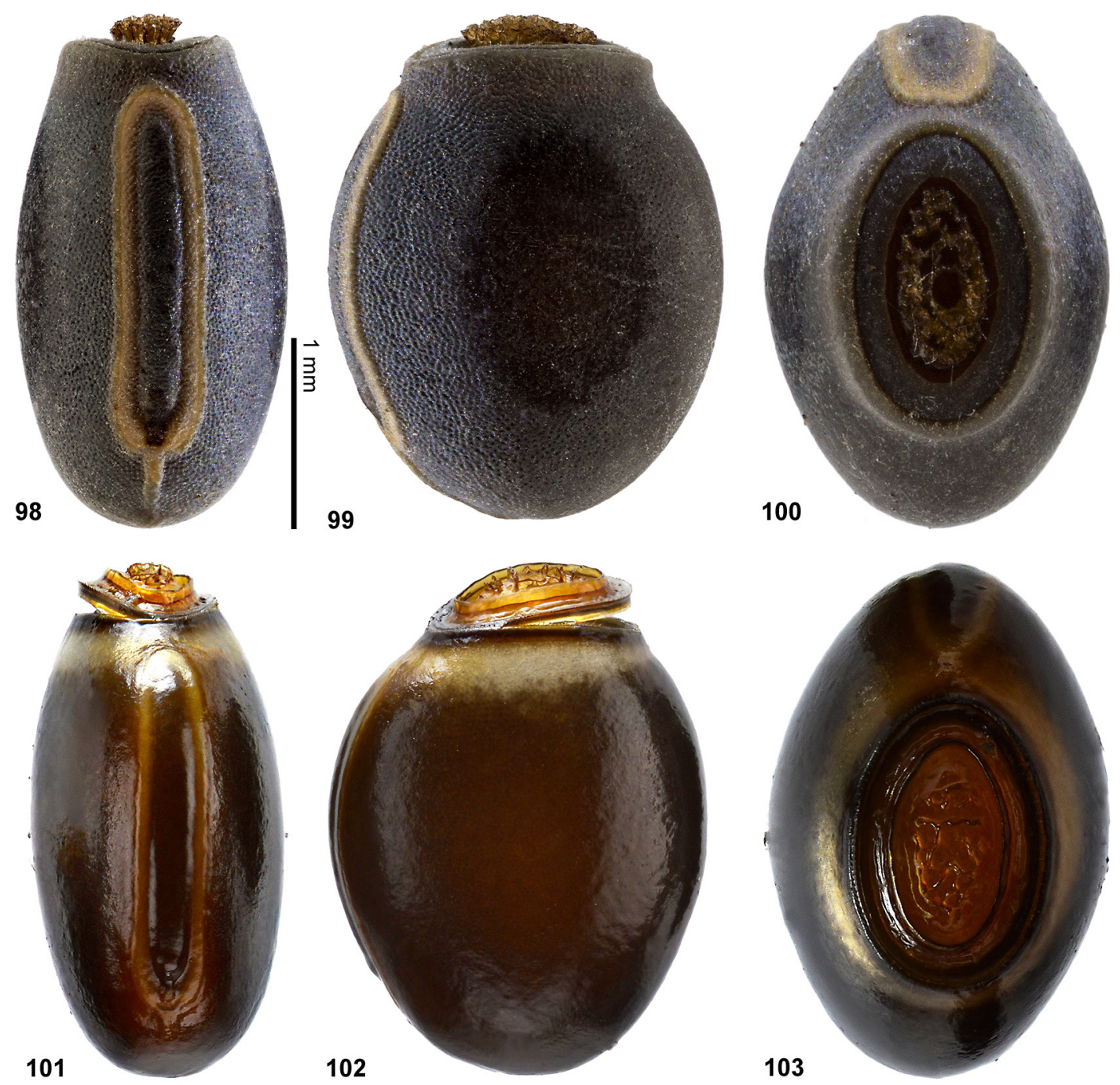

Figs 98-103. Phantasca quadrilobata (Chopard, 1911), eggs. 98. Type B, dorsal view. 99. Type B, lateral view. 100. Type $B$, anterior view. 101. Type A, dorsal view. 102. Type A, lateral view. 103. Type $\mathrm{A}$, anterior view. 
Brûlé 13.09.2014" (OC 0334-3); 1 đે, "Französisch Guyana, Commune de Roura, Montagne des Chevaux, RN2 PK22, 44' $56^{\prime \prime N}$ - 52 26'28"W, alt. 75 m, SEAG, leg. Stéphane Brûlé 14.09.2013, Lichtfang" (OC 0334-4); 1 $\widehat{\text {, }}$ "Französisch Guyana, Commune de Roura, Montagne des Chevaux, RN2 PK22, 444'56"N - 52²6'28"W, alt. 75 m, SEAG, leg. Stéphane Brûlé 20.01.2013” (OC 0334-5); $1 \widehat{\partial}$, "Französisch Guyana, Commune de Roura, Montagne des Chevaux, RN2 PK22, 444'56"N 52²6'28"W, alt. 75 m, SEAG, leg. Stéphane Brûlé 06.09.2014" (OC 0334-6); 1 ð̊, "Französisch Guyana, Commune de Roura, Montagne des Chevaux, RN2 PK22, 44ㄴ'56"N - 52 $26^{\prime} 28^{\prime \prime} \mathrm{W}$, alt. $75 \mathrm{~m}$, SEAG, leg. Stéphane Brûlé 24.04.2011" (OC 0334-11); 1 Oे, "Französisch Guyana, Commune de Matoury, Réserve du Mont Grand Matoury, 444'56"N - 52 $26^{\prime} 28^{\prime \prime W}, 75$ m, forest edge, leg. Stéphane Brûlé 28.09.2014" (OC 0334-2); 1 §ิ, "Französisch Guyana, Commune de Matoury, La Désirée, 451'0"N 52 19'60"W, SEAG, leg. Stéphane Brûlé 04.01.2014, Lichtfang" (OC 0334-7); 1 Ō, "Französisch Guyana, Commune de Régina, Nouragues, Saut Pararé, $4^{\circ} 02^{\prime} \mathrm{N}-52^{\circ} 41^{\prime} \mathrm{W}, \mathrm{SEAG}$, leg. Stéphane Brûlé 27.03.2010" (OC 0334-8); 1 đ, "Französisch Guyana, Commune de Régina, Nouragues, Saut Pararé, $4^{\circ} 02^{\prime} \mathrm{N}-52^{\circ} 41^{\prime} \mathrm{W}, \mathrm{SEAG}$, leg. Stéphane Brûlé 03.09.2010" (OC 0334-10); 1 đે, "Französisch Guyana, Commune de Saül, Aussichtspunkt Belvedere de Saül, 337'22"N - 5312'57"W, 326 m, SEAG, leg. Stéphane Brûlé 19.10.2010" (OC 0333-9); 1 đ, "Französisch Guyana, Commune de Roura, Montagne des Chevaux, RN2 PK22, 444'56"N - 52 26'28"W, alt. 75 m, SEAG, leg. Stéphane Brûlé 24.04.2011" (OC 0334-11); 1 $\hat{\jmath}$, "Französisch Guyana, Commune de Roura, Réserve Naturelle Trésor, Route de Kaw RN6 PK18, 4³6'39"N - 52¹6'46"W, alt. 252 m, SEAG, leg. Stéphane Brûlé 05.10.2009" (OC 0334-12); 1 ô, "Französisch Guyana, Commune de Régina, Piste forestière Tibourou, SEAG, Lichtfang, leg. Stéphane Brûlé 04.09.2008" (OC 0334-13); 1 Oૈ, 3 q 우, "Französisch Guyana, Ex Zucht O. Conle 2015, Gen F2, Commune de Saül, 10.2013, leg. Yannick Bellanger \& ASPER" (OC 033414 -0334- 17); 1 ô, "Französisch Guyana, Commune de Roura, Montagne des Chevaux, RN2 PK22, $4^{\circ} 44^{\prime} 56^{\prime \prime N}-52^{\circ} 26^{\prime 2} 28^{\prime W}$, alt. 75 m, SEAG, Lichtfang, leg. Stéphane Brûlé 20.08.2016" (OC 0334-18); 1 స , "Französisch Guyana, Commune de Matoury, La Désirée, Forêt de colline littorale, N 450'42,34" O 52²0'54,12”, S.E.A.G, Lichtfang, leg. Stéphane Brûlé 27.09.2014” (OC 0334-19); 1 đ̃, 3 우, 55 eggs, "ex Zucht F. Hennemann 2015, Herkunft: French Guiana, Saül, leg. Bellanger, Lelong \& Jourdan 8.-23.X.2013" (FH 0866-1-4, E).

\section{Diagnosis}

The colouration of males is similar to that of $P$. guianensis sp. nov. and $P$. phantasma, but the distinctive transverse pale cream, yellowish or almost white marking between the eyes well characterises this species (Fig. 92). The genital morphology indicates a close relationship to the latter species,, with which it shares the short and upcurving cerci. However, the cerci in P. quadrilobata are arcuate to almost sickle-shaped and gradually tapered towards an acutely pointed apex (blunt in P. phantasma), the anal segment has the lateral margins distinctly convex and the posterior margin only, with a small triangular excavation and the poculum is considerably smaller, roundly bowl-shaped, with the lateral margins indented (labiate and angled downward in P. phantasma). From P. guianensis sp. nov., they readily differ by the short cerci, which hardly reach to the posterior margin of the anal segment (very long and greatly projecting beyond apex of abdomen in $P$. guianensis sp. nov.) as well as the shape of the anal segment (parallel-sided in $P$. guianensis sp. nov.). Females are similar to those of $P$. guianensis sp. nov. but differ by the somewhat smaller size, more globose head, which bears a faint cream marking on the frons, presence of two transversely carinate swellings or humps on abdominal tergum VI, smaller epiproct, slightly shorter cerci, distinctly more slender legs and the absense of the red bases of the profemora seen in P. guianensis sp. nov. 


\section{Description}

Male (Figs 90-91)

Body. Size fairly large (body length 54.5-66.5 mm, Table 11); form very slender and typical for the genus.

CoLour. Body green, yellowish brown or pale brown, with very characteristic dark brown to black markings. Head greyish pale to mid brown, with a bold black transverse marking on frons and a roughly $\mathrm{V}$-shaped black marking on vertex. Between these black markings a distinctive pale cream, yellowish or almost white transverse area between the eyes. Lower portions of cheeks black. Scapus pale brown, with a faint dark brown spot extero-medially. Pedicellus of same colour as scapus and the rest of the antennae mid brown, with a slight reddish hue. Pronotum, with several dark longitudinal lines, including a fairly bold median stripe. Mesonotum, with a very slender dark line near lateral margins and four weakly defined dark brown markings in posterior portion. Metanotum mid to dark brown. Meso- and metasternum, with several irregular dark markings and speckles. Tegmina and costal region of alae ochre to greyish mid brown and all major veins dull yellow, the latter with a faint sepia longitudinal stripe near anterior margin. Anal region transparent with all major veins brown. Abdominal tergites II-VI each, with a very fine dark longitudinal median line and four dark spots posteriorly, VII, with two large dark markings post-medially. Two bold black, slightly diverging stripes on anal segment and sternum VII, usually with a pair of longitudinal black markings on posterior half. Poculum, with a transverse dark band medially. Front legs pale to mid brown, the profemora green basally. Mid and hind legs mid to dull green and with fairly contrasting black annulae. Knees cream coloured.

HEAD. Ovoid, with the vertex very gently convex and smooth; broadest at the eyes (Figs 92-93). Eyes large, projecting hemispherically and their length contained about $1.5 \times$ in that of cheeks. Antennae longer than body. Scapus rectangular but somewhat narrowed basally and $1.6 \times$ as long as wide, pedicellus subglobose and antennomere III a little longer than scapus and pedicellus combined.

THORAX. Pronotum slightly shorter but considerably narrower than head and very gently narrowed postmedially (Fig. 92). Transverse median sulcus moderately distinct, straight and expanding almost over entire width of segment. Mesothorax almost $3.2 \times$ as long as head and pronotum combined. Tegmina slender, spatulate, strongly constricted in the basal half and with the apical portion moderately broadened and angular. Alae roughly reaching to posterior margin of abdominal segment IV.

ABDOMEN. Median segment about $2.8 \times$ as long as metanotum. Segments II-VII gradually decreasing in length. II about $6 \times$ and VII hardly $3 \times$ as long as wide; the latter somewhat deflexed posteriorly. Tergum VIII shortest and broadest of all segments, strongly swollen and hardly longer than wide; the lateral margins very indistinctly separated from sternum VIII, with the fissure only visible in the posterior portion (Fig. 96). IX a little longer than VIII, narrowed anteriorly and gradually widening towards the posterior; the lateral margins deflexed, curved inward ventrally and almost completely fused with one another (an indistinct longitudinal fissure may be seen in the posterior portion) leaving only an almost circular, distinctly marginated hole or pit roughly in the middle (Fig. 97). Anal segment as broad as posterior portion of VIII, a little longer than wide and slightly cucullate; the posterior margin, with a narrow but fairly distinct triangular median excavation and the outer angles obtusely triangular (Fig. 95). The region of the median excavation, with about 3-4 blunt black teeth ventrally. Vomer very small, triangular in shape and with an acute apical hook (Fig. 97). Cerci short, arcuate to almost sickleshaped, upcurving and gradually constricted towards an acutely pointed tip; hardly projecting beyond anal segment (Figs 96-97). Sternum VIII strongly swollen and sub-globose (Fig. 96). Poculum small, bowl-shaped, with the basal portion strongly convex, the upper lateral margins distinctly excavated and the posterior margin upcurving, entire and broadly rounded (Fig. 96). 
Table 11. Measurements of Phantasca quadrilobata (Chopard, 1911) comb. nov. (in mm). LT = Lectotype; PLT = Paralectotype.

\begin{tabular}{|c|c|c|c|c|}
\hline & q, LT (MNHN) & †, PLT (MNHN) & $\hat{\sigma} \sigma^{\lambda}$ & qo \\
\hline Body & 109.5 & 105.0 & $54.5-66.5$ & $102.5-118.0$ \\
\hline Pronotum & 3.9 & 3.8 & $1.3-2.1$ & $4.0-4.5$ \\
\hline Mesonotum & 26.0 & 25.0 & $11.2-14.0$ & $24.7-29.0$ \\
\hline Metanotum & 7.5 & 7.2 & $2.8-2.9$ & $2.7-3.2$ \\
\hline Median segment & 9.0 & 8.4 & $7.4-7.6$ & $12.5-13.9$ \\
\hline Tegmina & - & - & $2.3-3.2$ & - \\
\hline Alae & - & - & $19.6-29.3$ & - \\
\hline Profemora & 27.0 & 24.2 & $18.6-20.3$ & $25.6-29.0$ \\
\hline Mesofemora & 18.6 & 17.0 & $12.4-14.0$ & $17.6-22.0$ \\
\hline Metafemora & 24.7 & 22.9 & $16.2-18.0$ & $21.3-27.5$ \\
\hline Protibiae & 30.7 & 28.1 & $20.5-23.8$ & $31.0-33.5$ \\
\hline Mesotibiae & 20.0 & 18.2 & $13.2-15.2$ & $18.7-23.0$ \\
\hline Metatibiae & 28.1 & 27.9 & $19.5-21.8$ & $25.0-32.2$ \\
\hline Antennae & $>60.0$ & & $59.5-68.0$ & $57.0-73.8$ \\
\hline
\end{tabular}

LEGS. All very long and slender, profemora somewhat longer than head, pro- and mesothorax combined and metatibiae projecting much beyond apex of abdomen. All basitarsi considerably longer than combined length of remaining tarsomeres.

Female (Figs 82-83)

Body. Size large (body length 102.5-118.0 mm, Table 11); form slender, with characteristic humps on abdominal tergum VI. Body smooth.

Colour. Variable; ranging from dull green over various shades of brown and grey, either plain or, with a variable degree of white or dark speckles and spots. Occassionally, with bold white markings on head and some or all body segments. Sometimes brown specimens may have green legs. Head usually, with a more or less defined dark V-shaped marking on vertex and a more pale (sometimes white) area between the eyes. Legs usually, with fairly distinct but irregular dark annulae. Basal portion of profemora always mid to dull green.

HEAD. Ovoid, broadest at the eyes, the vertex very convex and with a scarce longitudinal median sulcus; cheeks slightly narrowing towards the posterior (Figs 84-85). Eyes fairly small, circular and their length contained about $1.8 \times$ in that of cheeks. Antennae reaching about halfway along abdominal segment IV. Scapus and pedicellus as in males.

Thorax. Pronotum rectangular, somewhat shorter but considerably narrower than head; slightly constricted pre-medially (Fig. 84). Transverse median sulcus moderately distinct, gently curved and just not expanding over entire width of segment. Longitudinal median sulcus distinct. Mesothorax about $3 \times$ as long as head and pronotum combined, of uniform width.

ABDOMEN. Median segment about $1.2 \times$ as long as metanotum and very gently constricted medially. Abdominal segments II-V slightly increasing, VI-X decreasing in length; V on average some $2.5 \times$ as long as wide. II-V of uniform width, VII-X somewhat narrower than preceding. VI swollen and broadest 
of all segments, tergum, with posterior portion raised and protruded into two bluntly conical or transversely carinate swellings; these fairly variable in size and shape. Praeopercular organ formed by a small, obtuse median swelling at posterior margin of sternum VII (Fig. 88). Anal segment almost equal in length to IX. Tergites VIII-X of uniform width and somewhat narrower than preceding. Anal segment about equal in length to IX, slightly deflexed basally and somewhat narrowed in the posterior portion; the posterior margin roundly angular and with a very shallow and small median indention (Fig. 86). Epiproct very small, roundly triangular. Cerci small, conical, with the apex gently incurving and slightly projecting beyond posterior margin of anal segment (Fig. 87). Gonapophyses VIII elongated, filiform, upcurving at the apex and roughly reaching to apex of subgenital plate (Fig. 87). The latter boat-shaped, keeled longitudinally, with the lateral margins strongly angled downward apically; apex blunt and just not reaching the posterior margin of the anal segment (Fig. 88).

LEGs. All fairly long and slender. Anterodorsal carina of profemora moderately raised sub-basally. Medioventral carina of meso- and metatibiae deflexed to form a distinctive, rounded lobe sub-basally (Fig. 89). All basitarsi longer than remaining tarsomeres combined.

\section{Egg (Figs 98-103)}

There are two different types of eggs in this species, whose differences in colour and surface sculpturing of the capsule are summarized separately below. Medium-sized, ovoid, distinctly oval in cross-section, about $1.2 \times$ as long as high and about $1.8 \times$ as long as wide. Opercular collar distinct. Micropylar plate elongate, slender and very gently widened posteriorly; on average some $5 \times$ as long as wide and about $3 / 4$ the length of capsule. Outer margin slightly raised and the interior portion somewhat bulgy longitudinally. Micropylar cup small, bowl-shaped. Median line very short. Operculum flat and oval, with outer portion distinctly marginated; capitulum represented by a raised rim and some irregularly shaped acute ridges in the centre.

Type A (Figs 101-103): General colour plain dark brown, with a pale cream to grey rim just below opercular collar; entire surface strongly shiny. Micropylar plate, with inner portion dark blackish brown and outer portion reddish mid brown. Operculum dark brown, with a slight reddish wash and the capitular structures dull yellowish to orange. Capsule surface almost smooth and strongly shiny; minute pits can only be seen at strong magnification.

Type B (Figs 98-100): Plain dull grey, with a bold washed black central marking on lateral surfaces. Micropylar plate black, with the outer portion and median line dull ochre. Operculum dull grey and the capitular structures pale brown, with a slight yellowish hue. Complete capsule surface and micropylar plate minutely and densely pitted.

Measurements (in mm). Length (incl. operculum) 2.69, length 2.45, width 1.34, height 2.06, length of micropylar plate 1.85 , diameter of operculum $0.77 \times 1.11$.

\section{Remarks}

Chopard (1911: 343) described Bacteria 4-lobata based on two female syntypes from the collection of L. Le Moult in MNHN. The broader female, which has the front legs folded, is here selected as the lectotype to guarantee stability of the name. Examination of the male from Nouveau Chantier, in the collection of Le Moult in MNHN referred to as P. phantasma (Westwood, 1859) by Chopard (1911: 338), has proven to be P. quadrilobata (Chopard, 1911).

Both sexes show considerable variability in colouration. Females mostly show various shades of brown or grey but sometimes have a slight greenish hue or are almost entirely dark green or occasionally have large white markings on the head and almost all body segments. The two distinctive protuberances on abdominal tergum VI show considerable variability in size and shape, ranging from bluntly conical 
swellings to transversely carinate scales. Also, the sub-basal ventral lobe of the meso- and metatibiae is fairly variable in shape. While males are mostly buffy or ochre to mid brown, specimens may be green during the first days after their final ecdysis. Quite some variability is also seen in the shape of the black markings on the head, pronotum and terminal abdominal tergites. The eggs occur in two different types, which differ in colouration and sculpturing of the egg capsule.

Breeding in captivity was attempted from stock collected in Saül in 2013 but has proven difficult. The culture was lost after the second generation but allowed the authors to be sure of the matching between males and females. Hatching rates in the first generation were fairly low, with only about $50 \%$. At average temperatures of $20^{\circ} \mathrm{C}$ males reached maturity after about five months while females took a little longer. Rose (Rosa spp., Rosaceae), St. John's Wort (Hypericum patulum 'Hidcote', Hypericaceae) and eucalyptus (Eucalyptus spp., Myrtaceae) were readily accepted as alternative food plants. In the wild this species is known to feed on Gonzalagunia spp. (Rubiaceae), but presumably several other plants serve as a natural diet, since most species appear to be fairly polyphagous.

\section{Distribution}

French Guiana: Cayenne (MNHN); Nouveau Chantier (MNHN); St Laurent Du Maroni, Forêt de Balaté (MNHN); St Laurent Du Maroni, Rio Maroni (MNHN); Saut Boko, Crique Elepousing (MNHN); Commune de Saül (ASPER); Commune de Roura, Montagne de Kaw (MNHN); Commune de Roura, Route de Kaw (ASPER); Commune de Roura, Montagne des Chevaux (OC); Commune de Roura, Réserve Naturelle Trésor, Route de Kaw (OC); Commune de Roura, route de Roura (ASPER); Commune de Matoury, Réserve du Mont Grand Matoury (OC); Commune de Saül, Belvedere (OC); Commune de Régina, Piste forestière Tibourou (OC); Commune de Régina, Nouragues, Saut Pararé (OC); St. Elie (ASPER); Commune de Matoury, La Désirée, Forêt de colline littorale (OC).

Phantasca ruboligata sp. nov.

urn:lsid:zoobank.org:act:98068AF0-408F-4A33-B515-25CA9BD94B30

Figs 104-119

Phantasca sp. III - Jourdan, Lelong \& Bellanger 2014: 489.

\section{Material examined}

Holotype

FRENCH GUIANA: §̊, "Guyane, Montagne de Kaw, 5-12 VIII 92, Roubaud, Auvray, Rarchaert rec" (MNHN).

\section{Paratypes}

FRENCH GUIANA: 1 ภे, "Guyane, Montagne de Kaw, 5-12 VIII 92, Roubaud, Auvray, Rarchaert rec (MNHN); 1 ô, "27.VII, A7 S1 N12, P.E. Roubaud det" (MNHN); 1 + , no data, "Roubaud, Auvray, Rarchaert rec" (MNHN); 1 ठ̊, "Guyane, Saül, 8-23.X.2013, GUY13-070, leg. Y. Bellanger, P. Lelong \& T.Jourdan”(ASPER-YB); 1 9, “GUY15-098,9-VIII-2015, Guyane française, Route de Roura, N4 41.747' W52 ${ }^{\circ} 18.339$, rec. T. Jourdan, ASPER” (ASPER-PL); 1 ㅇ, "GUY15-097, 9-VIII-2015, Guyane française,

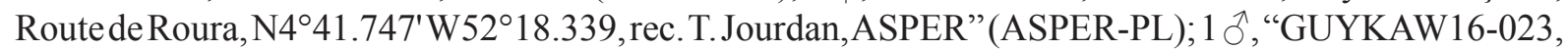
Guyane fr. - route de Kaw, Camp Caïman - PK28 depuis Roura, N4³4'11,7";W52¹2'41,8", 11.XI.2016, rec. P. Lelong \& Y. Bellanger" (ASPER-YB); 1 q, "GUYKAW16-057, Guyane fr. route de Kaw, Camp Caïman - PK27 depuis Roura, N4³4'13,1";W52¹2'53,9", 13.XI.2016, rec. P. Lelong \& Y. Bellanger" (ASPER-YB); 1 , "GUYKAW16-024, Guyane fr. - route de Kaw, Camp Caïman - PK28 depuis Roura, N4³4'11,7";W52 12'41,8", 11.XI.2016, rec. P. Lelong \& Y. Bellanger" (ASPER-PL); 1 đ, "GUYKAW16-045, Guyane fr. - route de Kaw, Camp Caïman - PK28 depuis Roura, N4³4'11,7"; W52 ${ }^{\circ} 12^{\prime} 41,8^{\prime \prime}, 12 . X I .2016$, rec. P. Lelong \& Y. Bellanger” (ASPER- 
PL); 1 †, "GUYKAW16-056, Guyane fr. - route de Kaw, Camp Caïman - PK27 depuis Roura, N4³4'13,1";W52 ${ }^{\circ} 12^{\prime} 53,9^{\prime}$, 13.XI.2016, rec. P. Lelong \& Y. Bellanger" (ASPER-PL); 1 ô, "Französisch Guyana, Commune de Saül, leg. L. Sénécaux 07.-08.1989" (OC 0333-1); 1 ô, "Französisch Guyana,

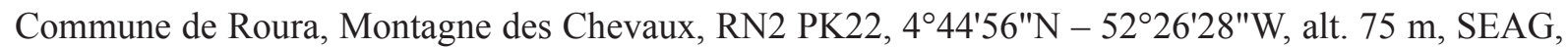
leg. Stéphane Brûlé 19.07.2014, Lichtfang" (OC 0333-2); 1 đે, "Französisch Guyana, Commune de Roura, Montagne des Chevaux, RN2 PK22, 444'56"N - 52²6'28"W, alt. 75 m, SEAG, leg. Stéphane Brûlé 20.01.2013" (OC 0333-3); 1 ô, "Französisch Guyana, Commune de Roura, Montagne des

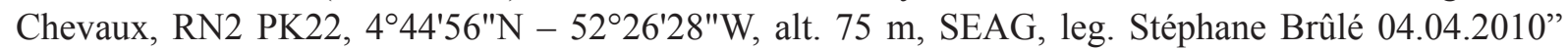
(OC 0333-4); 1 §ै, "Französisch Guyana, Commune de Roura, Montagne des Chevaux, RN2 PK22, $4^{\circ} 44^{\prime} 56^{\prime \prime} \mathrm{N}-52^{\circ} 26^{\prime} 28^{\prime \prime} \mathrm{W}$, alt. 75 m, SEAG, leg. Stéphane Brûlé 04.03.2013, Lichtfang" (OC 0333-5); 1 సै, "Französisch Guyana, Commune de Roura, Montagne des Chevaux, RN2 PK22, 444'56"N 52²6'28"W, alt. 75 m, SEAG, leg. Stéphane Brûlé 21.10.2012" (OC 0333-6); 1 ô, "Französisch Guyana, Commune de Roura, Montagne des Chevaux, RN2 PK22, 444'56"N - 52 $26^{\circ} 28^{\prime \prime} \mathrm{W}$, alt. $75 \mathrm{~m}$, SEAG, leg. Stéphane Brûlé 01.02.2011" (OC 0333-7); 1 đ’, "Französisch Guyana, Commune de Roura, Montagne des Chevaux, RN2 PK22, 444'56"N - 52²6'28"W, alt. 75 m, SEAG, leg. Stéphane Brûlé 19.12.2011" (OC 0333-8); 1 ठ , "Französisch Guyana, Commune de Roura, Montagne des Chevaux, RN2 PK22, 444'56"N - 52²6'28"W, alt. 75 m, SEAG, leg. Stéphane Brûlé 14.01.2012” (OC 033310); 1 , "Französisch Guyana, Commune de Roura, Montagne des Chevaux, RN2 PK22, 444'56"N 52²6'28"W, alt. 75 m, SEAG, leg. Stéphane Brûlé 18.03.2012" (OC 0333-11); 1 ô, "Französisch Guyana, Commune de Roura, Montagne des Chevaux, RN2 PK22, 4⒋'56"N - 52 $26^{\prime} 28^{\prime \prime} \mathrm{W}$, alt. $75 \mathrm{~m}$, SEAG, leg. Stéphane Brûlé 29.01.2012" (OC 0333-12); 1 ô, "Französisch Guyana, Commune de Roura, Montagne des Chevaux, RN2 PK22, 444'56"N - 52²6'28"W, alt. 75 m, SEAG, leg. Stéphane Brûlé 23.04.2012" (OC 0333-1); 1 §, "Französisch Guyana, Commune de Roura, Montagne des Chevaux, RN2 PK22, 44' $56^{\circ} \mathrm{N}-52^{\circ} 26^{\prime} 28^{\prime \prime W}$, alt. 75 m, SEAG, leg. Stéphane Brûlé 16.05.-11.07.2009” (OC 033314); 1 $\lambda$, "Französisch Guyana, Commune de Roura, Montagne des Chevaux, RN2 PK22, $4^{\circ} 44^{\prime} 56$ "N - 52²6'28"W, alt. 75 m, SEAG, leg. Stéphane Brûlé 01.11.2009” (OC 0333-1); 1 ô, "Französisch

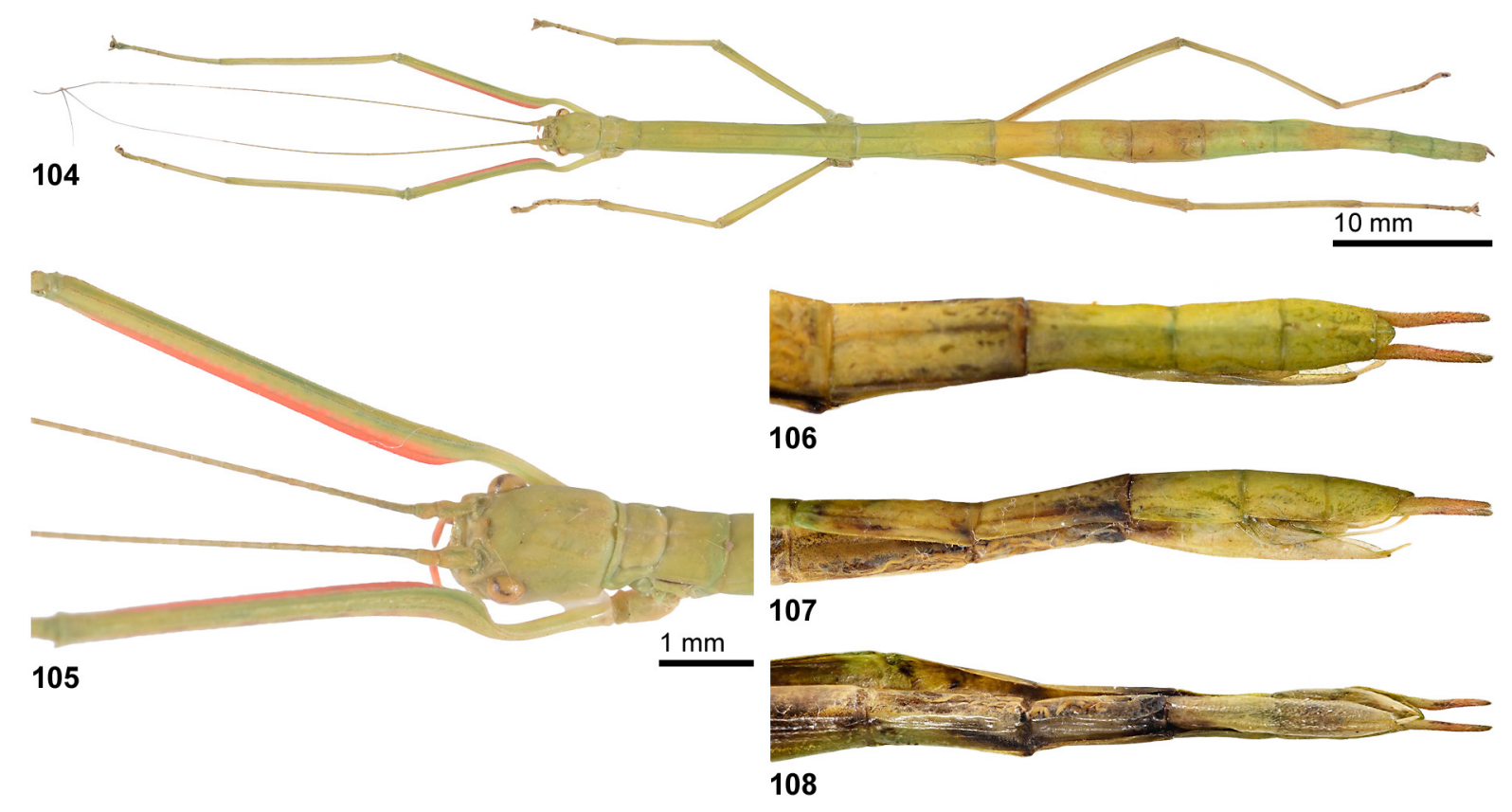

Figs 104-108. Phantasca ruboligata sp. nov. Paratype, ㅇ. 104. Habitus, dorsal view. 105. Head and pronotum, dorsal view. 106. Apex of abdomen, dorsal view. 107. Apex of abdomen, lateral view. 108. Apex of abdomen, ventral view. 
Guyana, Commune de Roura, Montagne des Chevaux, RN2 PK22, 44ㄴ'56"N - 52²6'28"W, alt. 75 m, SEAG, leg. Stéphane Brûlé 14.02.2010" (OC 0333-16; 1 q, "Französisch Guyana, Commune de Roura, Montagne des Chevaux, RN2 PK22, 44' $56^{\prime \prime} \mathrm{N}-52^{\circ} 26^{\prime} 28^{\prime \prime} \mathrm{W}$, alt. 75 m, SEAG, leg. Stéphane Brûlé 15.08.2014" (OC 0333-18); 1 đ̄, "Französisch Guyana, Commune de Roura, Montagne des

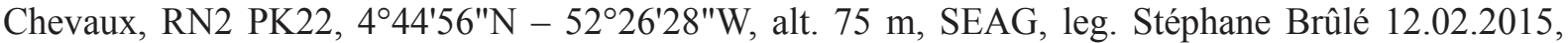
Lichtfang, Gen 0167" (OC 0333-20; 1 §ै, "Französisch Guyana, Commune de Roura, Montagne des Chevaux, RN2 PK22, 44' $56^{\prime \prime} \mathrm{N}-52^{\circ} 26^{\prime} 28^{\prime \prime} \mathrm{W}$, alt. 75 m, SEAG, leg. Stéphane Brûlé 12.02.2015, Lichtfang, Gen 0202" (OC 0333-21); 1 O, "Französisch Guyana, Commune de Roura, Montagne des Chevaux, RN2 PK22, 44' $56^{\prime \prime N}$ - 52 26'28"W, alt. 75 m, SEAG, leg. Stéphane Brûlé 12.02.2015, Gen 0164" (OC 0333-22); 1 Oे, "Französisch Guyana, Commune de Saül, Aussichtspunkt Belvedere de Saül, 337'22"N - 53ํ'12'57"W, 326 m, SEAG, leg. Stéphane Brûlé 07.03.2011” (OC 0333-9); 1 Ô, "Französisch Guyana, Commune de Saül, Aussichtspunkt Belvedere de Saül, 3³7'22"N - 53¹2'57"W, 326 m, SEAG, leg. Stéphane Brûlé 11.01.2011" (OC 0333-19); 1 đ, "Französisch Guyana, Commune de

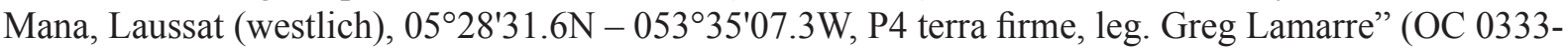
17); 1 ${ }^{\lambda}$, "Französisch Guyana, Commune de Roura, Montagne des Chevaux, RN2 PK22, 444'56"N - 52²6'28"W, alt. 75 m, SEAG, leg. Stéphane Brûlé 17.10.2015" (OC 0333-23); 1 ô,, "Französisch Guyana, Commune de Roura, Montagne des Chevaux, RN2 PK22, $4^{\circ} 44^{\prime} 56^{\prime \prime} \mathrm{N}-52^{\circ} 26^{\prime} 28^{\prime \prime} \mathrm{W}$, alt. 75 m, SEAG, leg. Stéphane Brûlé 13.12.2014" (OC 0333-24); 1 đ, "Französisch Guyana, Commune de Roura, Montagne des Chevaux, RN2 PK22, 4${ }^{\circ} 44^{\prime} 56^{\prime \prime} \mathrm{N}-52^{\circ} 26^{\prime} 28^{\prime \prime} \mathrm{W}$, alt. $75 \mathrm{~m}$, SEAG, Lichtfang, leg. Stéphane Brûlé 07.02.2015" (OC 0333-25); 3 eggs, "Französisch Guayana, Route de Roura,

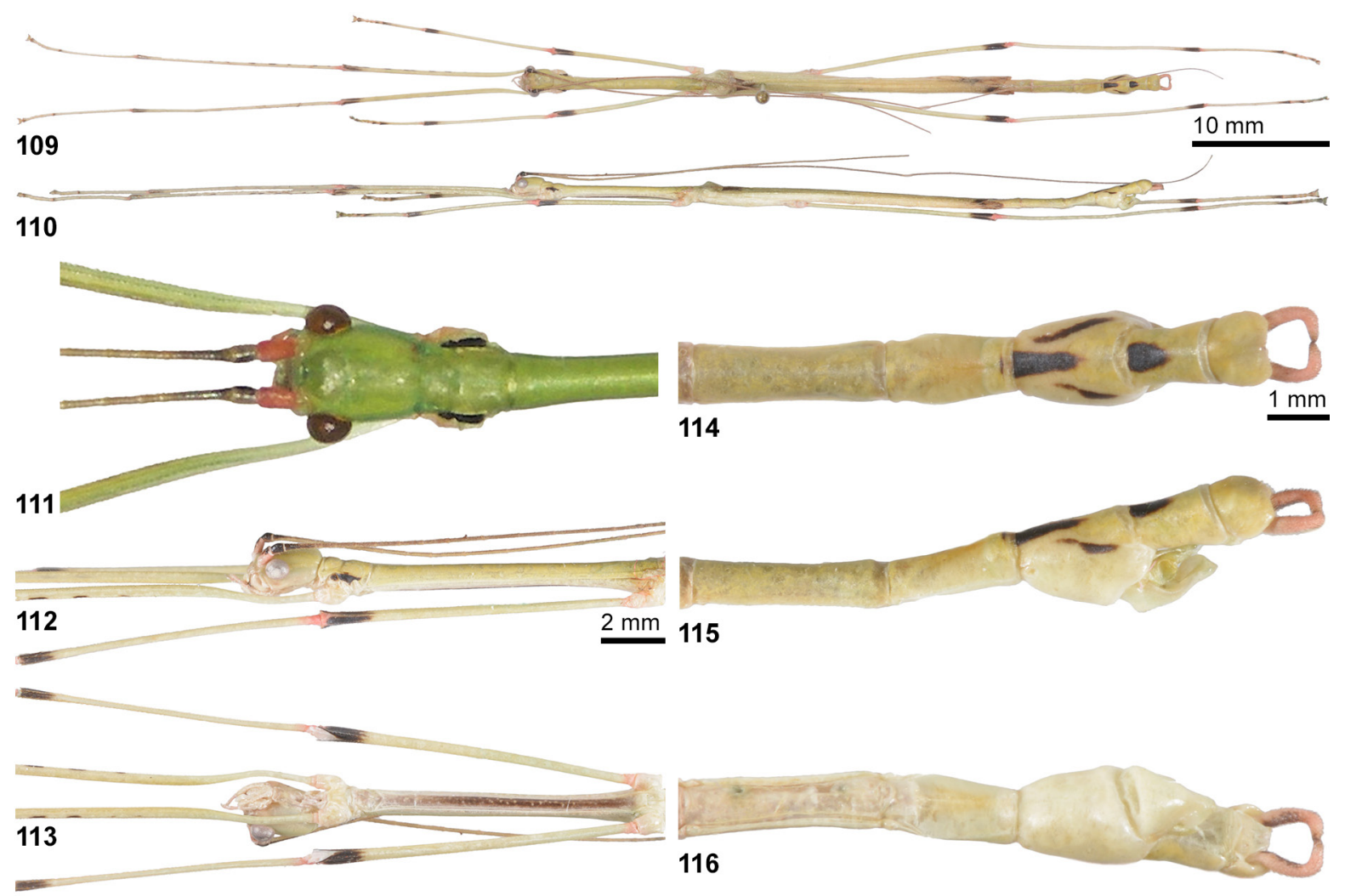

Figs 109-116. Phantasca ruboligata sp. nov. Paratypes, $\widehat{\partial}$. 109. Habitus, dorsal view. 110. Habitus, lateral view. 111. Head and pronotum, dorsal view. 112. Head and pro- and mesothorax, lateral view. 113. Head and pro- and mesothorax, ventral view. 114. Apex of abdomen, dorsal view. 115. Apex of abdomen, lateral view. 116. Apex of abdomen, ventral view. 


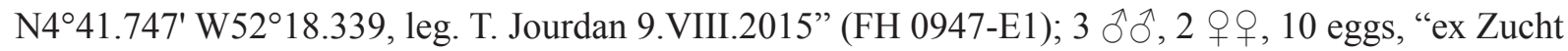
F. Hennemann 2017, Herkunft: Französisch Guayana, Route de Roura, N441.747' W52¹8.339, leg. T. Jourdan 9.VIII.2015" (FH 0947-1-0947-4, E2).

\section{Diagnosis}

Amongst the species of Phantasca currently known from French Guiana and the eastern regions of Brazil, males of this pretty new species are well characterised by the long, hook-like cerci that are otherwise only seen in P. heteronemia (Günther, 1940) from northwest Brazil and P. poeciloptera (Günther, 1940) from eastern Peru. They resemble P. amabile sp. nov. from Ecuador, but males of P. ruboligata sp. nov. differ by the almost entire posterior margin of the anal segment, much smaller poculum, unicoloured head, pronotum, mesonotum and abdominal tergites II-VI, green mesosternum, plain green costal region of the alae, which only have the extreme apex and intero-basal portion black, as well as the differently shaped black markings on abdominal tergites VIII and IX. Females are similar to those of $P$. nigrolineata sp. nov. but differ by the more stocky body and legs, bright red interior surface of the profemora (plain green in P. nigrolineata sp. nov.), longer median segment and longer, apically acutely pointed cerci, which are decidedly longer than the anal segment (blunt apically and at best equal in length to the anal segment in P. nigrolineata sp. nov.). The eggs (Figs 117-119) are fairly different from all other known eggs of the genus and would suggest that $P$. ruboligata sp. nov. belongs to a different genus, but the insect's morphology leaves no doubt that this species belongs in Phantasca.

\section{Etymology}

The name of this new species (rubus Lat. = red, ligatus Lat. = ligature) refers to the bright red scapus, coxae and bases of the tibiae.

\section{Description}

Male (Figs 109-110)

Body. Size fairly small (body length 41.4-51.3 mm, Table 12); form moderately slender and elongate.

Colour. Colouration very characteristic. General colour plain pale to mid green, sometimes, with a slight yellowish hue. Head, with a faint mid to dull green postocular streak along cheeks and lateral margins

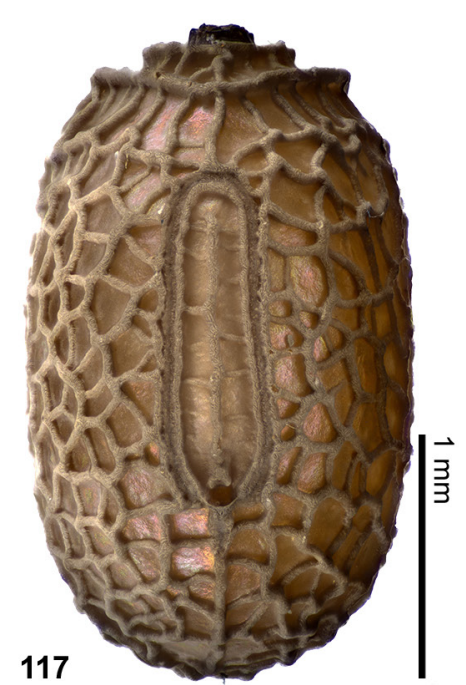

118
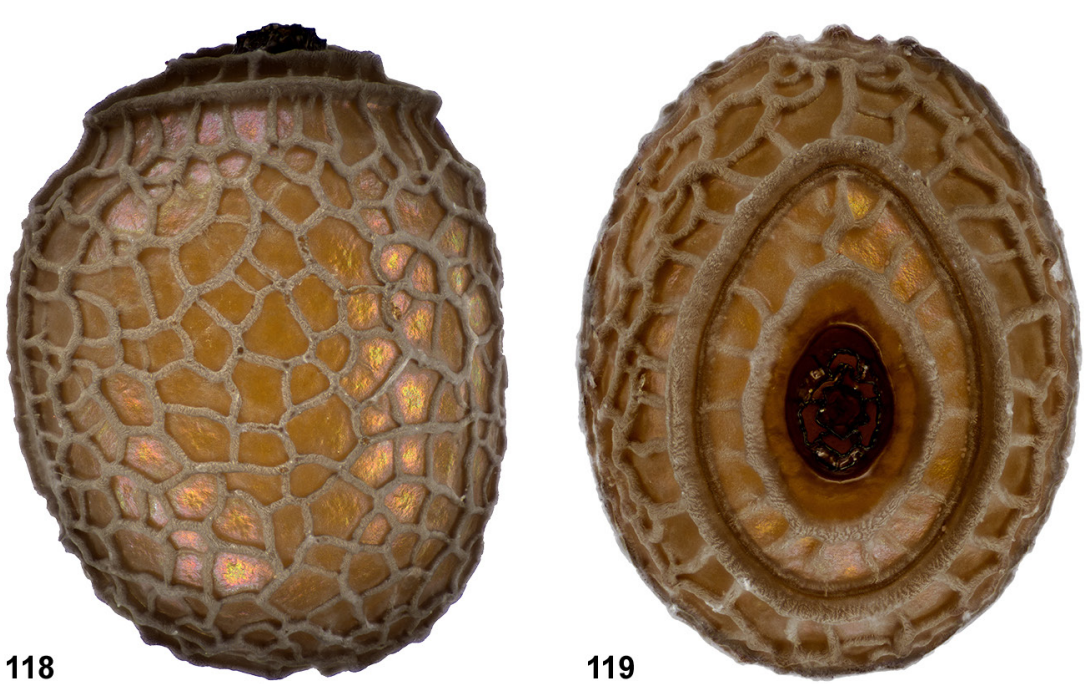

Figs 109-116. Phantasca ruboligata sp. nov. Paratypes, $\widehat{\partial}$. 109. Habitus, dorsal view. 110. Habitus, lateral view. 111. Head and pronotum, dorsal view. 112. Head and pro- and mesothorax, lateral view. 
Table 12. Measurements of Phantasca ruboligata sp. nov. (in mm). HT = Holotype; $\mathrm{PT}=$ Paratype.

\begin{tabular}{|c|c|c|c|c|}
\hline & $\hat{\partial}$, HT (MNHN) & q, PT (MNHN) & $\partial^{\lambda} \hat{o}^{\lambda}, \mathbf{P T}$ & $q$ q, PT \\
\hline Body & 49.8 & 60.0 & $41.4-51.3$ & $58.7-80.0$ \\
\hline Pronotum & 2.3 & 2.5 & $1.0-1.7$ & $2.6-3.4$ \\
\hline Mesonotum & 9.8 & 13.5 & $9.1-10.1$ & $12.3-19.3$ \\
\hline Metanotum & 3.2 & 3.5 & $2.3-2.8$ & $3.4-4.5$ \\
\hline Median segment & 5.5 & 5.0 & $5.4-5.7$ & $5.4-7.2$ \\
\hline Tegmina & 3.2 & - & $2.6-3.4$ & - \\
\hline Alae & 21.9 & - & $20.7-23.7$ & - \\
\hline Profemora & 16.4 & 13.8 & $15.2-16.5$ & $13.8-18.6$ \\
\hline Mesofemora & 11.5 & 9.2 & $10.4-11.6$ & $9.9-14.1$ \\
\hline Metafemora & 17.1 & 13.4 & $14.6-16.4$ & $13.7-18.0$ \\
\hline Protibiae & 18.0 & 12.7 & $16.2-18.0$ & $13.0-19.6$ \\
\hline Mesotibiae & 11.6 & 8.3 & $10.4-11.5$ & $9.2-13.4$ \\
\hline Metatibiae & 16.8 & 13.3 & $15.3-17.3$ & $14.7-18.2$ \\
\hline Antennae & ca. 57.0 & 48.7 & $47.0-60.0$ & $43.4-58.0$ \\
\hline
\end{tabular}

of mesonotum somewhat darker green than rest of body. Episternum I and epimerum I contrasting black (Fig. 111). Probasisternum and mesosternum dark brown (Fig. 113), metasternum dull orange. Tegmina and alae of same colour as body, with all major veins mid to dull green. Apex of tegmina red, apex and interobasal portion of costal region of alae black. Anal fan of alae transparent, with only the apical portion slightly greyish. Abdominal tergum VIII, with a bold black longitudinal marking antero-medially and two diverging black stripes post-laterally; IX only, with a bold black anteromedian marking. Cerci red. Antennae pale greyish brown, the scapus bright red, the pedicellus and antennomere III dull grey. All coxae, apex of all femora and base of all tibiae and tarsomeres bright red. Pre-apical portion of all femora as well as apex of all tibiae and all tarsomeres black. All femora and tibiae occasionally, with a few weakly defined black spots ventrally.

HEAD. Oval, sub-globose, with the vertex gently convex and about $1.2 \times$ as long as wide; broadest at the eyes (Fig. 111). Frons, with a pair of shallow humps between the eyes. Eyes large, circular, projecting hemispherically and their length contained about $1.5 \times$ in that of cheeks. Antennae slightly longer than body. Scapus somewhat narrowed basally and almost $1.5 \times$ as long as wide, pedicellus sub-globose and antennomere III almost $2 \times$ as long as pedicellus.

THORAX. Pronotum considerably shorter and narrower than head, the transverse median sulcus somewhat displaced towards the anterior, fairly distinct, almost straight and expanding over entire width of segment (Fig. 111). Mesothorax some 2.9× as long as head and pronotum combined (Fig. 112). Tegmina fairly broad for the genus, gradually narrowed towards the base, with the apical portion roundly spatulate. Alae reaching about halfway along abdominal segment $\mathrm{V}$.

ABdomen. Median segment about $5 \times$ as long as metanotum. Segments II-IV roughly equal in length and about $5 \times$ as long as wide; V-VII gradually decreasing in length, with VII only about half the length of II-IV. VII narrowed in anterior portion and slightly deflexed and rounded in posterior half. VIII strongly swollen, globose and considerably broader than all other segments; the lateral margins concave pre-basally and weakly separated from sternum VIII (Figs 115-116); the latter strongly swollen and laterally projecting over tergum, bulgy and with the upper anterior portions convex and protruded dorsally. Tergum IX slightly longer than VIII, constricted medially and slightly widening in posterior half; the lateral margins well separated ventrally. 
Vomer weakly developed, with only a very small triangular terminal hook. Anal segment slightly cucullate and hardly longer than wide; posterior margin, with a shallow indention medially and the outer lateral portions obtusely rounded (Fig. 114); thorn pads lacking. Poculum bowl-shaped, with the lateral margins strongly excavated (Fig. 115) and the apical portion narrowed, upcurving and bilabiate (Fig. 116). Cerci long, hookshaped and somewhat longer than anal segment; projecting considerably beyond apex of abdomen.

LEGs. All long and slender. Profemora a little longer than head, pro- and mesothorax combined, mesofemora somewhat longer than mesothorax and metatibiae, projecting considerably beyond apex of abdomen. Proand metabasitarsi more than $2 \times$ as long as the remaining tarsomeres combined; mesobasitarsus only about $1.5 \times$ as long as remaining tarsomeres combined.

Female (Fig. 104)

Body. Size medium (body length $58.7-80.0 \mathrm{~mm}$, Table 12); form moderately slender for the genus. Body entirely smooth.

Colour. Plain green, meso- and metasternum pale cream. Epimerum I, with a fine longitudinal black line along upper margin (Fig. 105). Legs plain green, with tarsi tawny and the lower portion of interior surface and inner portion of ventral surface of profemora bright red. Antennae ochraceous.

HeaD. Roundly rectangular, the vertex gently convex and with a scarce longitudinal median sulcus, cheeks slightly narrowing (Fig. 105). Frons, with two shallow pits between bases of antennae. Eyes of average size, circular and their length contained almost $2 \times$ in that of cheeks. Antennae reaching to posterior margin of abdominal segment III; otherwise as in males.

Thorax. Pronotum noticeably shorter and narrower than head, the anterolateral angles somewhat deflexed and the transverse median sulcus displaced towards the anterior, distinct, slightly curved and almost expanding over entire width of segment (Fig. 105). Mesothorax about $2.3 \times$ as long as head and pronotum combined, uniform in width.

AbDomen. Median segment only about $1.4 \times$ as long as metanotum and gently constricted medially. Abdominal segment II-IV slightly increasing in length, V about equal in length to IV and VI-VII decreasing in length and width; IV about $1.6 \times$ as long as wide. Praeopercular organ very indistinct and merely represented as a very shallow rough posteromedian swelling on sternum VII. Tergites VIII-X of uniform width and somewhat narrower than preceding. Anal segment a little shorter than IX, indistinctly tectinate longitudinally and somewhat narrowed towards the posterior; the posterior margin sub-rectangular, with a very shallow median indention (Fig. 106). Epiproct fairly large, roundly triangular, tectinate and considerably projecting over anal segment (Fig. 106). Gonapophyses VIII much elongated, slender, filiform and projecting beyond apex of subgenital plate (Fig. 107). Cerci very long, slender, straight, gradually constricted towards a slender tip and considerably longer than anal segment (Fig. 106-108). Subgenital plate elongate, with lateral margins convergent and weakly convex to the fairly acute apex, which fails to reach the apex of the anal segment by a brief distance; the apical half weakly carinate longitudinally.

Legs. All fairly long and slender. Anterodorsal carina of profemora moderately raised sub-basally. Profemora a little longer than mesothorax and metatibiae almost reaching apex of abdomen. Pro- and metabasitarsus somewhat longer than remaining tarsomeres combined, mesobasitarsus about equal to combined length of remaining tarsomeres.

Egg (Figs 117-119)

Small, ovoid, oval in cross-section, almost $1.2 \times$ as long as high and about $1.5 \times$ as long as wide. Dorsal surface considerably more convex than ventral surface, the dorsal margin somewhat protuded. Complete 
capsule surface covered by an irregular network of raised hairy ridges; the spaces in between almost smooth and glossy. Micropylar plate somewhat displaced towards the anterior, small, elongate and very gently widened sub-posteriorly; some $3.6 \times$ as long as wide and just a little more than half the length of capsule. Outer margin bulgy, raised and covered, with the same hairy structures as the ridges of the capsule; interior portion, with a longitudinal median hairy ridge and several transverse ridges connecting this, with the outer bulge. Micropylar cup small, bowl-shaped. Median line very short. Operculum convex, oval and slightly narrowed towards the dorsal surface; capitulum surrounded by a raised rim of hairy structures and outer portion, with several radial ridges. Capitulum small and an open network. General colour pale glossy ochre, the raised ridges of the capsule and operculum cream. Micropylar plate pale grey and capitulum dull reddish brown.

Measurements (in mm). Length (incl. operculum) 2.70, length 2.50, width 1.70, height 2.00, length of micropylar plate 1.30 , diameter of operculum $1.20 \times 1.40$.

\section{Remarks}

Males show quite some variability in the shape and size of the black markings on abdominal segments VIII and IX. The great number of specimens available shows this species is fairly common in some localities, e.g., Montagnes de Kaw and Montagne des Chevaux. Captive breeding in Europe is currently being attempted from stock collected in 2015. Hatching rates in the first generation were close to $90 \%$. Nymphs accepted eucalyptus (Eucalyptus spp., Myrtaceae) and St. John's wort (Hypericum patulum 'Hidcote', Hypericaceae) as alternative foodlants and took about seven months to reach maturity. Unfortunately, nothing is known about the natural food plants.

\section{Distribution}

French Guiana: Montagnes de Kaw, Piste de Kaw (MNHN); Commune de Roura, Route de Roura (ASPER); Commune de Roura, Montagne de Cheveaux (OC); Commune de Saül, Belvedere (OC); Commune de Mana, Laussat (OC).

Phantasca valgius (Westwood, 1859)

Figs 120-124

Phasma valgius Westwood, 1859: 126, pl. 10, fig. 3 (ठ).

Cladoxerus valgius - Kirby 1904: 358.

Phantasca valgia - Redtenbacher 1906: 111. — Zompro 2001: 223. — Otte \& Brock 2005: 264. Brock, Marshall, Beccaloni \& Harman 2016: 201.

\section{Material examined}

Holotype

BRAZIL: ग’, “Type; valgius Westw.; Phasma valgius Westw.; BMNH(E) \#844548” (NHMUK).

\section{Diagnosis}

Males (the only sex known) of this species are well characterised and readily distinguished from all other species by the distinctively dark longitudinal veins of the tegmina and costal region of the alae. Since the unique holotype of $P$. valgius (Westwood, 1859) is badly mutilated, discoloured and has most of the abdomen distorted and shrunken due to former preservation in spirits, any further distinguishing and characterizing features are impossible to define. The straight cerci, which clearly project beyond the apex of the abdomen, resemble those of $P$. nigrolineata sp. nov. and P. puppeia (Westwood, 1859), while the shape of the very small poculum resembles those of $P$. quadrilobata (Chopard, 1911). 


\section{Description}

Male (Fig. 120)

Body. Small for the genus (body length ca $50.0 \mathrm{~mm}$, Table 13); form moderately slender.

Colour. Pale buff. Tegmina and costal region of alae pale greyish buff, with all longitudinal veins dark brown; tegmina, with a small elongate-oval, sub-basal brown spot near anterior margin. Anal region of alae subhyaline, with a slight orange wash. Antennae of same colour as body but tending to become darker brown towards the apex and with some broad but faint darker annulations.

HeAd. Flattened (Fig. 121), some $1.3 \times$ as long as wide and broadest at the eyes; vertex slightly raised posteriorly and with a transverse row of minute blunt tubercles near posterior margin (Fig. 122). Eyes oval on outline, strongly projecting and their length contained only about $1.1 \times$ in that of cheeks. Antennae less filiform than in other members of the genus and at least reaching to abdominal segment IV (apices broken in the unique holotype). Scapus rectangular and about $1.2 \times$ as long as wide. Antennomere III slender and about $1.3 \times$ as long as pedicellus.

THorax. Pronotum slightly narrower than head, rectangular and some $1.2 \times$ as long as wide, with both the longitudinal median and transverse sulcus weakly defined. Mesothorax elongate, some $2.4 \times$ as long as head and prothorax combined. Mesonotum finely and sparsely granulose,, with a fine longitudinal median carina. Tegmina elongate-oval, constricted at the base and projecting slightly beyond posterior margin of metanotum; fully covering base of alae. Alae reaching 1/3 along abdominal segment $\mathrm{V}$.

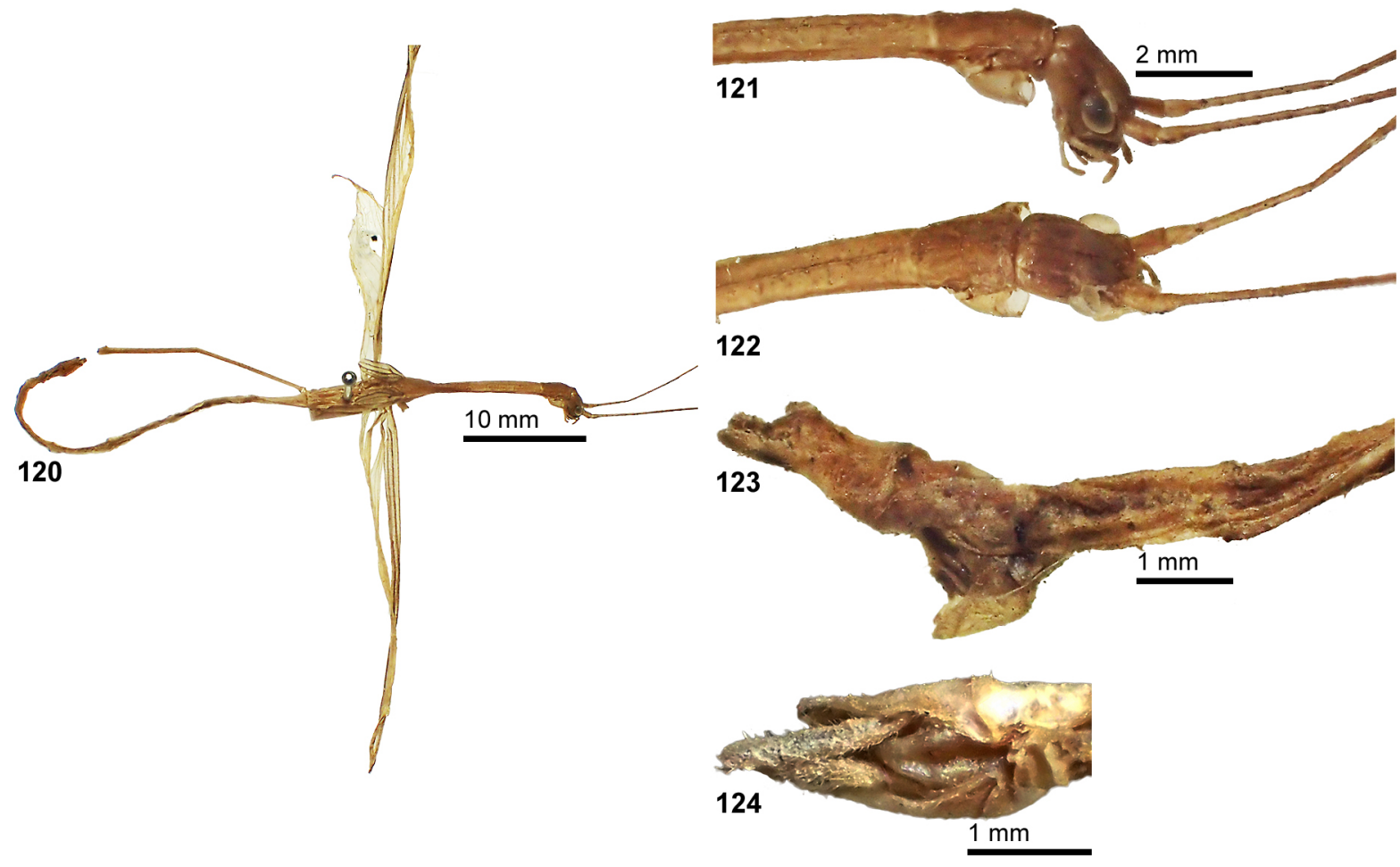

Figs 120-124. Phantasca valgius (Westwood, 1859). Holotype, $ð$. 120. Habitus, dorsal view. 121. Head and pronotum, lateral view. 122. Head and pronotum, dorsal view. 123. Apex of abdomen, lateral view. 124. Anal segment, ventral view. 
Table 13. Measurements of Phantasca valgius (Westwood, 1859) (in mm). HT = Holotype.

\begin{tabular}{lc}
\hline & $\hat{\text { O }, \text { HT } \text { (NHMUK) }}$ \\
\hline Body & ca 50.0 \\
Pronotum & 2.2 \\
Mesonotum & 10.9 \\
Metanotum & 2.1 \\
Median segment & 3.9 \\
Tegmina & 4.0 \\
Alae & 27.5 \\
Profemora & - \\
Mesofemora & - \\
Metafemora & ca 18.0 \\
Protibiae & - \\
Mesotibiae & - \\
Metatibiae & - \\
Antennae & $>30.0$ \\
\hline
\end{tabular}

ABDomen. Median segment fairly short for the genus and only about $1.3 \times$ as long as metanotum. Abdominal segments II-VI very elongate and on average about $6 \times$ as long as wide; VII shorter than all preceding. VIII gradually thickened and fully separated from sternum VIII. IX longer than VIII, constricted medially, with the lateral margins roundly deflexed in posterior half and almost touching each other ventrally. Anal segment considerably longer than wide, slightly gradually narrowed towards the posterior and gently tectiform (Fig. 123); the posterior margin, with a deep and narrow, roundly triangular notch, the outer angles projecting and obtusely triangular, with several minute denticles ventrally (Fig. 124). Cerci straight, obtuse, compressed basally, about $2 / 3$ the length of anal segment and decidedly projecting beyond its extremity. Vomer distinct, elongate, with a longitudinal median furrow and a single moderately pointed apical hook (Fig. 124). Poculum small, cup-shaped, with the posterior portion gradually flattened and the posterior margin obtusely angulate; reaching about halfway along tergum IX (Fig. 123).

LeGs. Moderately long and slender, mesofemora longer than mesothorax and hind legs distinctly projecting beyond apex of abdomen. Unicoloured except for a slightly darker apex of the femora. Mesoand metabasitarsus moderately elongate and sub-equal to combined length of remaining tarsomeres.

\section{Remarks}

The unique male holotype is badly damaged and incomplete (Fig. 120). It lacks both front and mid legs, the right hind leg, all tarsi as well as parts of the antennae and most of the anal fan of the alae. The specimen is also much deformed and discoloured due to a former preservation in spirits, the abdomen being strongly bent. This makes exact measuring of the specimen impossible. Female and egg unknown. 


\section{Distribution}

Not known. Possibly from northeast Brazil.

\section{Discussion}

The genus Phantasca Redtenbacher, 1906 has been revised at the species level and six new species from French Guiana and Ecuador are described. The systematic position of the genus is discussed, but must still be regarded as not fully clarified, although a close relationship to sections of Libethra Stål, 1875 (strigiventris-group) and some Jamaican species of Clonistria Stål, 1875 is indicated by the striking morphology of the male genitalia. Furthermore, supposedly closely related taxa are distributed throughout the more southern regions of Brazil and Paraguay, but belong to an as yet undescribed genus. A better knowledge of these species and a phylogenetic analysis seems warranted to better understand the taxonomic position and true relationships of Phantasca.

The genus now contains 13 known species and is distributed throughout wide parts of the Amazon Basin in the northern half of South America, including northern Brazil, French Guiana, southeastern Colombia, eastern Ecuador and northeastern Peru. According to Morrone (2006) this comprises the biogeographic provinces of Napo, Imerí, Guyana, Humid Guyana, Roraima, Amapa and Varzea of the Amazonian subregion. Unfortunately, seven species are so far only known from the males and the eggs of only four species have yet become known. The authors have at hand two further females that have not been incorporated in the present study because they might represent the opposite sex of species currently only known from the males. The strong sexual dimorphism, however, makes it impossible to attribute them to any of these species, with certitude. A female from East Peru (Prov. Huanuco, Panguana) might be the as yet unknown opposite sex of $P$. montana (Redtenbacher, 1906) and a female from South East Colombia is likely to be the opposite sex of P. poeciloptera (Günther, 1940). Hence, it is very much hoped that future collections will contain more material of this interesting genus, but both sexes from the same locality in particular, to enable us to match the corresponding males and females.

The delicate, winged males of Phantasca are well-flying insects, that are frequently attracted by light or malaise traps. This becomes particularly obvious by the extensive material collected by the SEAG in French Guiana, which includes numerous males of Phantasca but not a single female specimen. The wingless females can only be found by searching vegetation, with a torch at night or by knocking them from the vegetation, with butterfly nets, methods that have both not been carried out by the SEAG. Only little is known about the natural host plants of Phantasca spp., but P. nigrolineata sp. nov. and P. quadrilobata (Chopard, 1911) have been observed to feed on Psidium guajava (Myrtaceae) and Gonzalagunia sp. (Rubiaceae) in Saül, French Guiana in 2013.

It is worth noting that two different types of eggs occur in two species of Phantasca which differ in the colouration and sculpturing of the capsule surface, either being glossy or dull (P. guianensis sp. nov., P. quadrilobata). While eggs usually are very consistent concerning their morphology, within an individual species in the whole of Phasmatodea, a similar phenomenon can for instance be observed in certain species of the Oriental Necrosciinae genus Lopaphus Westwood, 1859 (see Hennemann et al. 1998: 201, fig. 4). 


\section{Acknowledgements}

The authors want to express their thanks to the following curators for access to the corresponding collections, loan of specimens and providing requested data or photos: Tony Robillard, Simon Poulain and Emmanuel Delfosse (MNHN, Paris), Dr. Susanne Randolf(NHMW, Vienna), Dr. George Beccaloni, Judith Marshall and Paul D. Brock (NHMUK, London) and Gunvi Lindberg (NHRS, Stockholm). Paul D. Brock kindly forwarded photos of the holotype of $P$. heteronemia in ZMPA. Stéphane Brûlé of the Société Entomologique Antilles-Guyane (SEAG) is kindly thanked for the good cooperation over the past years and making available much of the material studied herein. Thanks are also due to Thibault Rosant (French Guiana) and Julien Bonnaud (French Guiana) for assistance during night collectiong in French Guiana and providing specimens and photos. The last three authors (ASPER team) particularly thank the "Parc Amazonien de Guyane" for funding and expedition to Saül in 2013.

\section{References}

Bradler S. 2009. Die Phylogenie der Stab- und Gespenstschrecken (Insecta: Phasmatodea). Species, Phylogeny and Evolution 2 (1): 3-139.

Bradley J.C. \& Galil B.S. 1977. The taxonomic arrangement of the Phasmatodea, with keys to the subfamilies and tribes. Proceedings of the Entomological Society of Washington 79 (2): 176-208.

Bragg P.E. 2001. Phasmids of Borneo. Natural History Publications (Borneo), Kota Kinabalu.

Brock, P.D. 1998. Catalogue of type specimens of Stick- and Leaf-Insects in the Naturhistorisches Museum Wien (Insecta: Phasmida). Kataloge der wissenschaftlichen Sammlungen des Naturhistorischen Museums in Wien, 13(5): 5-72.

Brock P.D., Marshall J.A., Beccaloni G.W. \& Harman A.J.E. 2016. The types of Phasmida in the Natural History Museum, London, UK. Zootaxa 4179 (2): 151-208. https://doi.org/10.11646/zootaxa.4179.2.1

Chopard L. 1911. Contribution à la faune des orthoptères de la Guyane Française. Annales de la Société entomologique de France 80: 337-350.

Clark Sellick J.T. 1997. Descriptive terminology of the phasmid egg capsule, with an extended key to the genera based on egg structure. Systematic Entomology 22: 97-122. https://doi.org/10.1046/j.1365-3113.1997.d01-30.x

Clark Sellick J.T. 1998. The micropylar plate of the eggs of Phasmida, with a survey of the range of plate form, within the order. Systematic Entomology 23: 203-228. https://doi.org/10.1046/j.1365-3113.1998.00056.x

Conle O., Hennemann F. \& Gutiérrez Y. 2011. The Stick Insects of Colombia. A Catalogue and Bibliography, with the Descriptions of four New Genera and 74 New Species. Books on Demand GmbH, Norderstedt.

Günther K. 1932. Columbianische Phasmoiden aus der Sammlung des Rev. Apolinar Maria. Mit einer Übersicht über das Genus Libethra Stål. Mitteilungen aus dem Zoologischen Museum zu Berlin 18: 226-261.

Günther K. 1940. Über die Verbreitung einiger Insekten im Gebiete des Amazonenstromes und die Frage eines columbischen Faunendistriktes in der brasilianischen Subregion. Archiv für Naturgeschichte, N. F. 9: 450-500. 
Hennemann F.H. \& Conle O.V. 2007. Studies on Neotropical Phasmatodea IV. Jeremiodes n. gen., a new genus of the subfamily Cladomorphinae, and the description of two new species (Insecta, Phasmatodea, Cladomorphinae, Cladomorphini). Spixiana 30 (1): 1-11.

Hennemann F.H., Conle O.V. \& Seiler C. 1998. Bemerkungen zu Lopaphus caesius (Redtenbacher, 1908) nebst Beschreibung der Eier (Phasmatodea, Necrosciinae). Entomologische Zeitschrift 108 (5): 197-203.

Jourdan T., Lelong P. \& Bellanger Y. 2014. Contribution à l'inventaire des Phasmatodea de Saül, Guyane. Bulletin de la Société entomologique de France 119 (4): 487-498.

Kirby W.F. 1904. A Synonymic Catalogue of Orthoptera. 1. Orthoptera Euplexoptera, Cursoria et Gressoria. (Forficulidae, Hemimeridae, Blattidae, Mantidae, Phasmidae). Trustees of the British Museum (Natural History), London. Available from https://biodiversitylibrary.org/page/6196392 [accessed 14 Mar. 2018].

Liana A. 1996. A note on the collection of walkingsticks (Phasmatodea) in the Museum and Institute of Zoology of the Polish Academy of Sciences in Warsaw. Metaleptea 16 (1): 5.

Morrone J.J. 2006. Biogeographic areas and transition zones of Latin America and the Caribbean Islands based on panbiogeographic and cladistic analyses of the entomofauna. Annual Review of Entomology 51: 467-494. https://doi.org/10.1146/annurev.ento.50.071803.130447

Otte D. \& Brock P. 2005. Phasmid Species File. Catalog of Stick and Leaf Insects of the World. $2^{\text {nd }}$ Edition. The Insect Diversity Association and the Academy of Natural Sciences, Philadelphia.

Redtenbacher J. 1906. Die Insektenfamilie der Phasmiden. I. Phasmidae Areolatae. Verlag W. Engelmann, Leipzig.

Redtenbacher J. 1908. Die Insektenfamilie der Phasmiden. III. Phasmidae Anareolatae (Phibalosomini, Acrophyllini, Necrosciini). Verlag W. Engelmann, Leipzig.

Rehn J.A.G. \& Hebard M. 1938. New genera and species of West Indian Mantidae and Phasmidae (Orthoptera). Transactions of the American Entomological Society 64: 33-55.

Westwood J.O. 1859. Catalogue of Orthopterous Insects in the Collection of the British Museum. Part 1: Phasmidae. Trustees of the British Museum (Natural History), London.

Zompro O. 2001. A generic revision of the insect order Phasmatodea: the New World genera of the stick insect subfamily Diapheromeridae: Diapheromerinae $=$ Heteronemiidae: Heteronemiinae sensu Bradley \& Galil, 1977. Revue Suisse de Zoologie 108 (1): 189-255.

https://doi.org/10.5962/bhl.part.79626

Zompro O. 2003. Catalogue of type-material of the insect order Phasmatodea deposited in the Museum für Tierkunde Dresden, Germany. Phasmid Studies 11 (2): 31-44.

Zompro O. 2004a. Revision of the Genera of the Areolatae, including the Status of Timema and Agathemera (Insecta, Phasmatodea). Abhandlungen des naturwissenschaftlichen Vereins in Hamburg (NF) 37, Naturwissenschaftlicher Verein, Hamburg.

Zompro O. 2004b. A key to the stick-insect genera of the „Anareolatae“ of the New World, with descriptions of several new taxa (Insecta: Phasmatodea). Studies on Neotropical Fauna and Environment 39 (2): 133-144. https://doi.org/10.1080/01650520412331333783 
Manuscript received: 28 June 2017

Manuscript accepted: 26 October 2017

Published on: 15 May 2018

Topic editor: Gavin Broad

Desk editor: Jeroen Venderickx

Printed versions of all papers are also deposited in the libraries of the institutes that are members of the EJT consortium: Muséum national d'Histoire naturelle, Paris, France; Botanic Garden Meise, Belgium; Royal Museum for Central Africa, Tervuren, Belgium; Natural History Museum, London, United Kingdom; Royal Belgian Institute of Natural Sciences, Brussels, Belgium; Natural History Museum of Denmark, Copenhagen, Denmark; Naturalis Biodiversity Center, Leiden, the Netherlands; Museo Nacional de Ciencias Naturales-CSIC, Madrid, Spain; Real Jardín Botánico de Madrid CSIC, Spain; Zoological Research Museum Alexander Koenig, Bonn, Germany. 